\title{
Copyright
}

by

Bernhard Erich Reichert

2010 
The Dissertation Committee for Bernhard Erich Reichert certifies that this is the approved version of the following dissertation:

\section{Are self-evaluations helpful or harmful when employees are unaware of their marginal contribution to firm welfare?}

\section{Committee:}

Steven J. Kachelmeier, Co-Supervisor

Michael G. Williamson, Co-Supervisor

Urton Anderson

Janet Dukerich

Lisa L. Koonce 


\title{
Are self-evaluations helpful or harmful when employees are unaware of their marginal contribution to firm welfare?
}

\author{
by
}

Bernhard Erich Reichert, Dipl.-Kfm.; M.B.A.

\author{
Dissertation \\ Presented to the Faculty of the Graduate School of \\ The University of Texas at Austin \\ in Partial Fulfillment \\ of the Requirements \\ for the Degree of \\ Doctor of Philosophy
}

The University of Texas at Austin

August 2010 


\section{Dedication}

For my parents, my wife, and my dog. 


\section{Acknowledgements}

I am very grateful for the advice, encouragement, and support from my committee members, Urton Anderson, Janet Dukerich, Steve Kachelmeier (co-chair), Lisa Koonce, and Michael Williamson (co-chair). Each member of my committee has had a strong influence on my dissertation and on my overall experience as a doctoral student. I am fortunate to have two of the most recognized researchers in the field of experimental economics as my committee co-chairs. I am thankful to Steve Kachelmeier and Michael Williamson for their continued support and encouragement. Without their help none of this would have been possible.

I am very appreciative to Mark Wimby, Computer User Services Specialist, who went above and beyond when preparing the behavioral laboratory for my study. I am also thankful for the daily assistance provided by the administrative staff of the Accounting Department. I am very grateful to have received financial support from the Institute of Management Accountants.

I also want to thank my wife, Elisa, for her support in challenging times while this project took shape. In addition, I want to thank my parents for encouraging me to pursue this path.

And finally, I have been fortunate to have found friends in the doctoral program. I am particularly grateful to Margaret Christ and Kendall Bowlin for many discussions about this project and for sharing their Z-Tree expertise with me. 


\section{Are self-evaluations helpful or harmful when employees are unaware of their marginal contribution to firm welfare?}

Publication No.

Bernhard Erich Reichert, Ph.D.

The University of Texas at Austin, 2010

Co-Supervisors:

Steven J. Kachelmeier

Michael G. Williamson

This study examines whether managers should use self-evaluations to identify employee perception biases about performance when setting compensation in an environment in which employees receive subjective bonuses or are evaluated on subjective performance measures. This study aims to answer that question by considering a setting in which a principal knows more about the agent's production than even the agent can observe, where the difference in knowledge proxies for a world of subjective performance measures and bonuses. In such a setting, an agent might be 
overconfident in his/her ability. Such overconfidence would lead to a perception of being underpaid if the principal pays less than the agent believes s/he deserves. An agent who perceives himself/herself to be underpaid could potentially take retaliatory actions against the principal even when compensation accurately reflects performance, which would be costly to both parties.

In such a world, self-evaluations could have one of two effects. They could either be beneficial by allowing the principal to align compensation with agent self-perceptions, thereby mitigating the retaliation problem. Alternatively, self-evaluations could worsen retaliation tendencies if they reinforce the perceived inequity of compensation that does not match agent self-perceptions or if self-evaluations lead to an overestimation of the influence of agent reporting on the principal's compensation setting decision.

While the literature suggests that self-evaluations have a positive effect, recent studies indicate that the possibility of negative effects could be a potential outcome. The limitation of studies that find negative effects is that these studies use a field study approach, which cannot separate the effect of self-evaluations from other effects that are concurrently occurring in companies. Hence, it remains an empirical question whether their findings are an artifact of their environment or an effect of self-evaluations.

This study makes a contribution to the literature by using an experimental economics approach that affords a direct examination of the effect of asking for self-estimates on employee perception of performance. 
I present evidence consistent with the premise that self-evaluations increase retaliatory actions and, in turn, lower welfare. My findings show a cost of self-evaluations that appears due to explicitly asking for a self-estimate of task performance. 


\section{Table of Contents}

CHAPTER 1: INTRODUCTION

CHAPTER 2: LITERATURE REVIEW

2.1. Usage of self-evaluations in practice 12

2.2. Benefits and costs of self-evaluations 14

2.2.1. Potential benefits of self-evaluations 14

2.2.2. Potential costs of self-evaluations 16

2.3. Studies that examine the effect of self-evaluations 19

CHAPTER 3: BASIC CHARACTERISTICS OF THE EXPERIMENTAL SETTING 24

CHAPTER 4: HYPOTHESES $\quad 26$

4.1. Prediction of the effect of self-evaluations based on economic theory 26

4.2. Behavioral biases that affect agent and principal interaction 27

4.3. Potential effects of self-evaluations $\quad 29$

4.3.1. Potentially positive effects of self-evaluations 30

4.3.2. Potentially negative effects of self-evaluations 31

4.3.2.1. Retaliation due to perception of performance 31

4.3.2.2. Retaliation due to perception of participation 32

4.4. Hypothesis and potential patterns of results 34

4.5. Effect of strategic reporting $\quad 34$

$\begin{array}{ll}\text { CHAPTER 5: DESIGN } & 40\end{array}$

CHAPTER 6: RESULTS $\quad 47$

6.1. Effect of self-evaluations on retaliation and welfare $\quad 47$

6.2. Supplemental analyses $\quad 54$

6.2.1. Effect of self-evaluations on agent perception of performance 55

6.2.2. Robustness checks $\quad 61$

6.2.3.1. Agent perception of performance and retaliation in round two 62

6.2.3.2. Principal point taking round two 65

6.2.3.3. Strategic agent reporting behavior 66

6.2.3.4. Additional support for attribution bias $\quad 68$

6.2.3.5. Additional analysis of differences in initial overconfidence 69

CHAPTER 7: CONCLUSION 93 


\section{CHAPTER 1: INTRODUCTION}

This study examines the effect of self-evaluations on employee retaliation. More specifically, this study examines whether asking employees for an estimate of performance and making this estimate available to employers for their consideration as a discretionary factor when setting compensation leads to more or less employee retaliation and thereby higher or lower welfare in an environment in which employees are not aware of their marginal contribution to firm welfare.

Gaining a better understanding of the effect of agent self-evaluations on their tendency to retaliate is important, because existing empirical and theoretical findings indicate that self-evaluations could potentially have detrimental effects for companies. For instance, Waldman et al. (1998) find that $50 \%$ of businesses that incorporate selfevaluations in their reward systems subsequently abandon such measures. In addition, studies by Roberson et al. (1993) and Inderrieden et al. (2004) show lower levels of employee satisfaction when self-evaluations are employed. Campbell and Lee (1988) argue that self-evaluations should not be used for compensation setting due to their potential to create conflicts between the employee and employer.

These findings and conceptual objections pose a challenge to accounting researchers because studies show that many companies use self-evaluations as part of their performance evaluation systems (Raymark et al. 1999; Jaramillo et al. 2005). Most Fortune 500 companies incorporate employee self-evaluations in their performance 
evaluation systems (Cheung 1999). In addition, Bettenhausen and Fedor (1997) report that $58 \%$ of the 305 firms responding to a 1995 poll by the Rocky Mountain States Employer Council declared that self-appraisals are part of their performance evaluation systems.

This study provides insights about why self-evaluations might lead to adverse effects. Specifically, this study examines how the implementation of employee selfassessment affects employee retaliation against compensation when employees do not receive feedback on their performance other than compensation. To do so, I employ an experimental setting that has three specific characteristics that define the interaction between the employer and the employee.

The first characteristic is the absence of information about marginal contribution to firm welfare for the employee. The only feedback about performance that employees receive is compensation as determined by the employer. This compensation can either reflect actual performance or can be adjusted up- or downward. In contrast, employers receive employee performance information when determining compensation. This information asymmetry between employee and employer emulates a context in which an employer incentivizes an employee with a subjectively determined bonus that reflects the employer's assessment of employee performance. The asymmetry poses a challenge for the employee because, absent information about marginal contribution, employees have to rely on their self-assessments to gauge the fairness of the compensation they receive. 
The second characteristic is the role of the employer as residual claimant to firm welfare, meaning that the employer directly benefits economically from adjusting employee compensation downward. This creates an incentive for the employer to behave opportunistically, similar to compensation setting incentives in real world companies. Allowing the employer to adjust compensation opportunistically leaves the employee ambiguous about whether differences between perception of performance and compensation are due to an error in perception as opposed to opportunistic behavior by the employer.

The third characteristic is the ability of the employee to retaliate. The option to retaliate for the employee curtails employer opportunism. While retaliation is measured as a direct cost for both parties in this study, it can take many forms in real life, such as reduced effort, waste of resources, or employees changing jobs.

In an environment that is characterized by these three factors, two biases pose a dilemma with respect to how employees react to compensation. The first bias is in how employees view their performance and the second bias is how they attribute differences between perceived performance and compensation.

Research on perception shows that, given uncertainty about their performance, decision makers tend to overestimate their performance (Sunatak et al. 1996; Kruger and Dunning 1999; Klayman et al. 1999; Moore and Cain 2007). Overconfidence has been demonstrated for a variety of tasks (Leary 2007). 
Overconfidence becomes an economically relevant problem in a compensationsetting context due to a second bias, which is how decision makers attribute differences between perception of performance and outcomes. Research on attribution shows that decision makers express a non-negativity bias, which means decision makers attribute differences between perception and outcomes to factors that reflect least negatively on themselves (Reifenberg 1986; Wilson and Dunn 2004; Goerke et al. 2004). This implies that decision makers attribute compensation below their expectation to the compensation setting behavior of the principal, while attributing compensation above their expectation to errors in their own self-assessment.

Applied to the compensation setting process, both biases present a dilemma for the employer since overconfident employees could potentially be inclined to retaliate even in the presence of fair compensation that accurately reflects their performance. In turn, the employer has no means by which s/he could identify perception biases. Extracting self-evaluations from employees could potentially affect these two biases in three different ways.

First, self-evaluations could potentially have a retaliation decreasing and welfare increasing effect if self-evaluations are utilized by employees to communicate perception biases that already exist, independent of extracting self-evaluations. In this case, selfevaluations would enable employers to identify overconfident employees, adjust compensation accordingly, and thereby increase their welfare by avoiding retaliation. 
Conversely, employers could lower compensation for underconfident employees without increasing the risk of retaliation.

Second, self-evaluations could result in an increase in retaliation. One potential reason for higher retaliation is that self-evaluations could affect employee perception of performance by reinforcing any employee biases in perception and by making any differences between perception and compensation more salient. Employees could potentially increase their perception of performance or their confidence in their estimate as a result of having to provide an estimate. Such an effect could lead to higher retaliation and lower welfare.

Third, self-evaluations could also lead to stronger retaliation if employees have a biased perception and employees see self-evaluations as an invitation to participate in the compensation setting process, yet employers subsequently ignore such an invitation. Reporting to the employer by the employee could create a trust relationship between both parties. A lack of consideration of the reporting could be seen by the agent as a trust violation and could potentially be met with higher retaliation, which would lead to lower welfare. Such an effect would be comparable to behavior observed in the pseudo participation literature (Libby 1999; Byrne and Damon 2008), in which an expectation of participation leads to higher retaliation if such an expectation is not fulfilled.

This study is designed to examine and separate all three possible effects of selfevaluations on retaliation and welfare. The basic experiment utilizes a treatment-control design in which elicited employee self-evaluations are either present or absent, and 
participants assume the role of either principal or agent. Within this overall treatment, I examine three variations to separate the possible causal drivers of any observed treatment effect: (1) a condition in which the agent reports self-evaluations to the principal, (2) a condition in which the agent reports self-evaluations to the principal, but with additional incentives for accurate self-perceptions, and (3) a condition in which the agent reports self-evaluations to the experimenter, but not to the principal (Figure 1). Treatment condition (1) is of primary practical interest, while treatment condition (2) uses the tools of experimentation to separate anchoring effects (i.e., the mere act of self-evaluation) from the more strategic effects of intentionally distorting self-evaluations in order to "game" the principal. Condition (3), reporting to the experimenter, in comparison to conditions (1) and (2), reporting to the principal, separates any retaliation effect from agent anchoring from retaliation due to agents' expectation about the effect of their reporting on the principal.

Agents and principals interact in this study in a three-stage game for two rounds (Figure 2). Participants remain in the same role in the second round, but with a different counterpart than in the first round. In the first stage, agents work on answering multiplechoice knowledge questions without receiving feedback on their performance. In the reporting conditions, agents then provide a self-estimate of their performance. In the second stage, principals set agent compensation, which they can adjust up or down from actual performance. Any decrease in the agent's compensation increases the principal's compensation, and vice versa. In the third stage, agents receive information about the 
amount of their compensation and are given an option to retaliate against the principal by reducing the principal's compensation. Retaliation is costly for the agent and thus reduces welfare for both parties.

To gain a better understanding of what drives agent decisions in this study, I collect two kinds of perception of performance information. The first perception information is collected as the agent's reporting to the principal in the reporting conditions. The second perception of performance information is collected at the end of the session. The second kind of perception information has the advantage that it is available for all four conditions and that the reporting at this point should be free from any incentives for agents to misstate their performance, because all interactions with principals have taken place at that point. The second perception information is the basis for the analysis of agent perception of performance in this study.

Results show that asking agents for self-evaluations leads to higher retaliation. Higher retaliation in the reporting conditions results from higher agent perception of performance. Agents prompted for a self-evaluation appear to anchor on this estimate, while agents who were not prompted for an estimate consider the information about performance that is inherent in compensation and adjust their perception downward.

This study offers four primary contributions to the literature. First, the study shows a cost of self-evaluations in the form of higher employee retaliation when employees estimate their performance. Thus, self-ratings not only unmask existing perception biases, but also amplify them. Such a cost poses a behavioral effect that has 
thus far not been shown to exist in the literature, a gap pointed out by Roberson et al. (1993). Ittner et al. (2003) point out the importance of knowing about such behavioral effects, because they potentially moderate economics-based explanations and help us understand firm performance measurement practices, such as the $50 \%$ rate of abandonment of evaluation systems that incorporate self-evaluations (Waldman et al. 1998).

Second, the results provide insights into why this cost emerges. This study shows that retaliation appears to be due to a difference in priors that agents have when they receive compensation information, depending on whether or not they were prompted for a self-estimate. This insight contributes to resolving a conflict in the literature, which is whether the act of asking for an estimate of performance or the reporting relationship between the principal and agent that is created by having agents submit self-evaluations leads to higher retaliation.

A third contribution of this study is to show that overconfidence in selfevaluations is not a strategic move by the agent, but instead likely results from a cognitive bias by agents. Agent behavior in the no-reporting condition reveals that agents are overconfident in the absence of objective information about their performance and are prone to retaliation. Agent reporting of performance in the reporting to the principal with accuracy incentives condition clearly demonstrates that this higher perception of performance is due to overconfidence as a perception bias and not the artifact of strategic reporting. This finding is of interest to the literature on subjective performance measures, 
because it allows an evaluation of the economic feasibility of leniency in evaluations (Prendergast 1999; Moers 2005; Bol 2008).

Finally, a fourth contribution of this study lies in the design choice that it employs. Modeling subjective performance measures in a laboratory setting poses a problem for researchers because it is difficult to provide feedback on performance dimensions such as quality or service in a timely manner. This study offers a means by which such a challenge can be avoided by taking a key characteristic of subjective performance measures, which is the lack of objective feedback and by modeling this characteristic.

This dissertation is structured in seven chapters. Chapter 2 provides an overview of the relevant literature. Chapter 3 provides a basic explanation of the setting to facilitate the understanding of the hypotheses development, which is in Chapter 4. Chapter 5 provides a more in-depth discussion of the design. Chapter 6 discusses the results and Chapter 7 summarizes the findings. 
Figure 1

Summary of Conditions

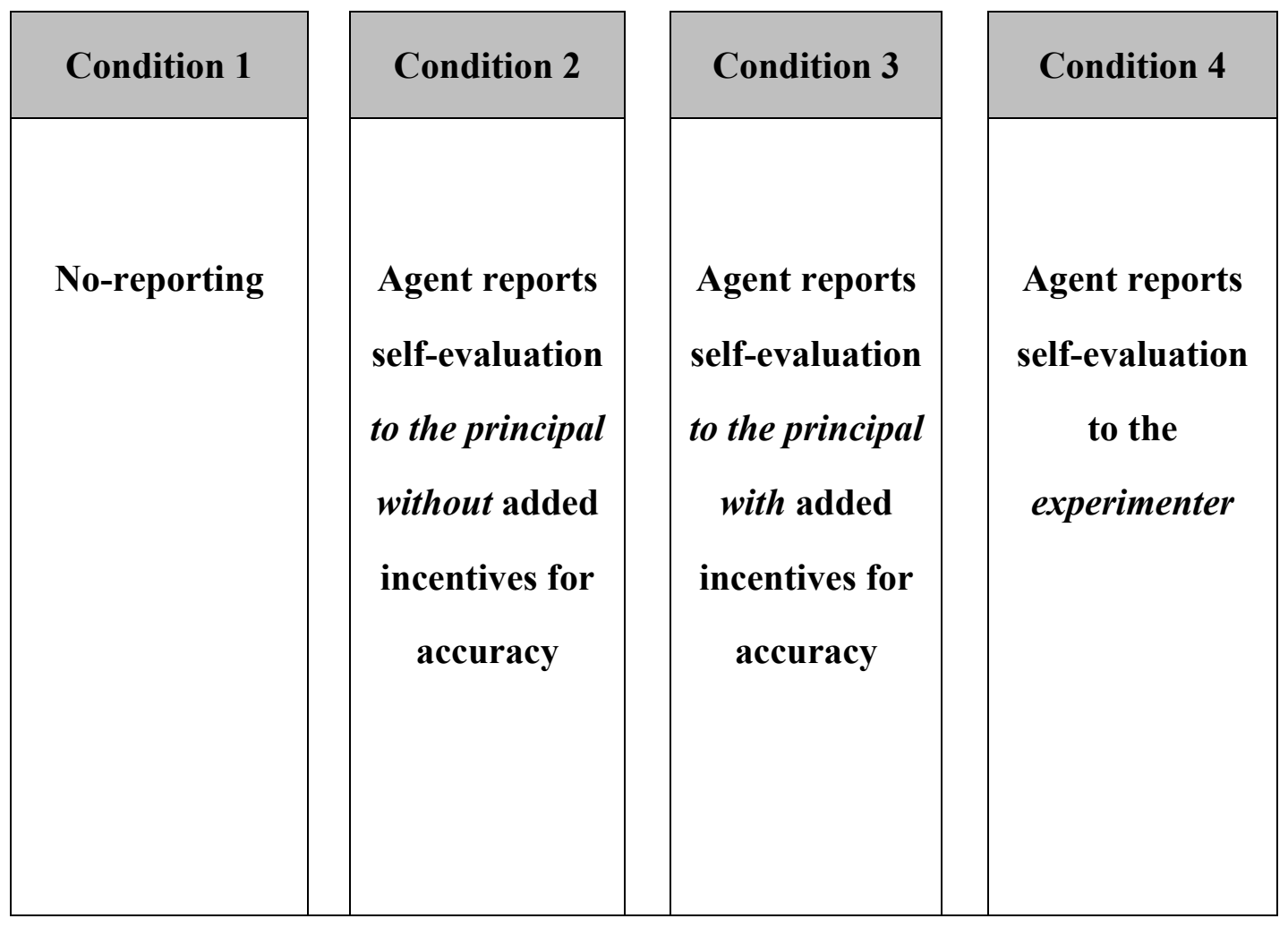




\section{Figure 2}

\section{Summary of Research Setting}

\section{Part 1:}

All agents work on knowledge answering task and estimate their performance. No feedback is given until the end of the experiment. -> Estimates used to calibrate analysis of part 2.

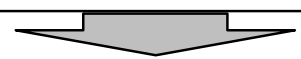

\section{Part 2:}

\section{Stage 1:}

Agents work on a task. Principal and agent welfare increase with agent effort. Agents in the reporting conditions provide an estimate of performance.

\section{Stage 2:}

Principals determine agent compensation. Upward adjustments from actual performance lower principal compensation and vice versa.

\section{Stage 3:}

Agent learns compensation amount. Agent can choose to reduce principal compensation at a cost of $1 / 3$ of a point per 1 point reduction.

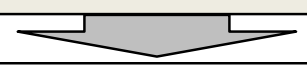

Agents in all conditions provide an estimate of performance for part two after all interactions with the principal. These data are used for a supplemental analysis

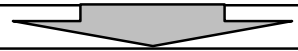

Agents and principals receive information about performance in part 1 of the study and compensation information per round and in total.

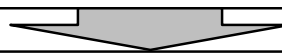

Agents and principals answer post-experimental questionnaire. 


\section{CHAPTER 2: LITERATURE REVIEW}

This chapter is structured in three parts. The first part provides a summary of empirical findings about the usage of self-evaluations in companies. The second part provides a discussion of costs and benefits of using self-evaluations. The third part summarizes studies that have examined the effect of self-evaluations.

\subsection{Usage of self-evaluations in practice}

Before examining the effect of self-evaluations, it is worth considering whether companies actually use self-evaluations to gauge their economic significance. While a comprehensive summary of the usage of self-evaluations in companies is not available, the literature suggests that self-evaluations are a widely used instrument in companies of various sizes. Cheung (1999) and Church (1997) claim that most Fortune 500 companies use self-evaluations in some form. Bettenhausen and Fedor (1997) provide information about how common self-evaluations are in small to medium sized companies. They report that $58 \%$ of the 305 firms responding to a 1995 poll by the Rocky Mountain States Employer Council claim using self-appraisal in their performance evaluation systems.

Jamarillo et al. (2005) claim that self-evaluations are usually used in the context of subjective evaluations. Yammarino and Atwater (1997) point out self-evaluations are commonly used in the context of 360-degree evaluations. Especially the usage of selfevaluations in the context of 360-degree evaluations is noteworthy because employers have additional sources of information about performance in that condition. This means 
employers in that environment do not use self-evaluations to gain information about performance per se, but about the perception of performance and any potential biases.

Based on the literature, it is not quite clear whether those companies that report using self-evaluations do in fact use the instrument for all positions or just for a select few positions. However, my understanding from conversations with managers is that companies use self-evaluations indiscriminately for a wide range of positions.

Employers commonly try to incorporate self-evaluations in reward systems, meaning that they strive to consider self-evaluations when determining compensation, because they want to get a return on resources used for collecting this information and want to underline the importance of the instrument. However, even when no direct formal link exists between self-evaluations and compensation, it is likely that an indirect link exists. Commonly, self-evaluation information is collected in close proximity to the time when annual bonuses are determined. Employers would have a difficult time ignoring any knowledge about self-assessments and not to consider it when determining bonuses.

Romano (1994) provides information on the cost of collecting self-evaluation information. The author estimates that the cost of gathering self-evaluations is between $\$ 10$ and $\$ 25$ per report. While the cost of communicating and storing self-report information has decreased in past years due to advances in information technology, the main component of the cost for gathering this information is likely to be the time that employees dedicate to this exercise. The length of self-evaluation reports varies, but 
some questionnaires have up to 40 questions. Reports of such a length are likely to require a significant time commitment.

In summary, the findings in the empirical literature on self-evaluations emphasize the economic importance of this instrument. Many companies use self-evaluations and their usage represents a cost.

\subsection{Benefits and costs of self-evaluations}

The literature identifies several pros and cons of self-evaluations. I provide a summary of arguments in favor and arguments that indicate potential costs of selfevaluations. I develop a framework for the subsequent analysis of studies that examine the overall effect of self-evaluations.

\subsubsection{Potential benefits of self-evaluations}

The majority of the literature views self-evaluations as a positive element (Cawley et al. 1998). Several positive effects have been suggested.

Among the potential positive effects of self-evaluations is their effect on employee perception of participation (Folger and Greenberg 1985; Blakely 1993). Selfevaluations are assumed to have a positive effect on perception of procedural fairness. This assumption is based on studies that find a positive effect of participation on perception of fairness. In addition to having an effect on the perception of procedural fairness, self-evaluations can be used as a tool to signal a certain management style, 
which can lead to more trust in the employer by the employee. For instance managers could elicit self-evaluations to signal a participative management style and concern for their employees (Elicker et al. 2006).

The participation literature differentiates between value-expressing voice and instrumental voice (Greenberg 1986). Value-expressing voice describes a setting in which employees comment on the outcome of the compensation process, while instrumental voice means that employees provide input that influences the compensation setting process and ultimately its outcome (Korsgaard and Roberson 1995). Selfevaluations are considered an instrumental voice. The assumption is that instrumental voice is valued in and of itself regardless of its impact on compensation (Cawley et al. 1998; Geddes et al. 2003; Elicker et al. 2006).

Another potentially positive effect of self-evaluations that has been proposed in the literature is that managers could use self-evaluations to learn more about task requirements, about employee job performance, or about employee perception of performance (Geddes et al. 2003). In this role self-evaluations would mitigate information asymmetries between the employer and the employee. Extracting performance information from employees could potentially yield benefits for employers by reducing their information gathering costs.

Another potential benefit from asking employees to evaluate their performance is that self-evaluations make them think about their actions and help them identify areas for 
personal growth. A critical evaluation induced by self-reflection might improve the selfselection processes (Jones and Fletcher 2002).

In summary three potential benefits of self-evaluations are their influence on participation, the information that they yield about task and performance, and improved employee self-selection.

\subsubsection{Potential costs of self-evaluations}

In contrast to the potential benefits of self-evaluations, the literature proposes several costs.

One of the foremost criticisms against self-evaluations is that they do not yield accurate information about performance. A stream of studies in the management literature examined the accuracy of self-evaluations. They did so with the aim to establish the validity of self-evaluations as a measure of performance for research.

Studies that examine the accuracy of self-evaluations commonly compare selfperception with other measures that the authors of these studies deem more accurate (Atwater and Yammarino 1992; Church 1997). One common measure with which selfevaluations are compared is employer ratings (Jaramillo et al. 2005). Studies find correlations between 0.29 and 0.38 between the two (Mabe and West 1982; Harris and Schaubroeck 1988; Bommer et al. 1995). Jaramillo et al. (2005) find that managers' perceptions are more accurate than employee perceptions, explaining twice as much variation in actual performance. Wohler et al. (1989) find that subordinate peers' ratings 
are more similar to supervisor ratings than self-ratings. Studies that examine self-ratings in non-compensation and compensation contexts commonly find less employee overconfidence in the non-compensation context (Fahr and Werbel 1986; Avery and Murphy 1998). This indicates that higher self-ratings in compensation contexts are at least partly due to strategic reporting behavior. However, even in a non-compensation context, employees have an upward biased perception of performance. In summary, studies that examine employee perception accuracy find that employees are overconfident in their ability; on average such overconfidence is further aggravated by financial incentives.

Employee perception bias reduces the value of self-evaluations as an information tool and poses a problem in regard to the potential benefits of perceived participation. In addition, when self-evaluations are utilized employers might not have incentives to rectify any employee perception bias, because that would require giving negative feedback. Ample studies show that managers refrain from giving negative feedback, which leads to an upward shifted clustering of evaluations on scales - a phenomenon that is commonly referred to in the literature as leniency bias (e.g., Moers 2005). A possible reason why managers are lenient could be that giving negative feedback imposes a cost on employers in form of employee disappointment and potential conflict creation (Shore et al. 1998). In addition, giving negative feedback could potentially reflect negatively on the employer who hired the employee and overall on the performance of a department. In particular, a negative reflection on the department might not be desirable for principals in 
times of economic turmoil when costs have to be reduced, and in good times, managers might intentionally refrain from reducing their capacity to establish a cushion for bad times (Harris 1994). Refraining from giving negative feedback creates the problem of preventing employees from receiving information that indicates to them that they are overconfident. Hence they cannot improve the accuracy of their perceptions.

Given this dilemma, Campbell and Lee (1988) suggest that self-evaluations should not be used in a compensation setting context because they introduce a potential friction between the employer and employee. They suggest self-evaluations should only be used for what they refer to as administrative purposes such as identifying training needs. Korsgaard (1996) proposes that, given disagreements between self-ratings and other ratings, self-evaluations might actually have a negative impact on reactions to feedback because self-evaluations could stipulate disagreement between managers and employees. However Korsgaard does not test this proposition in a compensation-setting context.

In summary one of the most prevailing criticism of using self-evaluations is that employee perception is biased and that many obstacles hinder employee identification and adjustment of such biases. 


\subsection{Studies that examine the effect of self-evaluations}

I identified, based on a meta-analysis by Cawley et al. (1998), three studies that examine the effect of self-evaluations: Taylor et al. (1995), Roberson et al. (1993), and Inderrieden et al. (2004).

Taylor et al. (1995) examine the effect of following due process in a compensation setting process on employee perception. Self-evaluations are part of a range of instruments that define a due process environment. They assign managers in a company to one of two possible conditions and manipulate elements of a due process in performance evaluation. In a treatment group, managers receive training about due process elements of performance appraisal. A control group does not receive such instructions about a due process. The study finds a positive effect of the due process training and implementation on employee perception of fairness of the compensation setting process. However, it is not possible to gauge to what extent this perception is due to self-evaluations, because self-evaluations are part of a range of due process measures. Moreover, Cawley et al. (1998) find that value expressive participation as expressed by employees being able to comment on a compensation setting outcome leads to stronger satisfaction compared to instrumental participation, which means that employees have an input in the compensation setting process. Hence, it could very well be that the positive effects in the Taylor et al. study result from due process elements other than selfevaluation. 
Two studies that directly examine the effect of self-evaluations and provide less ambiguous results are Roberson et al. (1993) and Inderrieden et al. (2004).

Roberson et al. (1993) examine the effect of self-evaluations in a study where they assign participants to one of two conditions. One group of employees was asked to self-assess their performance before a performance review interview and bring their assessment to the meeting, where it would be used as an input factor. The other group was not asked to provide such a self-assessment. Contrary to predictions, the study finds that employees in the self-appraisal condition perceived they had less control over the compensation setting process and were less in agreement with managers. The study proposes two explanations for the observed effects. One proposed explanation is that self-evaluations lead to an overestimation of the influence that employees think they have on employers. The other explanation is that the act of assessing one's performance might increase the ratee's confidence in the accuracy of the assessment. However, the study is due to its design not able to separate both explanations. In addition, because the study utilizes a field study setting, it is not clear whether the results are an artifact of the environment or an actual result of the self-evaluations manipulation.

Inderrieden et al. (2004) also examine the effect of self-evaluations on job satisfaction and fairness perception. However, in their study, the authors allow managers to self-select into a condition where managers ask for a self-evaluation or a condition where such reporting is absent. Participants in the study are employees at a state university. Self-evaluations in the reporting condition were extracted before an annual 
performance review interview. Managers determined a subjective performance bonus as part of the review interview. One-third of the managers requested self-evaluations from their employees. Inderrieden et al. find that the opportunity to self-rate was negatively related to perceived fairness of ratings and to job satisfaction, which is an outcome that is opposite to what the authors predicted. The authors propose as a possible explanation for their findings that the opportunity to self-rate could potentially raise employees' expectation of influence on the employer's decision. If that expectation is not met it could lead to frustration. However, the authors cannot rule out other explanations for this negative effect, such as the effect of asking for an estimate. In addition, the option to self-select might be sending a signal to employees that might contribute to a negative reaction. Such a signal would not be possible in companies that uniformly adopt selfevaluation reports.

The results of the previous two studies indicate that self-evaluations might actually have a detrimental effect. The findings of these studies are remarkable due to the overwhelming opinion in the literature that associates self-evaluations with positive effects (Cawley et al. 1998). Two factors complicate evaluating the findings of these studies. First, the studies base their conclusions on data collected in field settings. This allows for the possibility that the results are due to factors other than the manipulations since companies commonly changed a variety of measures before and while the manipulations as described in the studies were implemented. Second, the studies cannot conclusively identify the specific cause why negative effects occur. Both studies point 
out two potential explanations, but are not able to separate one from the other. Given these two dilemmas and the perception of the effect of self-evaluations in the literature it is still an empirical question whether self-evaluations can have a potentially negative effect and what might lead to such a potentially negative effect.

Experimental economics can make a unique contribution to answering these two questions, first about the potential effect of self-evaluations, and second about a potential reason for a negative effect. The strength of experimental economics is in providing a highly stylized environment to examine the effect of self-evaluations. The structured environment of an experimental economics setting affords control over other effects that usually coincide, in real world with self-evaluations such as annual performance review interviews and how they are conducted.

In addition, experimental economics is particularly suited to making a contribution by separating possible effects. Using an experimental economics approach allows the researcher to specifically manipulate the party to whom the self-report is directed, thereby identifying whether potential dissatisfaction is due to asking for an estimate or to a pseudo participation argument.

Additionally, using an experimental economics approach helps to address several other issues that have been identified in the literature. Being able to examine selfevaluations in a stylized environment allows for determining and observing actual performance, which is often not possible in field settings. The lack of an objective measure in subjective real world environments is referred to as the "criterion problem" 
(John and Robins 1994). Being able to establish actual performance in this study enables me to determine whether the employer or employee has a biased perception of performance.

A further benefit of using an experimental economics approach is that it ensures that employee and employer have the same understanding and information of what the task is and what constitutes good performance. In field studies, managers and employees could potentially have a different definition of what constitutes good performance (Facteau and Craig 2001; Diefendorff et al. 2005). 


\section{CHAPTER 3: BASIC CHARACTERISTICS OF THE EXPERIMENTAL SETTING}

This chapter summarizes the basic experimental task to facilitate the development of hypotheses. A more detailed experimental design section that provides a more in depth explanation of parameter choices follows in Chapter 5.

In the main part of the study, part two, participants assume the role of either agent or principal. Participants interact for two rounds. Participants remain in the same role in round two, but interact with a different partner. Figure 2 shows the interaction of the principal and agent on a timeline.

Part two of the study consists of three stages. In the first stage, agents engage in a work task (answering trivia questions), exerting effort in return for compensation as determined by the principal. Higher production increases agent and principal welfare equally. Agents do not receive performance feedback other than compensation, while the principal receives accurate information about agent performance. Agent compensation is performance based, but can be adjusted up- or downward by the principal in stage two.

In stage two, principals set agent compensation. Reductions in agent compensation increase principal compensation and vice versa. Any reduction in agent compensation reflects opportunistic behavior by the principal. Decisions by the principal to take points from the agent have the form of a zero-sum game between the principal and agent. 
In the third stage, the agent learns compensation as determined by the principal. After learning this information, agents are given the choice to reduce principal compensation (i.e., retaliation). Retaliation is costly for both the principal and the agent. The principal learns the amount of agent retaliation before being rematched.

The intent of rematching is to avoid a potential hold-up problem. A matching of the same principal-agent pair in the second round could have increased the likelihood of retaliation in the first round in the reporting conditions. Agents would have had an incentive to retaliate in the first round to "teach" the principal for the second round, which would have created a hold-up problem. Introducing this hold-up problem would have biased the setting against finding a positive effect of self-evaluations.

However, the lack of repeated interaction of the same partners comes at a cost, which is the absence of reputation building. The abstraction from reputation seems to be justifiable given that at least in some work settings it is impossible or prohibitively costly for employers to determine agent type. For instance, it is at least in some work environments difficult for employers to see when agents are shirking or demotivating other agents. 


\section{CHAPTER 4: HYPOTHESES}

\subsection{Prediction of the effect of self-evaluations based on economic theory}

The setting of this study allows deriving a base prediction of what effect selfevaluations should have on principal point taking behavior and agent retaliation based on economic theory. Assuming rational economic behavior for agents and principals, selfevaluations should not have an effect on the outcome of the interaction between principal and agent. The reason is that rational agents do not retaliate against compensation setting by principals because such retaliation is costly. Because retaliation strictly leads to a destruction of welfare, it is economically not a sensible strategy. In addition, agents would always exert effort, because the parameters in this study are set in a way that more effort always has a positive return (c.p. type of principal). The reason for a positive return is, that the maximum number of points that the principal can take from the agent is limited, which leaves the agent with a positive return for better performance.

In the absence of agent retaliation and effort reduction, economically rational principals behave opportunistically to the maximum extent possible. Without retaliation, principals take the maximum number of points possible regardless of agent communication as expressed in self-evaluation reports. Hence, the unique Nash equilibrium is that agent and principal behavior should be comparable across all conditions and self-evaluations should be without effect. 


\subsection{Behavioral biases that affect agent and principal interaction}

Two biases and one preference make the previously described Nash-equilibrium an unlikely outcome. These biases and preferences are preferences for fairness, overconfidence, and a non-negativity bias that decision makers express in how they attribute differences between their perception and compensation (Figure 3). The three biases also provide the foundation for the effect of self-evaluations on agent retaliation.

The first bias that makes the Nash-equilibrium an unlikely outcome is a preference for fairness. Several studies in the management and economics literature indicate that decision makers have preferences for fairness (Motowidlo 1982; Fehr and Falk 2002; Jawahar 2007; Lau and Moser 2008). Research on ultimatum games, for instance, shows that decision makers retaliate against outcomes that they perceive as unfair even when retaliation is costly (Thaler 1988). Given these findings, the assumption of zero retaliation based on the assumption of rational economic behavior is not likely to reflect actual agent behavior, especially when agents perceive that they are treated unfairly. The perception of fairness hinges on the following two biases, namely the perception of performance (second bias) and the attribution of any differences between perception and compensation (third bias) (Figure 3).

The second bias that affects the equilibrium between agent and principal is in regard to perception. Research in psychology shows that decision makers have a biased perception of their performance (Alicke 1985). Decision makers over- or underestimate their performance. Overconfidence has been shown to be more prevalent than 
underconfidence (DeBondt and Thaler 1985; Brenner et al. 1996; Soll and Klayman 2004; Moore and Healy 2007). Church (1997) claims that rating one's performance higher on a given set of behavioral indices than others is particularly true for work-related assessments. On average, decision makers are overconfident in their performance, particularly for challenging tasks and when estimating absolute as opposed to relative performance (Suantak et al. 1996; Wilson et al. 2004; Leary 2007). However, while research indicates that many decision makers have preferences for positive feedback, studies also indicate that at least some decision makers are underconfident and perceive negative feedback as more trustworthy than positive (Swann and Read 1981).

Overconfidence is reinforced by the lack of information about perception errors and a lack of feedback. Overconfident decision makers face the dilemma that often times they are wrong; yet, there is no feedback indicating that they are wrong. Hence they lack a signal indicating a bias and thus do not receive a signal to acquire knowledge about the accurate solution (Leary 2007).

Overconfidence becomes economically relevant due to the third bias that affects how self-evaluations influence the interaction between principal and agent. This bias is in how decision makers attribute differences between perceived performance and compensation that they receive (Reifenberg 1986; Goerke et al. 2004). Decision makers express a self-serving bias in how they attribute differences between perceived performance and evaluations (Kelley and Michela 1980; Liden and Mitchell 1985; Green et al. 1985; Johnston and Kim 1994; Banaji and Prentice 1994; Teas and McElroy 2004). 
Research shows that people tend to attribute differences to a factor that helps them to avoid a negative reflection on their ability (Alicke 1985; Metcalf 1998; Yates et al. 1996; Kruger and Dunning 1999; Blanton et al. 2001; Wilson and Dunn 2004). Decision makers attribute differences to a source that most favorably reflects on their ability and performance, a behavior that has been described as non-negativity bias (Campbell and Sedikides 1999; Bloomfield and Luft 2006; Leary 2007). Avoiding a negative reflection helps most people to maintain a positive self-image (Jussim et al. 1995; Gramzow et al. 2003). People get comfort from cultivating a positive self-image because, in addition to making them feel good about themselves, it gives them a sense of control and predictability (Banaji and Prentice 1994).

\subsection{Potential effects of self-evaluations}

The previously described effects are the basis for any prediction of an impact of self-evaluations. At least some of the previously described effects are necessary for selfevaluations to make a difference compared to the absence of such reports. Based on this framework of the previously listed three effects self-evaluations could potentially lead to three different outcomes. The following paragraphs develop propositions for potentially positive and negative effects of self-evaluations. 


\subsubsection{Potentially positive effects of self-evaluations}

Self-evaluations could potentially have a welfare increasing effect by decreasing retaliation if they do not affect existing overconfidence and attribution behavior. Such a retaliation decreasing effect hinges on the existence of the previously described overconfidence and attribution biases that have been shown to exist independently, but to my knowledge have not been examined together in the context of compensation setting.

If both the overconfidence and attribution biases apply in this setting, then selfevaluations could potentially be used to communicate perception biases and thus enable principals to set compensation in accordance with the direction of the biases (MacLeod 2003). Knowing the type of agent's perception bias enables the principal to increase his/ her welfare by lowering compensation for underconfident agents and increasing compensation for overconfident agents (Figure 4, Panel A). Higher compensation for overconfident agents helps the principal to avoid costly retaliation. In contrast, lower compensation for underconfident agents directly increases welfare without increasing the risk of retaliation. Both effects would leave the principal better off in an environment that allows for agent retaliation.

Hence, self-evaluations could potentially be a useful and welfare-increasing tool, even in settings where the principal knows actual agent performance, but the agent does not receive objective feedback. 


\subsubsection{Potentially negative effects of self-evaluations}

Conversely, self-evaluation reports could potentially have retaliation increasing and welfare decreasing effects by two different means. The first effect by which selfevaluations could lead to higher retaliation is by influencing the perception of performance. The second means by which self-evaluations could affect retaliation is by affecting perception of participation.

\subsubsection{Retaliation due to perception of performance}

Self-evaluations could potentially lead to differences in retaliation and to an increase in retaliation by affecting perception of performance. Asking for selfevaluations could potentially lead to an increase in overconfidence or to an increase in the confidence in an estimate.

Such an increase in overconfidence or the confidence in an estimate could be due to agent anchoring on a perception of performance. Research has shown that even irrational and benign anchors, such as restating the three digits of a social security number affect decisions (Ariely et al. 2003). Asking for an estimate of performance creates a possible anchor for agents when they receive information about their compensation. The reason for such an effect is that decision makers commonly focus on such anchors when subsequently making decisions and do not sufficiently adjust from them. Having a preconceived notion of performance before receiving compensation could pose such an anchor. Such an anchor would inhibit agents from considering the 
information about performance that is inherent in the compensation amount. A desire for consistency could limit the extent to which individuals incorporate new feedback in their self-concepts (Korsgaard 1996).

In addition, self-evaluations as an anchor would make any difference between perception of performance and compensation more salient, because asking for selfevaluations may raise the rater's confidence in the accuracy of such a self-appraisal because deriving a self-appraisal requires effort (Klimoski and Jones 1989). Higher retaliation in all three reporting conditions regardless of the addressee of the reporting would lend support to the prediction of such an effect (Figure 4, Panel B).

\subsubsection{Retaliation due to perception of participation}

Another possible reason for higher retaliation as a result of self-evaluations is that they could form or increase agents' expectation of influence on the principal's compensation setting decision. In this case self-evaluations would not affect agent perception of performance or agent attribution behavior, but they would affect agent expectation of principal consideration of any existing perception biases.

Agents could see self-evaluations as an invitation to participate in the compensation setting process thereby overestimating their influence on the principal's decision (Thornton 1980; Elicker et al. 2006). While the agent's expectation of participation in the compensation setting process is commonly considered to have a positive effect (Korsgaard and Roberson 1995; Cawley et al. 1998), such an expectation 
could also have the opposite effect if asking for a self-estimate is viewed as an invitation to participate and if agents develop trust in a certain outcome and a certain principal behavior. In this case, a perceived lack of consideration of the reporting by the principal when setting compensation could be perceived as a breach of trust by the agent, which would lead to higher retaliation. Such an effect, resulting from a breach of trust, has been shown to exist in the pseudo participation literature (Libby 1999). Both effects would lead to higher retaliation in the reporting to the principal conditions, as compared to the reporting to the experimenter condition and the no-reporting condition (Figure 4, Panel C).

Comparing retaliation within the reporting conditions enables me to identify the reason for a potential retaliation increasing effect of self-evaluations. The difference in retaliation between the reporting to the principal without and with accuracy incentives conditions and the reporting to the experimenter condition indicates the extent to which retaliation is due to the agent's expectation of having an impact on the principal's decision or to self-evaluations affecting agent perception of performance. If retaliation in all reporting conditions is comparable, then retaliation is due to the effect of selfevaluations on perception of performance (Figure 4, Panel B). Conversely, if selfevaluations affect perception of participation, then retaliation in the reporting to the principal conditions is stronger compared to the other conditions (Figure 4, Panel C). 


\subsection{Hypothesis and potential patterns of results}

Given the bi-directional possibilities set forth above, instead of providing directional hypotheses, I test the null hypothesis of no differences against the two-tailed alternatives that self-evaluations could lead to an increase or decrease in retaliation.

\subsection{Effect of strategic reporting}

The above pattern of results could be altered by one factor that has thus far not been discussed. This factor is the potential for strategic reporting behavior by the agent. Agents could potentially use self-evaluations to extract additional welfare from the principal. They could do so by intentionally overstating their perception to extract additional welfare from the principal. Such strategic reporting behavior could potentially lead to higher agent welfare and lower retaliation in the reporting to the principal without accuracy incentives condition. Strategic reporting could alter the above pattern of results by leading to higher welfare and less retaliation in the reporting to the principal without accuracy incentives condition.

However, this study is designed to identify the extent of strategic reporting by separating overreporting as a result of strategic behavior from overconfidence resulting from a cognitive bias. The difference in reporting between the reporting to the principal with accuracy incentives condition and the reporting to the principal without accuracy incentives condition allows to determine the extent of strategic reporting. Conversely, any overconfidence in the reporting to the principal with accuracy incentives indicates a 
true cognitive bias because agents in that condition receive an economic incentive to be accurate. 
Figure 3

Biases that affect Retaliation

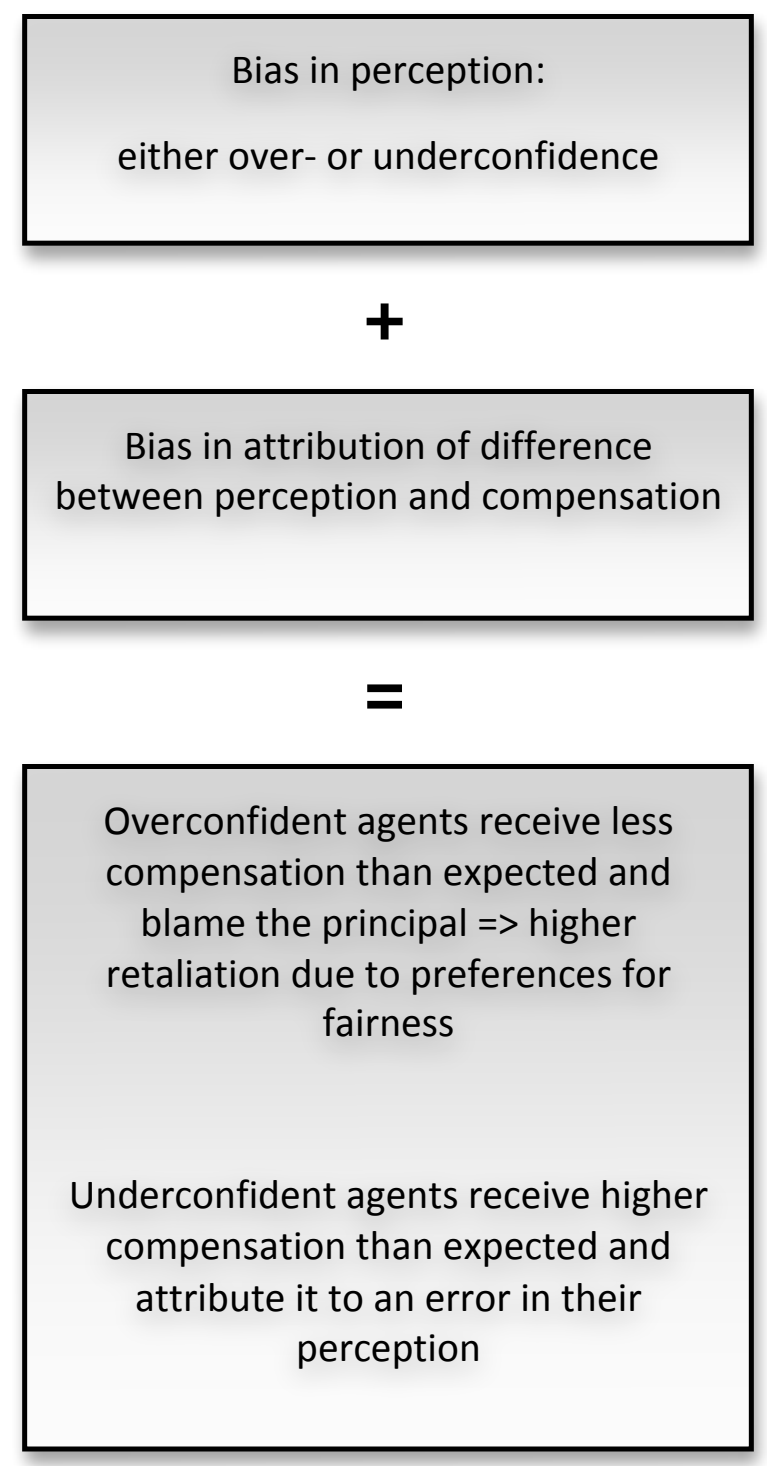


Figure 4

Agent Retaliation Potential Effects

\section{Panel A: $\quad$ Potential Prediction a Retaliation Reducing Effect of Self-Evaluations}

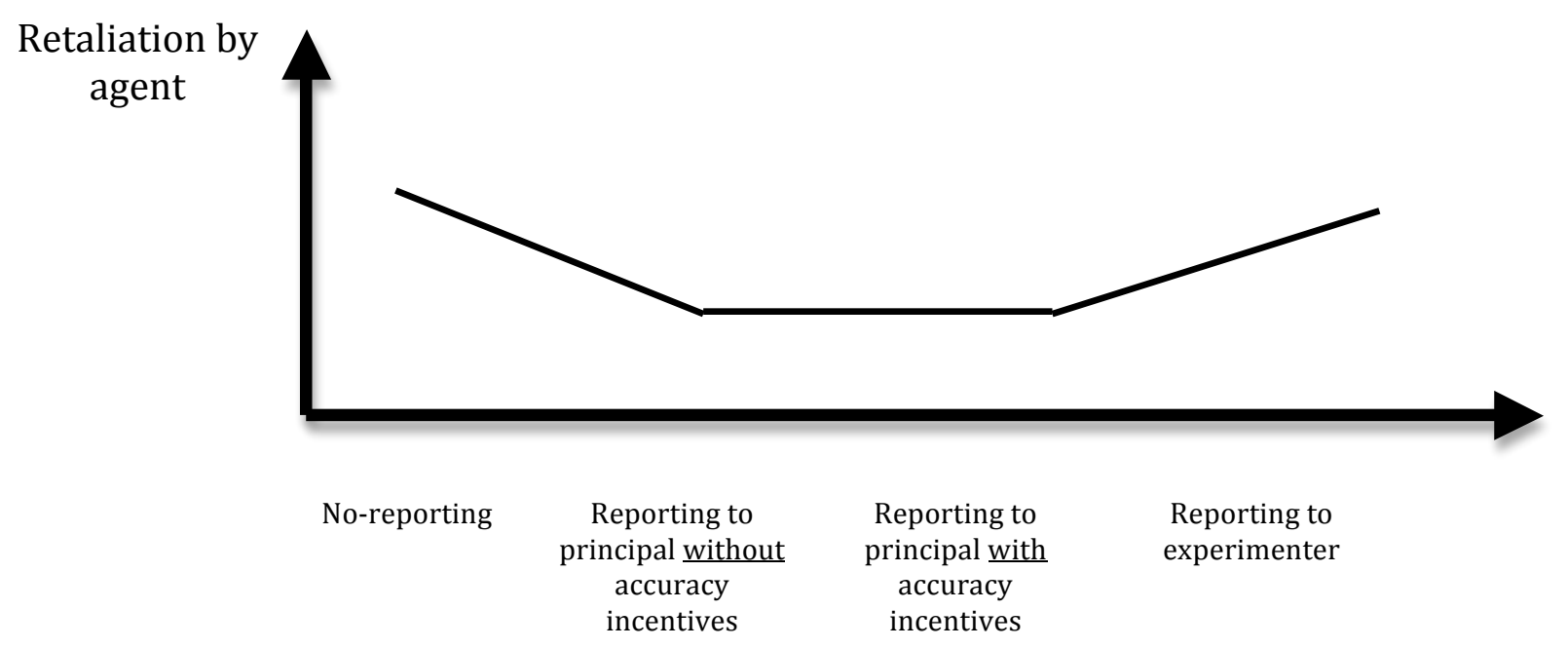

Panel A: Shows predicted agent retaliation assuming a retaliation decreasing effect of self-evaluations. Retaliation is lower in both reporting to the principal conditions due to agents communicating perception bias to the principal. 


\section{Panel B: Potential Prediction a Retaliation Increasing Effect of Self- Evaluations due to asking for an Estimate}

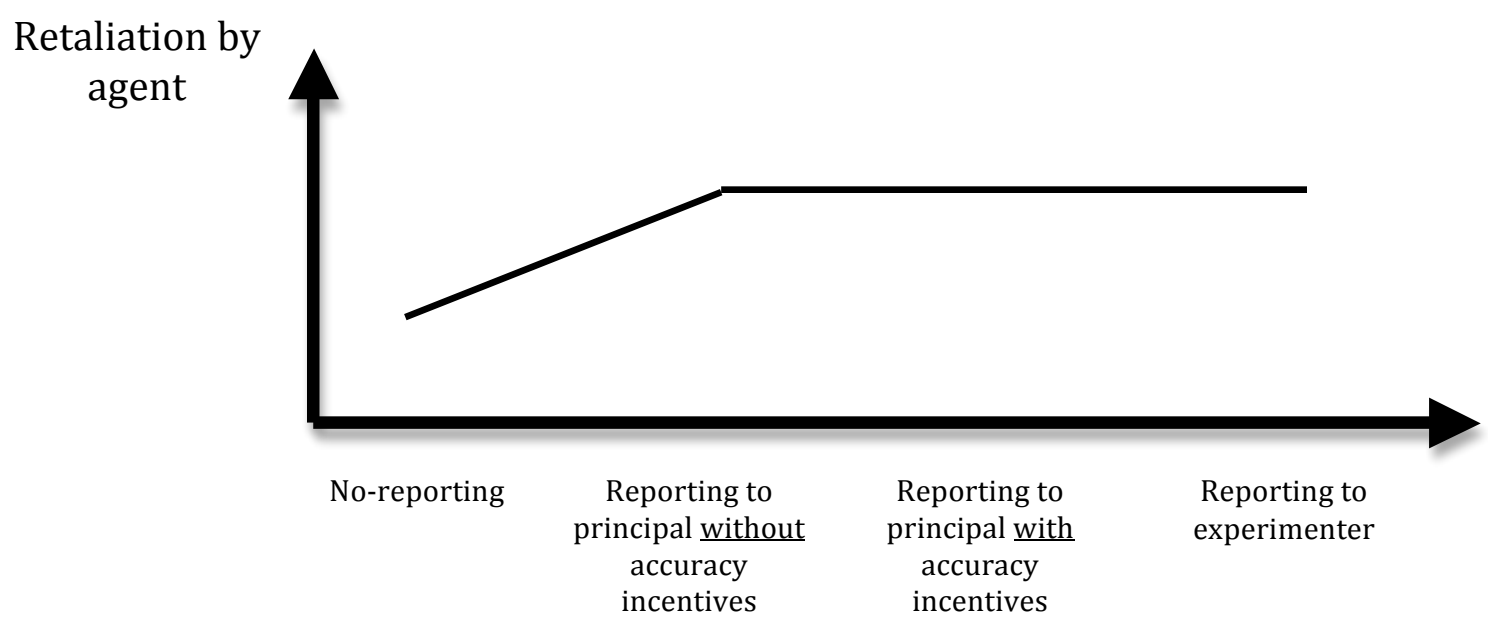

Panel B: Shows predicted agent retaliation assuming retaliation increasing effect. Retaliation is higher in all estimate conditions if the self-evaluations affect perception of performance. 


\section{Panel C: Potential Prediction a Retaliation Increasing Effect of Self- Evaluations due to Pseudo Participation}

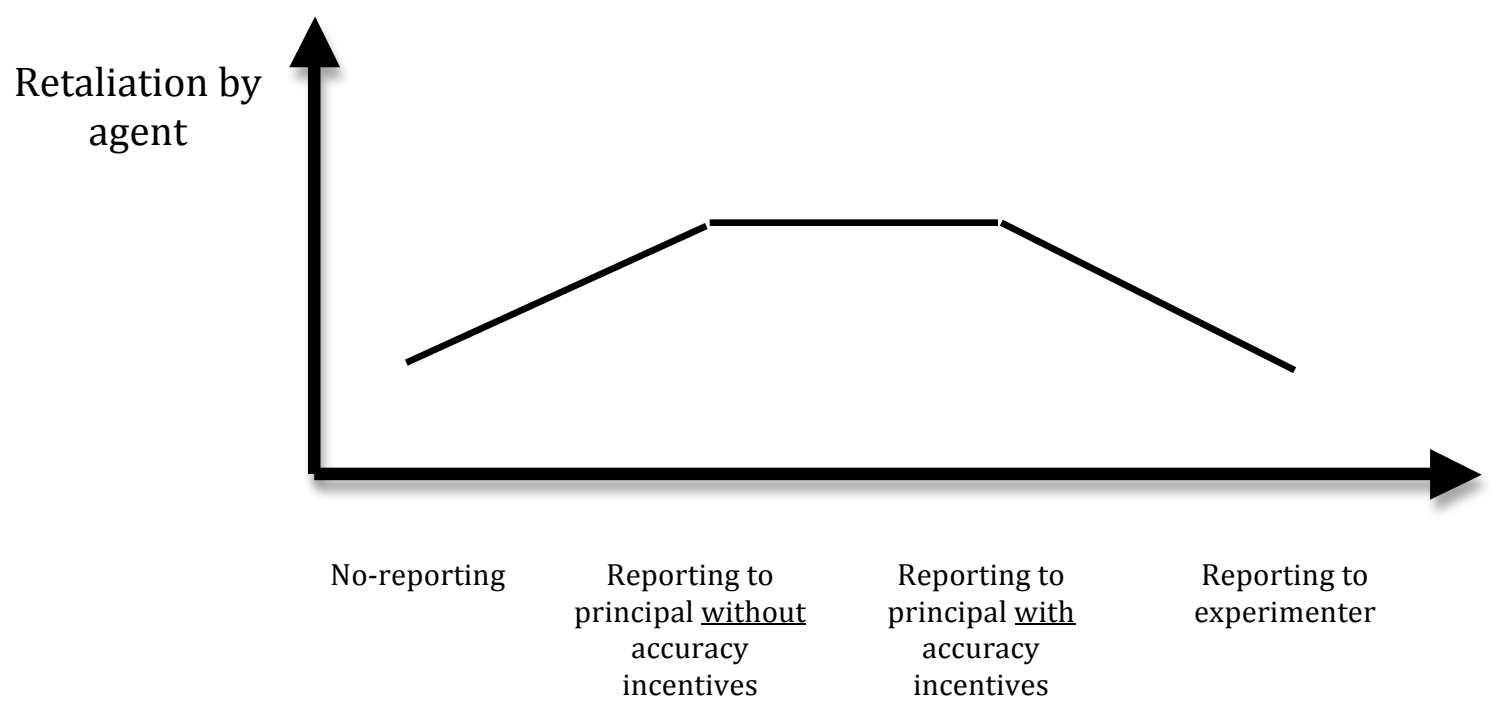

Panel C: Shows predicted agent retaliation assuming retaliation increasing effect. Higher retaliation in the reporting conditions is due to pseudo participation argument. Agents retaliate because they assume principals would consider their reporting, but they do not. 


\section{CHAPTER 5: DESIGN}

A total of 162 students recruited from undergraduate business classes participated in the experiment. Participants were informed in the recruiting material that the experiment involved answering history trivia questions. Informing participants of the purpose of the study was done to ensure that participants have sufficient motivation to perform well. Such a procedure has been followed by Camerer and Lovallo (1999). In addition, the recruiting material promised participants a minimum compensation of $\$ 5$ for 75 minutes of participation.

Participants interacted via computers using the experimental economics software platform Z-Tree (Fischbacher 2007), ensuring participant anonymity throughout the experiment, which was guaranteed to participants in the instructions (for screen shots of

the interface see Appendix 4). Instructions were provided electronically at the beginning of part one and part two (see Appendix 2 for instructions). Participants had to acknowledge their understanding and answer manipulation check questions in true/ false format correctly in order to advance to the experimental task (see Appendix 3 for questions). Incorrect answers prompted participants to retake questions until they provided the correct answer. Instructions were also handed out in paper form to allow participations to refer to them as needed during the study.

The experiment consisted of two parts. All participants performed the first part in the same way, without experimental manipulations, and without knowledge of their role 
or the task in the second part. In the first part of the experiment, participants answered 25 questions and provided an estimate of the number of questions they thought they answered correctly. Participants were informed before they started answering questions that they would be asked for an estimate of performance at the end of the task.

The questions were in multiple-choice form, with four possible answer choices. The questions were history trivia questions. Knowledge question answering tasks have commonly been used in studies on performance perception biases (Block and Harper 1991; Klayman et al. 1999; Ludwig and Nafziger 2007). The questions for the study were identified from online sources and books with a medium to high level of difficulty (Lang 1997; Kranes 1998). The difficulty level of the questions was determined in two pilot studies to ensure comparable levels of difficulty for all questions in parts 1 and 2 of the study.

The purpose of part one was to enable me to obtain information about the type of bias in their self-perceptions that participants had before the start of the experiment. This bias is the initial over- or underconfidence that participants were prone to before any experimental manipulations. This information was collected for the benefit of the experimenter to be later used as a covariate in all statistical analyses to calibrate the results from part two of the study. The first part of the experiment is not intended to improve participant accuracy of estimation or to provide any feedback about performance or accuracy to participants. Hence, participants did not receive any feedback about their performance or the accuracy of their estimate in part one until the end of the experiment. 
The second part, which is the main part of the experiment, involved the same experimental task as part one. At the beginning of part two participants, received instructions that contained information on the reporting condition to which they were assigned, but not yet on their role. After reading the instructions for part two and answering pre-experimental comprehension questions, participants were given the chance to familiarize themselves with the software interface in two trial rounds (see appendix 4 for screenshots of interface). ${ }^{1}$ Participants interacted with themselves in the two trial rounds without performing the actual experimental task, but did go through the various elements of the interaction part of the software. At the end of the second trial round, participants learned their designated role as participant A or B. A and B stood for agent and principal respectively. Letters were intentionally chosen to avoid any loaded terms. The role assignment and matching of interaction partners was random.

Part two had the form of a three-stage game (Figure 2). In stage one, agents were asked to answer trivia questions. While agents were working on the questions, principals were reading the same questions and answer choices, but did not actually answer them. Presenting principals with these same questions was intended to let principals familiarize them with the level of difficulty of the questions.

\footnotetext{
${ }^{1}$ For both rounds participants had to assume that a number of questions had been answered correctly. For round one, participants were asked to assume five questions had been answered correctly, while for round two they were asked to assume 20 questions had been answered correctly. Participants were told that those values neither reflected nor implied likely performance and that they were chosen arbitrarily. The values were chosen to reflect a low and a high value to avoid that participants would develop an expectation of possible performance.
} 
After they finished answering all 25 questions agents were asked to provide an estimate of the number of questions they answered correctly. Agents in the reporting conditions knew at the beginning of each round that they would be asked for an estimate after completing all questions. In the reporting an estimate to the principal without accuracy incentives condition, agents were asked to provide an "estimate, which will be provided to participant $\mathrm{B}$, of the number of questions" answered correctly. In the reporting to the principal with accuracy incentives condition, agents were given the same information but with additional information about the point adjustment for accuracy, as described shortly. In the reporting an estimate to the experimenter condition, agents were asked for an estimate of their performance without a reference to participant B. In the second stage, principals determined agent compensation. In the third stage, agents learned the compensation score awarded by the principal and determined any adjustments to the principal's score.

At the end of the second round of part two of the study, - after all interactions had taken place - all agents were asked for an additional second estimate of how many questions they thought they had answered correctly in round one and two of part two of the study. This estimate of performance was collected in addition to self-evaluation reports that agents reported to principals in the respective conditions (Figure 5 provides a timeline of estimates of performance that were collected). After providing that information, participants learned their compensation for part one and part two of the study and in total. At the end of the session, additional information in regard to 
participants' demographics and motivation for their decisions was collected using a postexperimental questionnaire.

Compensation to the principal and agent depended on points earned during the experiment. Points were converted to cash at a rate of $\$ 0.35$ per point. Participants gained one point for every correct answer in part one and two. In part one, principals gained points for their own answers, whereas in part two they gained points for answers provided by the agent with whom they were paired.

Agents' and principals' scores changed with any adjustments made by the principal to agents' score in stage two and any retaliatory choices that agents made in stage three. The principal's downward adjustment decision of the agent's score was limited to $75 \%$ percent of points earned by an agent in the respective round. Retaliation for the agent is costly and lowered the agent's score. For every point by which the agent lowered the principal's score the agent incurred a cost of $1 / 3$ of a point. This difference between cost and effect of retaliation was intentionally chosen to account for the fact that the principal retained points that were taken from the agent.

In addition to point changes from decisions, agents and principals received an endowment of 20 points in each round. Such an endowment served two purposes. First, agents need to have sufficient funds to retaliate against principals, or principals could be strictly better off by taking as many points from agents as possible to limit agent retaliation. Second, principals need sufficient funds to be able to adjust agent compensation upward for overconfident agents. 
In the condition with self-reporting with accuracy incentives, agents' scores were adjusted depending on the accuracy of their estimates at the end of the session. Specifically, the agents in a session who placed in the top half in terms of self-perception accuracy received a bonus of 10 points, while the score of agents in the bottom half was reduced by 10 points. Accuracy was calculated as absolute value of the difference between estimated score and actual score for each round. A lower score indicated higher accuracy, while a higher score indicated lower accuracy.

Accuracy incentives are a zero-sum game among the agents. The size of accuracy incentives was intentionally set to be large to dominate any incentives to hold up principals. While outweighing incentives to extract welfare from principals, the incentives are still small enough not to induce abstaining from answering questions in order to achieve a low score that could be predicted with high accuracy. 
Figure 5

\section{Agent Perception Information}

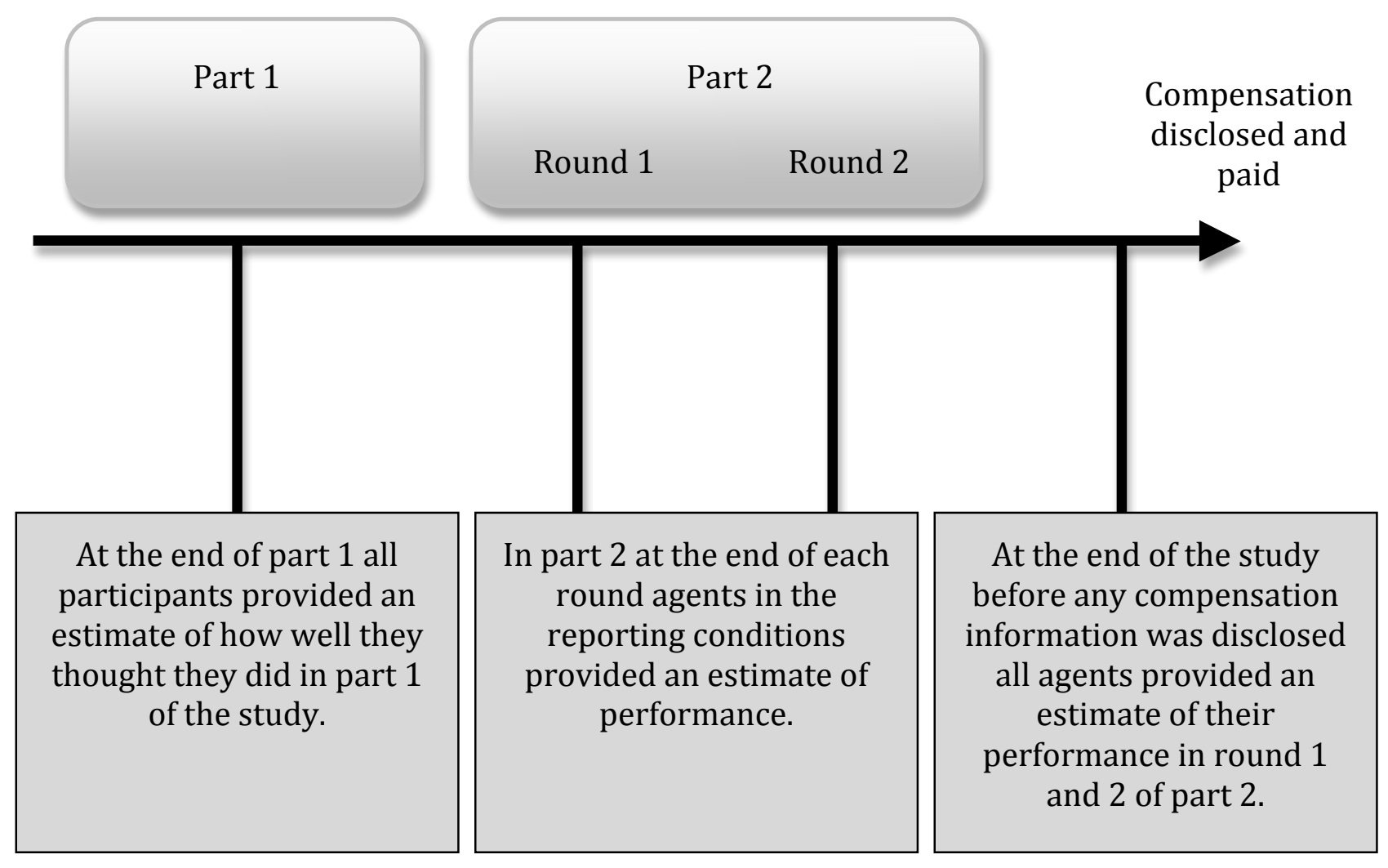

This figure shows perception information that was extracted from participants during the experiment. 


\section{CHAPTER 6: RESULTS}

This chapter consists of two sections. The first section examines the effect of self-evaluations on agent retaliation against principals, and principal and agent welfare. This section contains the economically tangible part of the results because the data result from actual decisions.

The second part presents supplemental analyses, including an analysis that examines agent perception of performance to further collaborate conclusions derived in the first section. In addition, it encompasses several robustness checks. First, I examine changes in principal and agent decisions in the second round of part two of the study to determine the robustness of the findings against agent and principal learning. Second, I examine the extent of strategic reporting to determine the feasibility of using selfevaluations in practice in environments that do not emphasize accountability for the reporting.

\subsection{Effect of self-evaluations on retaliation and welfare}

Table 1, Panel A tallies descriptive statistics for agent retaliation, production, and principal compensation setting by condition. Of primary interest is agent retaliation against principal compensation setting. I am interested in two effects. First, I am interested in retaliation in the no-reporting condition as compared to the reporting conditions to determine whether self-evaluations have a negative or a positive effect. 
Second, I am interested in differences in retaliation between the reporting to the principal conditions and the reporting to the experimenter condition to determine whether asking agents for an estimate or whether reporting to the principal has an incremental effect on retaliation.

Table 1, Panel A also shows combined retaliation, calculated as the sum of retaliation in both rounds of part two. Average combined retaliation is 8.50 points in the reporting to the principal with accuracy incentives condition, 7.55 points in the reporting to experimenter, and 4.85 points in the reporting to the principal without accuracy incentives condition. Retaliation in the no-reporting condition is 3.47 points. These means show higher retaliation in all three reporting conditions as compared to the noreporting condition (Figure 6), consistent with the premise that self-evaluations do not lead to less retaliation, but rather to an increase. In addition, the indiscriminant presence of retaliation in all reporting conditions indicates that retaliation is likely due to agents forming a perception of performance and not to the reporting relationship that is created by the reporting situation.

An ANCOVA in Table 2, Panel A using a two-tailed test comparing retaliation in the three reporting conditions to retaliation in the no-reporting condition shows that the difference in retaliation is marginally significant (two-tailed $p=.069) .{ }^{2}$ I use ranked values in this and in subsequent tests, where appropriate, to control for outliers and I use two-tailed test statistics. This test uses principal point taking as a covariate to account for

\footnotetext{
${ }^{2}$ I compare the three reporting conditions as an estimate condition with the no-reporting conditions to
} achieve an increase in power. 
differences in principal perception existing before the beginning of the experiment. In addition, all tests use covariates to control for differences in initial confidence as expressed by agents in part one (see robustness checks section for a discussion of potential implications). The comparison of retaliation suggests that agent retaliation in the three reporting conditions is higher than in the no-reporting condition, providing additional support for the prediction of a retaliation increasing effect of self-evaluations due to agents forming a perception of performance.

A pairwise comparison of retaliation in the no-reporting condition individually with each reporting condition provides further insights into what causes retaliation. A comparison of the no-reporting condition with the reporting to the principal with accuracy incentives condition shows the difference is statistically significant $(p=.015$, Table 2, Panel C). This finding is consistent with the previous conclusion that selfevaluations lead to higher retaliation due to agents forming a perception of performance. However, despite higher average retaliation in the other two reporting conditions compared to the no-reporting condition, statistical comparisons of the no-reporting condition with the reporting to the principal without accuracy incentives condition ( $p=$ .424 , Table 2, Panel B) and the no-reporting condition compared to reporting to the experimenter condition $(\mathrm{p}=.486$, Table 2 , Panel $\mathrm{D})$ show that those differences are not statistically significant.

To explore further, I next recognize that, while retaliation expresses agent reaction to compensation setting, it captures only part of the principal and agent 
interaction that affects principal welfare. An important part that retaliation by itself is not capturing is principal welfare improvement from point taking, which is likely to be a contributing factor to retaliation. However, as Table 1, Panel A shows, contrary to expectation, principal point taking is highest in the no-reporting condition, when retaliation is lowest. Thus, in this condition principals gain from both (1) lower retaliation and (2) lower compensation relative to achieved production.

To gain a better understanding of the economic effect of self-evaluations on principal welfare, I create a combined economic score that captures principal point taking and agent retaliation in one measure. This combined economic measure is calculated as principal point taking net of agent retaliation. Table 1, Panel A shows the means for this score by condition. Positive values indicate a welfare gain for the principal, while negative values indicate a welfare loss.

The combined economic score is highest in the no-reporting condition, with 0.53 points, and lowest in the reporting with accuracy incentives condition, with -6.10 points. The score in the reporting without accuracy incentives condition is -3.10 points and in the reporting to the experimenter condition -4.69 points, both lower than in the no-reporting condition. The pattern of means of the combined economic measure suggests that principals fare best in the no-reporting condition and fare worst in the condition where agents have incentives to report accurate self-perceptions to the principal.

I conduct three tests to examine the statistical significance of the differences in the economic measure between the conditions. First, I compare the no-reporting 
condition to all three reporting conditions to gain an understanding of the significance of the difference between the reporting and the no-reporting conditions. Second, I compare the combined economic score in the three reporting conditions with each other to determine whether the reporting conditions differ from each other. Third, I compare each treatment condition with the no-reporting condition to determine what is driving any potential significance of the first test.

The first test, comparing the combined economic measure in the no reporting condition with the three reporting conditions shows that the difference between the two groups is statistically significant with a two-tailed p-value of .036 (Table 3, Panel A). This indicates that principals are better off in the no-reporting condition as compared to the reporting conditions. This confirms the previous conclusion that self-estimates lead to higher retaliation due to agents forming a perception of performance.

The second test, comparing the combined measure in the three reporting conditions with each other shows that the three reporting conditions are not statistically different from each other $(\mathrm{p}=.616$, Table 3, Panel B). Principals in the reporting conditions fare similarly, and hence the form of the reporting does not seem to affect them positively or negatively. The lack of statistical significance in retaliation between the conditions again supports the conclusion that self-evaluations lead to higher retaliation due to agents forming a perception of performance. If the reporting relationship that is created by having agents report to principals were a retaliation- 
increasing factor, then this test should show a significant difference in retaliation between the reporting to the principal conditions and the reporting to the experimenter condition.

As a third test, I compare the combined score in the no-reporting condition with each reporting condition separately as a pairwise comparison. The difference in the combined economic measure between the no-reporting condition and the reporting with accuracy incentives condition is statistically significant $(p=.062$, Table 3 , Panel D). The difference between the reporting an estimate without accuracy incentives condition and the no-reporting condition is also significant $(\mathrm{p}=.062$, Table 3 , Panel C). However, the difference between the reporting to the experimenter condition and the no-reporting condition is not significant $(\mathrm{p}=.236$, Table 3 , Panel E), which results from including initial perception differences as shown in part 1 of the study as covariate.

Thus far the results show higher retaliation in the reporting conditions. This indicates that asking agents for self-evaluations leaves principals worse off. The pattern of the means and the lack of statistically significant differences in retaliation between the reporting conditions support the notion that self-evaluations have a negative effect on retaliation by affecting perceptions of performance. However, the lack of significance between the reporting to the experimenter condition and the no-reporting condition leaves some ambiguity regarding the conclusion that self-evaluations lead to higher retaliation by affecting perception of performance. The reason for this ambiguity is that despite separating means, statistical significance is not achieved due to high noise in the data. 
However, additional analyses reported in the supplemental analysis section provide further collaboration of the conclusions derived in this section.

Two of the three components of welfare in this study have thus far been examined in the analysis. The remaining component not yet analyzed is production. An analysis of differences in production between conditions (Table 4, Panel A) indicates that the difference in production is not statistically significant $(\mathrm{p}=.381)$, suggesting that production does not differ between conditions and is thus unlikely to be a feasible alternative explanation for the observed results.

I also examine principal and agent welfare to determine the overall impact of differences in point taking and retaliation on welfare. Table 1, Panel A shows principal and agent welfare by condition. Welfare is calculated as the sum of the point score for agent and principal each across both rounds in part two.

Principal welfare is highest in the no-reporting condition with 50.95 points, where retaliation is lowest and the combined effect of retaliation and principal point taking is highest (Figure 7). In comparison, welfare for principals is lower in all three selfreporting conditions, with its lowest value in the reporting an estimate with accuracy incentives condition (43.70 points).

Table 5, Panel A shows that the difference in principal welfare between the noreporting condition and the reporting an estimate conditions is statistically significant (two-tailed $\mathrm{p}=.027$ ). Moreover, principal welfare in the reporting to the principal without accuracy condition and in the reporting to the principal with accuracy incentives 
condition compared to welfare in the no-reporting condition is statistically significant with p-values of .027 and .070 respectively (Table 5, Panels B and C). However, the difference in principal welfare between the no-reporting condition and the reporting to the experimenter condition is not statistically significant $(\mathrm{p}=.288$, Table 5 , Panel D). This pattern of results reinforces the conclusions from the previous analyses.

In contrast to principal welfare, agent welfare is distributed over a much narrower range (Figure 4). Agent welfare is highest with 45.93 points in the reporting an estimate without accuracy incentives condition and lowest in the reporting an estimate without accuracy incentives condition with 44.57 points. However, the differences in agent welfare by conditions are not statistically significant $(\mathrm{p}>.50)$.

The results thus far show that asking agents for a self-estimate leads to higher retaliation. Higher retaliation in the reporting conditions is reflected in lower principal welfare. This higher retaliation appears to be due to estimating performance and not to the implicitly expected consideration of the reporting that is created by the reporting relationship.

\subsection{Supplemental analyses}

This supplemental analysis has two parts. First, I examine agent perception of performance to gain a better understanding of what is driving differences in retaliation and welfare between the reporting and the no-reporting conditions. 
Second, I conduct robustness checks. As robustness checks I examine changes in agent and principal decisions in round two compared to round one. The purpose of this test is to determine whether agents or principals express learning that could potentially limit implications that can be drawn from this study.

Next, I examine the strategic reporting behavior of agents. The goal of this test is to determine whether self-evaluations are an instrument that can be feasibly deployed in practice even in environments that do not emphasize strong and direct accountability for what is being reported.

In addition, I also conduct several supplemental robustness checks to address potential issues.

\subsubsection{Effect of self-evaluations on agent perception of performance}

I conduct a supplemental analysis of agent perception of performance to gain a better understanding of the reason for differences in retaliation that were observed in the first part. I examine agent perception of performance to further understand how selfevaluations affect agent decisions. Perception is important because it is a determining factor for retaliation. Its significance is indicated by the high correlation between retaliation and the difference between perceived performance and actual compensation in rounds one $.279(\mathrm{p}=.028)$ and two $.274(\mathrm{p}=.031)$ of part two (Table 1, Panel B and Panel C). 
Agents provided two kinds of estimates of their performance in part 2 of this study (Figure 5). The first kind of perception data was provided in form of agent reporting to the principal while interacting with the principal. The second kind of perception data was provided by all agents in all conditions at the end of the experiment and before agents learned their compensation. Agents knew the second estimate was only communicated to the experimenter. I use this later self-perception data for the following supplemental analysis because the data provide two advantages. First, these data are available for all four conditions, and second, these data reflect perceived performance at the point at which all principal-agent interactions had taken place and no economic advantage would be gained from overstating performance. ${ }^{3}$

Based on these perception data, I calculate a measure of perception bias. The measure is calculated as the difference between the estimate of questions answered correctly and actual performance. Table 6, Panel A shows the means of this perception bias measure by condition. The data show agents are overconfident in all conditions and in both parts of the study.

Of particular interest is overconfidence in part two of the study, because any difference after controlling for initial differences in part one would have to be due to the self-evaluation treatment. Overconfidence in the no-reporting condition is 2.05 points in

\footnotetext{
${ }^{3}$ The only condition where estimates of performance might not fully reflect true agent perception of performance is the reporting an estimate of performance to the principal without accuracy incentives condition. In that condition agents had an incentive to overstate their performance in their reporting to the interaction partner. Agents might be reluctant to reveal such behavior at the end of the experiment if they perceive it as unethical and overstate their reporting to the experimenter.
} 
round one and 1.89 points in round two. In comparison, agents in the reporting an estimate to the principal without accuracy incentives condition overestimated their performance by 4.30 points and 6.85 points, as compared to 5.15 and 4.90 in the reporting an estimate with accuracy incentives condition, and 6.68 and 5.23 in the reporting an estimate to the experimenter condition. Hence overconfidence in all reporting conditions is higher than in the no-reporting conditions.

To determine the statistical significance of these differences, I compare overconfidence in the no-reporting condition to overconfidence in the reporting conditions by round. Table 6 , Panel B and Panel C indicate statistically significant differences (Panel B, $p=.03$ for round one; Panel $\mathrm{C}, \mathrm{p}=.05$ for round two). These results indicate that, even while controlling for initial differences in perception, agents in the reporting condition are significantly more overconfident than agents in the noreporting condition. 4

One potential explanation for such a difference in perception is that overconfident agents anchor on their estimates in the reporting conditions. I use a subsample of the initial population to test this explanation. The subsample uses agents that were overconfident or accurate in their perception of performance in part one. I restrict the

\footnotetext{
${ }^{4}$ I conduct a second test as an additional robustness check due to initial differences in perception as demonstrated by the data for part one. The second test examines the change in overconfidence from part one to part two for the no-reporting condition and the aggregate of the reporting conditions each (Table 6, Panel D). The data shows agent overconfidence increases in all conditions from part one to part two. However, the increase is lower in the no-reporting condition. Panel $\mathrm{E}$ shows the results for t-tests comparing perceived performance in part one with perceived performance in part two. The increase in overconfidence in the reporting conditions is statistically significant $(\mathrm{p}<.01)$, but not in the no-reporting condition ( $\mathrm{p}=.29$, Table 6 , Panel E). Hence, the second test confirms the results of the first.
} 
analysis to this sample because only agents who were overconfident in part one have the choice to either adjust their perception in part two downward or to anchor on a higher estimate assuming that those agents are also most likely to be overconfident in part two.

Table 7, Panel A shows average overconfidence in part one and two for the subsample by condition. Of particular interest is the change in overconfidence from part one to part two for this subgroup. The means show a distinct difference in the change in overconfidence by agents from part one to part two between the no-reporting condition and the reporting conditions. Overconfidence increases from part one to part two for agents in the three reporting conditions, while it decreases in the no-reporting condition. In the no-reporting condition, overconfidence decreases from 4.50 points in part one to on average 3.58 points in part two. In comparison, overconfidence in the reporting an estimate to the principal without accuracy incentives condition increases from 4.44 to 5.94, on average. In the reporting with accuracy incentives condition, it increases from 4.81 to 5.09, and in the reporting an estimate to the experimenter condition, it increases from 5.05 to 6.19 . Table 7 , Panel $\mathrm{C}$ shows a test of the significance in change of average overconfidence from part 1 to part 2 . While the means separate, the difference is not statistically different, which is due to a high level of noise in the data (Table 7, Panel C, p $=0.17)$.

This difference in trends in the overall dataset and the subsample suggests a different use of information about performance that is inherent in compensation by agents, depending on whether agents were prompted for a self-estimate in part two. 
Agents who were asked to estimate their performance before they receive compensation information have a prior perception of what their performance should be. When determining the accuracy of their compensation, agents appear to anchor on this prior perception and do not lower their estimate.

In comparison, the decrease in perception in the no-reporting condition suggests that agents who have not been prompted for an estimate of performance have not anchored on a value when they receive compensation information. Without this prior, they appear to be more likely to take information about performance that is inherent in compensation in consideration, adjusting their overconfidence downward and arriving at a lower level of perception.

The anchoring argument is further collaborated by answers to a question about the accuracy of reporting. A question in the post-experimental questionnaire asked agents about the level of accuracy of their reporting to the principal. On a 7-point Likert scale, agents in the reporting without accuracy condition reported 5.35, in the reporting with accuracy incentives condition 6.20 , and in the reporting to the experimenter condition 5.55 (Table 8). The high levels of perceived accuracy in reporting indicate that agents in the reporting condition did not just default to a simple heuristic by reporting a number in part one and not giving this number any consideration in subsequent rounds to avoid effort. The higher level of accuracy indicates that agents exerted effort and are likely subject to a cognitive bias. 
An alternative and possibly applicable explanation for the anchoring process is provided by theories that focus on the affect experienced from consequences that result from asking for self-estimates. One such theory is for instance decision affect theory. Decision affect theory is similar to disappointment theory or regret theory and it proposes that counterfactual thinking creates emotional experiences (Mellers et al 1997, Roese 1997). According to decision affect theory forming a perception of a potential outcome by self-assessing performance creates an emotional experience. Not achieving the expected result when receiving compensation creates an emotional surprise, which could contribute to retaliation. Since participants in the no-reporting condition do not form such an experience, they might not develop such an emotional reaction when receiving compensation.

Decision affect theory describes an alternative explanation for the previously described anchoring process. However, based on the data analysis thus far and based on the available data it is not possible to further examine the specific nature of the anchoring process.

This supplemental analysis supports two conclusions. First, these results provide insights into the process that leads to differences in retaliation. Namely, agents who are asked to estimate their performance appear to anchor on this estimate, while agents who are not asked to estimate their performance take into account what compensation information tells them about their performance and adjust their perception's accordingly. 
Second, these results help to reconcile the lack of statistical significance between the reporting to the experimenter condition and the no-reporting condition in the primary analysis. An increase in perception of performance in part two in the reporting to the experimenter condition compared to a decrease in the no-reporting condition together with an increase in perception in both reporting to the principal conditions suggests that the same mechanism is at work in the reporting to the experimenter condition that drives the retaliation in the reporting to the principal conditions. Hence, merely asking for an estimate of performance, even if it is not reported to the principal, likely affects perceptions of performance.

\subsubsection{Robustness checks}

As robustness checks, I conduct several analyses. First, I examine agent and principal behavior in the second round in comparison to the first round. Such a robustness check identifies potential agent or principal learning, as any adjustments to agent overconfidence and any improvement in agent accuracy of perception could potentially limit the conclusions that can be drawn from the analyses in part 1 of this section.

Second, I examine the extent to which agents engage in strategic reporting to determine whether self-evaluations are an instrument that can feasibly be employed even in corporate environments that do not incentivize or emphasize reporting accuracy. 
Third, I examine how common attribution biases as an essential pre-condition for self-evaluations to have an effect are. I do so by analyzing participant responses to a stylized setting in the post-experimental questionnaire.

Fourth, I analyze initial differences in overconfidence that participants expressed in part one of the study. I examine those differences and address their implications in regard to the results and the recruiting population.

\subsubsection{Agent perception of performance and retaliation in round two}

Learning could occur in form of agents adjusting and improving their perception of performance in round two as compared to round one. Agents could potentially adjust their perception bias and thereby improve the accuracy of their perception in the second round compared to the first round. One potential explanation for why such an increase in accuracy could occur is that agents who are overconfident in round one and two receive negative feedback from two different principals. Potentially, agents who are overconfident in round two could perceive the second negative feedback as more credible because it comes from a second source and it establishes a pattern that could raise doubts about the initial perception of performance.

In addition, agents who are overconfident in both rounds and retaliated against principal compensation setting in round one could adjust their retaliation behavior in round two even if they did not improve the accuracy of their perception in round two. Such an adjustment of retaliation behavior could be driven by discouragement about the 
effect of retaliation. That is, agents who receive lower than expected compensation in round two could simply give up on retaliation because they perceive it as ineffective and take whatever compensation the principal determined without incurring an additional cost to retaliate again in round two.

Both adjustments could potentially limit the implications of the results of this study, because they would imply that the problem of retaliation or higher compensation demands resulting from asking for self-evaluations diminishes over time.

To test for any potential adjustments I examine changes in agent retaliation in the second round compared to the first round. Table 1, Panel A provides descriptive statistics for agent retaliation in round one and two. Agent retaliation in round two is with an average point deduction of 3.38 points higher than in round one with 2.78 points. Retaliation even increases from round one to round two in the two reporting to the principal conditions, where it increases from 3.15 points to 3.53 points. These results indicate that agents do not seem to adjust their retaliation behavior downward from round one to round two. This seems to rule out the proposed effect of any downward adjustment of retaliation behavior by agents in the second round due to an increase in accuracy or a possible perception of ineffectiveness of retaliation. However, this test has a caveat, which is that exploring decisions by the entire group of agents mixes over- and underconfident agents.

A more specific test of the validity of the results over time is to directly examine retaliation in round two by agents who were overconfident in round one. Table 10, Panel 
C provides descriptive statistics for retaliation in round one and round two for this subgroup. Retaliation increases from 3 points in round one to 3.41 points in round two. Panel D shows that the increase in retaliation is not statistically significant thereby showing, that agents do not adjust their behavior, which indicates that they do not improve the accuracy of their perception and do not change their perception about retaliation.

The lack of an adjustment in retaliation in round two by agents who are overconfident in round one provides reassurance in regard to the robustness of the results. The study has as a unique design feature a rematching of principal and agent after the first round. While this feature provides certain disadvantages, it provides a strong test of the robustness of attribution behavior. Negative feedback in round two comes from an additional second source in this study, while in real world settings, feedback often comes over time multiple times from the same source. The lack of change in retaliation suggests that perception bias is a robust phenomenon that decision makers feel strongly about. The lack of change indicates that the results are robust to learning and robust over time. This result also seems to confirm findings in the literature that decision makers value their own perception as more trustworthy compared to judgments of others (Pronin et al. 2004). 


\subsubsection{Principal point taking round two}

In addition to changes in agent retaliation, I also examine changes in principal point taking in round two. Changes in principal point taking are of interest for this study because the principal's point taking strategy has implications for the agent's ability to learn. Any upward adjustments by the principal of his/her point taking behavior in round two to meet agent compensation expectations would hinder the agent's ability to receive feedback that accurately reflects performance and would impair the agent's ability to develop an accurate perception of performance.

Table 1, Panel A indicates that principals reduce their point taking from round one to round two in both reporting a self-estimate with and without accuracy incentives conditions. Principals in the reporting an estimate to the principal without accuracy incentives condition reduce their point taking from 1.25 points to 0.50 points $(\Delta-0.75)$, and principals in the reporting with accuracy incentives condition reduce their point taking from 1.75 to 0.65 points $(\Delta-1.10)$. This trend contrasts with a lower decrease in point taking in the no-reporting condition, from 2.11 to $1.89(\Delta-0.22)$, and with an increase in point taking in the reporting an estimate to the experimenter condition from 0.95 points to 1.91 points $(\Delta+0.96)$.

The pattern of changes in point taking indicates that principals are more inclined to give in to agent compensation expectations in at least two out the four conditions in the second round. This indicates that agent learning is hindered, because instead of receiving negative feedback compared to their expectations, agents receive more positive feedback, 
which confirms their initial perception bias and attribution of any differences between perception and compensation to principal compensation setting. This pattern likely hinders the agent's ability to develop an accurate perception of performance for overconfident agents.

\subsubsection{Strategic agent reporting behavior}

One aspect that could limit the applicability of self-evaluations is that they can potentially be used by agents to extract welfare from principals by intentionally misstating perceptions of performance. The possibility of this behavior has thus far not been explicitly examined.

If existent, strategic reporting should be most pronounced in the reporting to the principal without accuracy incentives condition. Hence, to gain a better understanding in how far self-evaluations create tension by introducing strategic reporting behavior, I examine the difference between perceived performance as reported by agents at the end of the experiment and the estimate of performance that agents reported to the principal in each round for the three reporting conditions.

Table 11, Panel A provides descriptive statistics of the average difference between the two measures. In the reporting to the principal without accuracy incentives condition, agents overstated their reporting to the principal by a cumulative .35 points over both rounds. In the reporting to the principal with accuracy incentives condition and in the reporting to the experimenter condition agents understated their performance by 
.30 points and .05 points, respectively. These results indicate that most participants reported their true perception of performance, even when they did not receive incentives for the accuracy of their reporting.

Answers provided by agents to a question about the accuracy of their reporting to the principal in the post-experimental questionnaire confirm this conclusion. Agents reported on a 7-point Likert scale ( $7=$ the highest level of reporting accuracy) average levels of accuracy for the reporting conditions between 5.35 and 6.20 (Table 8, Panel A). The close level of accuracy in reporting again indicates the absence of any sizable strategic reporting in the reporting to the principal without accuracy incentives condition.

I also examine the distribution of self-estimates that agents report to principals to determine whether there are more outliers in any one of the reporting conditions. Table 11, Panel B shows the distribution of reported estimates for round one and two by condition. The table shows that slightly more participants reported values above 15 points in the reporting to the principal without accuracy incentives condition as compared to the other two reporting conditions. However, the difference is marginal.

The previous analyses show an absence of sizable strategic reporting. This is an important finding because it shows that it is feasible to use self-evaluations in practice even in an environment that does not emphasize direct and strong accountability for what agents report. However, this finding might be subject to the caveat of the specific reporting environment in this study. That is, agents in this experiment report to a 
principal who has knowledge of actual agent performance. Absent such knowledge, the extent of strategic reporting by agents might be different.

\subsubsection{Additional support for attribution bias}

The previous results provide insights into the effects of self-evaluations. These results hinge on the existence of an economically relevant bias in attribution behavior. Without a bias in attribution behavior, self-evaluations could potentially be without any effect. Hence showing that an attribution bias for differences between perception and evaluations exists is fairly crucial for the applicability of findings from this study.

Two questions in the post-experimental questionnaire provide additional support for the existence of this bias. The two questions asked participants to attribute a positive or negative difference between their perception of performance and compensation either to an error in their perception or to the compensation setting behavior of the principal. The first question asked participants whether they would attribute a difference between compensation and perception to the principal's compensation setting behavior or to an error in their perception assuming higher perception than compensation (meaning a negative surprise). The second question asks agents for their attribution behavior with the same answer choices however assuming a lower perception than actual compensation (meaning a positive surprise). In the case where compensation was higher than estimated performance (positive surprise) $68.60 \%$ of the participants attributed the difference to an error in their perception as opposed to a principal awarding more points (Table 9, Panel 
A). In comparison, when compensation was assumed to be lower than expected (negative surprise) $45.42 \%$ of participants attributed the difference to an error in their perception and the majority blamed the principal for the difference. The difference in attribution behavior is statistically significant (Table 9, Panel B, p $<0.01$ ).

\subsubsection{Additional analysis of differences in initial overconfidence}

Table 6, Panel A shows agent overconfidence in part one of the study, which was intended to identify the perception types of participants. Agents in the no-reporting and no-estimation condition overestimate their performance in part one by 1.68 questions, while agents in the reporting an estimate without accuracy incentives condition overestimate their performance by 3.35 points, with accuracy incentives by 3.55 points, and in the reporting an estimate to the experimenter condition by 4.77 points. The difference between the no-reporting no-estimate condition and the reporting of an estimate conditions together is statistically significant $(\mathrm{p}=.05)$. This indicates that agents in the no-reporting and no-estimate condition were less confident to begin with, which requires additional steps to ensure that this difference in perception is not driving the above results. I control for difference in perception in part one by using the difference between perceived performance and actual performance in part one of the study as a covariate in all analysis to ensure the validity of the above results.

I also conduct extensive analysis to ensure that samples in all four conditions are drawn from an identical population. I find no difference in other characteristics between 
conditions. The results depicted in Appendix 1 speak to that and provide greater assurance that the samples are indeed from the same population. 


\section{Table 1}

\section{Descriptive Statistics}

Panel A: $\quad$ Means (Standard Deviation)

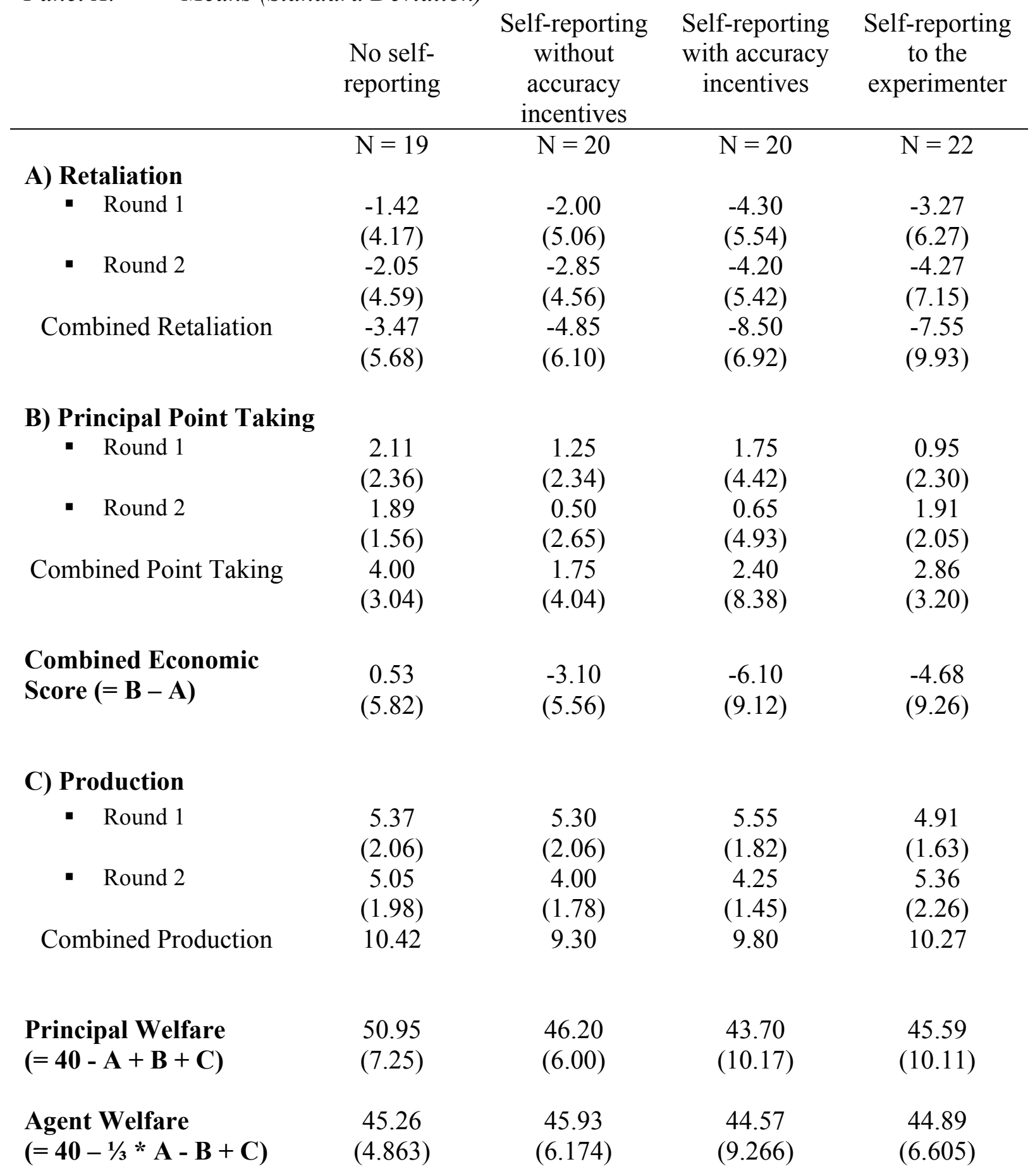


Table 2

\section{ANCOVA for the Effect of Reporting on Combined Retaliation}

Panel A: $\quad$ ANCOVA for the Effect of Reporting on Ranked Combined Retaliation (Sum of Retaliation in Round 1 and 2)

\begin{tabular}{|c|c|c|c|c|}
\hline Factor & d.f. & $\begin{array}{l}\text { Sum of } \\
\text { Squares }\end{array}$ & $F$-value & $\begin{array}{c}p \text {-value } \\
\text { (two- } \\
\text { tailed) }\end{array}$ \\
\hline Reporting & 1 & $1,499.18$ & 3.399 & 0.069 \\
\hline $\begin{array}{l}\text { Ranked difference perceived } \\
\text { agent performance part } 1\end{array}$ & 1 & $1,353.21$ & 3.068 & 0.084 \\
\hline $\begin{array}{l}\text { Ranked combined principal } \\
\text { point taking }\end{array}$ & 1 & $5,314.23$ & 12.048 & 0.001 \\
\hline Error & 78 & & & \\
\hline
\end{tabular}

Panel B: $\quad$ ANCOVA comparing the No-Reporting Condition to the Reporting without Accuracy Incentives Condition (Conditions 1 and 2) on Combined Retaliation

\begin{tabular}{|c|c|c|c|c|}
\hline Factor & d.f. & $\begin{array}{l}\text { Sum of } \\
\text { Squares }\end{array}$ & $F$-value & $\begin{array}{c}p \text {-value } \\
\text { (two- } \\
\text { tailed) }\end{array}$ \\
\hline Reporting & 1 & 70.49 & 0.654 & 0.424 \\
\hline $\begin{array}{l}\text { Ranked difference perceived } \\
\text { performance part } 1\end{array}$ & 1 & 488.97 & 4.536 & 0.040 \\
\hline $\begin{array}{l}\text { Ranked combined principal } \\
\text { point taking }\end{array}$ & 1 & 180.48 & 1.674 & 0.204 \\
\hline Error & 36 & & & \\
\hline
\end{tabular}


Panel C: $\quad$ ANCOVA comparing the No-Reporting Condition to the Reporting with Accuracy Incentives Condition (Conditions 1 and 3) on Combined Retaliation

\begin{tabular}{|c|c|c|c|c|}
\hline Factor & d.f. & $\begin{array}{l}\text { Sum of } \\
\text { Squares }\end{array}$ & F-value & $\begin{array}{c}p \text {-value } \\
\text { (two- } \\
\text { tailed) }\end{array}$ \\
\hline Reporting & 1 & 543.60 & 6.519 & 0.015 \\
\hline $\begin{array}{l}\text { Ranked difference perceived } \\
\text { performance part } 1\end{array}$ & 1 & 582.03 & 6.980 & 0.012 \\
\hline $\begin{array}{l}\text { Ranked combined principal } \\
\text { point taking }\end{array}$ & 1 & 374.94 & 4.497 & 0.041 \\
\hline Error & 36 & & & \\
\hline
\end{tabular}

Panel D: $\quad$ ANCOVA comparing the No-Reporting Condition to the Reporting to the Experimenter Condition (Conditions 1 and 4) on Combined Retaliation

\begin{tabular}{|c|c|c|c|c|}
\hline Factor & d.f. & $\begin{array}{l}\text { Sum of } \\
\text { Squares }\end{array}$ & F-value & $\begin{array}{c}p \text {-value } \\
\text { (two- } \\
\text { tailed) }\end{array}$ \\
\hline Reporting & 1 & 54.76 & .494 & 0.486 \\
\hline $\begin{array}{l}\text { Ranked difference perceived } \\
\text { performance part } 1\end{array}$ & 1 & 285.29 & 2.575 & 0.117 \\
\hline $\begin{array}{l}\text { Ranked combined principal } \\
\text { point taking }\end{array}$ & 1 & 76.85 & .694 & 0.410 \\
\hline Error & 38 & & & \\
\hline
\end{tabular}


Panel E:

Correlation between Perception Bias and Retaliation in Part 2 Round 1

Pearson correlation coefficient

0.279

p-value (two-tailed)

0.028

Panel F:

Correlation between Perception Bias and Retaliation in Part 2 Round 2

Pearson correlation coefficient

p-value (two-tailed)
0.274

0.031 


\section{Table 3}

\section{ANCOVA for the Effect of Reporting on Combined Economic Score}

Panel A: $\quad$ ANCOVA for the Effect of Reporting on the Ranked Combined Economic Score (Retaliation in Round 1 and 2 net of Principal Point Taking in Round 1 and 2)

\begin{tabular}{|c|c|c|c|c|}
\hline Factor & d.f. & $\begin{array}{l}\text { Sum of } \\
\text { Squares }\end{array}$ & $F$-value & $\begin{array}{c}p \text {-value } \\
\text { (two- } \\
\text { tailed) }\end{array}$ \\
\hline Reporting & 1 & $2,199.28$ & 4.535 & 0.036 \\
\hline $\begin{array}{l}\text { Ranked difference perceived } \\
\text { agent performance part } 1\end{array}$ & 1 & $2,325.15$ & 4.794 & 0.032 \\
\hline Error & 79 & & & \\
\hline
\end{tabular}

Panel B: $\quad$ ANCOVA for the Effect of Reporting of Estimates (conditions 2, 3, and 4) on Ranked Combined Economic Score

\begin{tabular}{|c|c|c|c|c|}
\hline Factor & d.f. & $\begin{array}{l}\text { Sum of } \\
\text { Squares }\end{array}$ & F-value & $\begin{array}{c}p \text {-value } \\
\text { (two- } \\
\text { tailed) }\end{array}$ \\
\hline Reporting & 2 & 158.68 & .489 & 0.616 \\
\hline $\begin{array}{l}\text { Ranked difference perceived } \\
\text { performance part } 1\end{array}$ & 1 & 695.54 & 2.142 & 0.149 \\
\hline Error & 59 & & & \\
\hline
\end{tabular}


Panel C: $\quad$ ANCOVA Comparing the No-Reporting Condition to the Reporting without Accuracy Incentives Condition (Conditions 1 and 2) on Ranked Combined Economic Score

\begin{tabular}{|c|c|c|c|c|}
\hline Factor & d.f. & $\begin{array}{l}\text { Sum of } \\
\text { Squares }\end{array}$ & F-value & $\begin{array}{c}p \text {-value } \\
\text { (two- } \\
\text { tailed) }\end{array}$ \\
\hline Reporting & 1 & 413.47 & 3.710 & 0.062 \\
\hline $\begin{array}{l}\text { Ranked difference perceived } \\
\text { performance part } 1\end{array}$ & 1 & 259.70 & 2.330 & 0.136 \\
\hline Error & 37 & & & \\
\hline
\end{tabular}

Panel D: $\quad$ ANCOVA Comparing the No-Reporting Condition to the Reporting with Accuracy Incentives Condition (Conditions 1 and 3) on Ranked Combined Economic Score

\begin{tabular}{|c|c|c|c|c|}
\hline Factor & d.f. & $\begin{array}{l}\text { Sum of } \\
\text { Squares }\end{array}$ & F-value & $\begin{array}{c}p \text {-value } \\
\text { (two- } \\
\text { tailed) }\end{array}$ \\
\hline Reporting & 1 & 339.68 & 3.718 & 0.062 \\
\hline $\begin{array}{l}\text { Ranked difference perceived } \\
\text { performance part } 1\end{array}$ & 1 & 835.98 & 9.150 & 0.005 \\
\hline Error & 37 & & & \\
\hline
\end{tabular}


Panel E: $\quad$ ANCOVA Comparing the No-Reporting Condition to the Reporting to the Experimenter Condition (Conditions 1 and 4) on Ranked Combined Economic Score

\begin{tabular}{|c|c|c|c|c|}
\hline Factor & d.f. & $\begin{array}{l}\text { Sum of } \\
\text { Squares }\end{array}$ & $F$-value & $\begin{array}{c}p \text {-value } \\
\text { (two- } \\
\text { tailed) }\end{array}$ \\
\hline Reporting & 1 & 178.30 & 1.452 & 0.236 \\
\hline $\begin{array}{l}\text { Ranked difference perceived } \\
\text { performance part } 1\end{array}$ & 1 & 517.97 & 4.218 & 0.047 \\
\hline Error & 39 & & & \\
\hline
\end{tabular}


Table 4

ANOVA for the Effect of Reporting on Agent Production Part 2

Panel A: $\quad$ ANOVA Results

\begin{tabular}{|c|c|c|c|c|}
\hline Factor & d.f. & $\begin{array}{l}\text { Sum of } \\
\text { Squares }\end{array}$ & $F$-value & $\begin{array}{c}p \text {-value } \\
\text { (two- } \\
\text { tailed) }\end{array}$ \\
\hline Reporting & 1 & 5.493 & 0.777 & 0.381 \\
\hline Error & 80 & & & \\
\hline
\end{tabular}




\section{Table 5}

\section{ANCOVA for the Effect of Reporting on Principal Welfare}

Panel A: $\quad$ ANCOVA for Reporting an Estimate on Ranked Principal Welfare

\begin{tabular}{|c|c|c|c|c|}
\hline Factor & d.f. & $\begin{array}{l}\text { Sum of } \\
\text { Squares }\end{array}$ & $F$-value & $\begin{array}{c}p \text {-value } \\
\text { (two- } \\
\text { tailed) }\end{array}$ \\
\hline Reporting & 1 & $2,397.85$ & 5.057 & 0.027 \\
\hline $\begin{array}{l}\text { Ranked difference perceived } \\
\text { performance part } 1\end{array}$ & 1 & $2,808.25$ & 5.923 & 0.017 \\
\hline Error & 79 & & & \\
\hline
\end{tabular}

Panel B: $\quad$ ANCOVA comparing the No-Reporting Condition to the Reporting without Accuracy Incentives Condition (Conditions 1 and 2) on Ranked Principal Welfare

\begin{tabular}{|c|c|c|c|c|}
\hline Factor & d.f. & $\begin{array}{l}\text { Sum of } \\
\text { Squares }\end{array}$ & $F$-value & $\begin{array}{c}p \text {-value } \\
\text { (two- } \\
\text { tailed) }\end{array}$ \\
\hline Reporting & 1 & 541.00 & 5.299 & 0.027 \\
\hline $\begin{array}{l}\text { Ranked difference perceived } \\
\text { performance part } 1\end{array}$ & 1 & 397.35 & 3.892 & 0.056 \\
\hline Error & 37 & & & \\
\hline
\end{tabular}


Panel C: $\quad$ ANCOVA Comparing the No-Reporting Condition to the Reporting with Accuracy Incentives Condition (Conditions 1 and 3) on Ranked Principal Welfare

\begin{tabular}{|c|c|c|c|c|}
\hline Factor & d.f. & $\begin{array}{l}\text { Sum of } \\
\text { Squares }\end{array}$ & $F$-value & $\begin{array}{c}p \text {-value } \\
\text { (two- } \\
\text { tailed) }\end{array}$ \\
\hline Reporting & 1 & 319.63 & 3.479 & 0.070 \\
\hline $\begin{array}{l}\text { Ranked difference perceived } \\
\text { performance part } 1\end{array}$ & 1 & 854.34 & 9.298 & 0.004 \\
\hline Error & 37 & & & \\
\hline
\end{tabular}

Panel D: $\quad$ ANCOVA Comparing the No-Reporting Condition to the Reporting to the Experimenter Condition (Conditions 1 and 4) on Ranked Principal Welfare

\begin{tabular}{|c|c|c|c|c|}
\hline Factor & d.f. & $\begin{array}{l}\text { Sum of } \\
\text { Squares }\end{array}$ & F-value & $\begin{array}{c}p \text {-value } \\
\text { (two- } \\
\text { tailed) }\end{array}$ \\
\hline Reporting & 1 & 146.52 & 1.163 & 0.288 \\
\hline $\begin{array}{l}\text { Ranked difference perceived } \\
\text { performance part } 1\end{array}$ & 1 & 489.71 & 3.888 & 0.056 \\
\hline Error & 39 & & & \\
\hline
\end{tabular}




\section{Table 6}

\section{Agent Overconfidence in Part 1 and Part 2 Using Supplemental Data}

Panel A: $\quad$ Means (Standard Deviation) for Agent Overconfidence (Calculated as the Difference between Estimated Performance and Actual Performance by Agents)

\begin{tabular}{|c|c|c|c|c|}
\hline & $\begin{array}{l}\text { No self- } \\
\text { reporting }\end{array}$ & $\begin{array}{c}\text { Self- } \\
\text { reporting } \\
\text { without } \\
\text { accuracy } \\
\text { incentives }\end{array}$ & $\begin{array}{c}\text { Self- } \\
\text { reporting } \\
\text { with } \\
\text { accuracy } \\
\text { incentives }\end{array}$ & $\begin{array}{l}\text { Self-reporting } \\
\text { to the } \\
\text { experimenter }\end{array}$ \\
\hline & $\mathrm{N}=19$ & $\mathrm{~N}=20$ & $\mathrm{~N}=20$ & $\mathrm{~N}=22$ \\
\hline - $\quad$ Part 1 & $\begin{array}{c}1.68 \\
(4.84)\end{array}$ & $\begin{array}{c}3.35 \\
(3.90)\end{array}$ & $\begin{array}{c}3.55 \\
(4.44)\end{array}$ & $\begin{array}{c}4.77 \\
(4.01)\end{array}$ \\
\hline - $\quad$ Part 2 Round 1 & $\begin{array}{c}2.05 \\
(4.54)\end{array}$ & $\begin{array}{c}4.30 \\
(5.14)\end{array}$ & $\begin{array}{c}5.15 \\
(3.57)\end{array}$ & $\begin{array}{c}6.68 \\
(4.20)\end{array}$ \\
\hline - $\quad$ Part 2 Round 2 & $\begin{array}{c}1.89 \\
(4.56)\end{array}$ & $\begin{array}{c}6.85 \\
(6.52)\end{array}$ & $\begin{array}{c}4.90 \\
(4.32)\end{array}$ & $\begin{array}{c}5.23 \\
(5.63)\end{array}$ \\
\hline \multicolumn{5}{|c|}{$\begin{array}{ll}\text { Panel B: } & \text { ANCOVA for the Effect of Reporting on Overconfidence in Round } 1 \\
& \text { (Difference between Estimated Performance and Actual Performance) }\end{array}$} \\
\hline Factor & d.f. & $\begin{array}{l}\text { Sum of } \\
\text { Squares }\end{array}$ & $F$-value & $\begin{array}{c}p \text {-value } \\
\text { (two- } \\
\text { tailed) }\end{array}$ \\
\hline Reporting & 1 & 78.56 & 4.84 & 0.03 \\
\hline $\begin{array}{l}\text { Ranked difference perceived } \\
\text { performance part } 1\end{array}$ & 1 & 281.34 & 17.32 & $<0.01$ \\
\hline Error & 79 & & & \\
\hline
\end{tabular}


Panel C: $\quad$ ANCOVA for the Effect of Reporting on Overconfidence in Round 2 (Difference between Estimated Performance and Actual Performance)

\begin{tabular}{|c|c|c|c|c|}
\hline Factor & d.f. & $\begin{array}{l}\text { Sum of } \\
\text { Squares }\end{array}$ & F-value & $\begin{array}{c}p \text {-value } \\
\text { (two- } \\
\text { tailed) }\end{array}$ \\
\hline Reporting & 1 & 97.21 & 4.00 & 0.05 \\
\hline $\begin{array}{l}\text { Ranked difference perceived } \\
\text { performance part } 1\end{array}$ & 1 & 351.50 & 14.47 & $<0.01$ \\
\hline Error & 79 & & & \\
\hline
\end{tabular}

Panel D: $\quad$ Means (Standard Deviation) for Difference between Perceived Performance and Actual Performance

No estimate of Estimate of performance performance
$\mathrm{N}=19$
$\mathrm{N}=62$

Part 1

1.68

3.92

(4.84)

Part 2 (average)

2.92

6.06

Panel E: $\quad$ Comparison between Perception of Performance by Agents in Part 1 and Part 2 split by Estimation

p-value

t-value (two-tailed)

$\begin{array}{llll}\text { No estimate of performance } & \mathrm{N}=19 & -1.10 & 0.29 \\ \text { Estimate of performance } & \mathrm{N}=62 & -3.72 & <0.01\end{array}$




\section{Table 7}

\section{Agent Overconfidence for Agents Who Are Overconfident or Accurate in Part 1}

Panel A: $\quad$ Means (Standard Deviation) of Difference between Perception of Performance and Performance for Agents who were Overconfident or Accurate in their Perception of Performance in Part 1

\begin{tabular}{|c|c|c|c|c|}
\hline & $\begin{array}{l}\text { No self- } \\
\text { reporting }\end{array}$ & $\begin{array}{l}\text { Self- } \\
\text { reporting } \\
\text { without } \\
\text { accuracy } \\
\text { incentives }\end{array}$ & $\begin{array}{l}\text { Self- } \\
\text { reporting } \\
\text { with } \\
\text { accuracy } \\
\text { incentives }\end{array}$ & $\begin{array}{l}\text { Self- } \\
\text { reporting to } \\
\text { the } \\
\text { experimenter }\end{array}$ \\
\hline & $\mathrm{N}=12$ & $\mathrm{~N}=16$ & $\mathrm{~N}=16$ & $\mathrm{~N}=21$ \\
\hline Part 1 & $\begin{array}{c}4.50 \\
(3.78)\end{array}$ & $\begin{array}{c}4.44 \\
(3.60)\end{array}$ & $\begin{array}{c}4.81 \\
(4.05)\end{array}$ & $\begin{array}{c}5.05 \\
(3.90)\end{array}$ \\
\hline - $\quad$ Part 2 Round 1 & $\begin{array}{c}3.33 \\
(5.14)\end{array}$ & $\begin{array}{c}4.94 \\
(5.39)\end{array}$ & $\begin{array}{c}5.19 \\
(3.15)\end{array}$ & $\begin{array}{c}6.90 \\
(4.17)\end{array}$ \\
\hline - $\quad$ Part 2 Round 2 & $\begin{array}{c}3.83 \\
(4.55)\end{array}$ & $\begin{array}{c}6.94 \\
(7.21)\end{array}$ & $\begin{array}{c}5.00 \\
(4.84)\end{array}$ & $\begin{array}{c}5.48 \\
(5.65)\end{array}$ \\
\hline Average for Part 2 & $\begin{array}{c}3.58 \\
(4.57)\end{array}$ & $\begin{array}{c}5.94 \\
(4.79)\end{array}$ & $\begin{array}{c}5.09 \\
(3.40)\end{array}$ & $\begin{array}{c}6.19 \\
(4.46)\end{array}$ \\
\hline $\begin{array}{l}\text { Change from Part } 1 \text { to } \\
\text { Part } 2 \text { Average }\end{array}$ & $\begin{array}{l}-0.92 \\
(5.26)\end{array}$ & $\begin{array}{c}1.50 \\
(4.79)\end{array}$ & $\begin{array}{c}0.28 \\
(3.93)\end{array}$ & $\begin{array}{c}1.14 \\
(3.69)\end{array}$ \\
\hline
\end{tabular}


Panel B: $\quad$ ANCOVA for the Effect of Reporting on Difference between Perceived Performance in Part 2 and Actual Performance for Agents who were Overconfident or Accurate in Their Perception in Part 1

\begin{tabular}{|c|c|c|c|c|}
\hline Factor & d.f. & $\begin{array}{l}\text { Sum of } \\
\text { Squares }\end{array}$ & F-value & $\begin{array}{c}p \text {-value } \\
\text { (two- } \\
\text { tailed) }\end{array}$ \\
\hline Reporting & 1 & $1,270.52$ & 4.192 & 0.045 \\
\hline $\begin{array}{l}\text { Ranked difference perceived } \\
\text { performance part } 1\end{array}$ & 1 & $2,636.26$ & 8.698 & 0.004 \\
\hline Error & 63 & & & \\
\hline
\end{tabular}

Panel C: $\quad$ ANCOVA for the Effect of Reporting on Difference in Change of Perceived Performance from Part 1 to Part 2 for Agents who were Overconfident or Accurate in Their Perception in Part 1

\begin{tabular}{|c|c|c|c|c|}
\hline Factor & d.f. & $\begin{array}{l}\text { Sum of } \\
\text { Squares }\end{array}$ & F-value & $\begin{array}{c}p \text {-value } \\
\text { (two- } \\
\text { tailed) }\end{array}$ \\
\hline Reporting & 1 & 142.37 & 1.923 & 0.170 \\
\hline Error & 63 & & & \\
\hline
\end{tabular}




\section{Table 8}

\section{Level of Accuracy in Reporting}

Panel A: $\quad$ Means (Standard Deviation) of Accuracy in Reporting on a 7-point Likert scale

$\begin{array}{ccc}\begin{array}{c}\text { Self- } \\ \text { reporting } \\ \text { without } \\ \text { accuracy } \\ \text { incentives }\end{array} & \begin{array}{c}\text { Self- } \\ \text { reporting } \\ \text { with } \\ \text { accuracy } \\ \text { incentives }\end{array} & \begin{array}{c}\text { Self- } \\ \text { reporting to } \\ \text { the } \\ \text { experimenter }\end{array} \\ \mathrm{N}=20 & \mathrm{~N}=20 & \mathrm{~N}=22 \\ & & \\ 5.35 & 6.20 & 5.55 \\ (1.53) & (0.95) & (1.77)\end{array}$




\section{Table 9}

\section{Agent Attributions of Differences between Perception and Compensation}

Panel A: $\quad$ Means (Standard Deviation) of Attribution of Difference between Perception and Compensation on a 100 Point Scale

\begin{tabular}{cc}
$\begin{array}{c}\text { Higher than } \\
\text { expected } \\
\text { compensation }\end{array}$ & $\begin{array}{c}\text { Lower than } \\
\text { expected } \\
\text { compensation }\end{array}$ \\
\hline $\mathrm{N}=77$ & $\mathrm{~N}=77$
\end{tabular}

To error in own

45.42

68.60

perception

(29.39)

(31.29)

To compensation setting

54.58

31.40

behavior of the principal

(29.76)

Panel B: $\quad$ Comparison between Attribution depending on higher or lower than expected Compensation Condition

\begin{tabular}{lccc} 
& t-value & $\begin{array}{c}p \text {-value } \\
\text { (two- } \\
\text { tailed })\end{array}$ \\
\hline Attribution & $\mathrm{N}=77$ & 4.44 & $<0.01$
\end{tabular}


Table 10

\section{Agent Overconfidence and Retaliation for Agents overconfident in Round 1 in Round 2}

Panel A: $\quad$ Perception of Performance of Agents who were overconfident in their Ability in Round 1

$\begin{array}{ccc} & \begin{array}{c}\text { Overconfidence } \\ \text { in round 1 }\end{array} & \begin{array}{c}\text { Overconfidence } \\ \text { in round } 2\end{array} \\ \text { Mean } & \mathrm{N}=68 & \mathrm{~N}=68 \\ \text { (Standard Deviation) } & 5.68 & 5.21 \\ \text { Median } & (4.01) & (4.87) \\ 25^{\text {th }} \text { percentile } & 5.00 & 5.00 \\ 50^{\text {th }} \text { percentile } & 2.25 & 1.25 \\ 75^{\text {th }} \text { percentile } & 5.00 & 5.00 \\ \end{array}$

Panel B: $\quad$ Comparison of Overconfidence in round 1 and 2 by Agents who were overconfident in Round 1

p-value

t-value (two-tailed)

Bias in perception in round $1 \quad \mathrm{~N}=68 \quad 0.891 \quad 0.376$ versus round 2 
Panel C: $\quad$ Average Retaliation by Agents who were overconfident in Round 1 for Rounds 1 and 2

\begin{tabular}{lcc} 
& $\begin{array}{c}\text { Retaliation in } \\
\text { round 1 }\end{array}$ & $\begin{array}{c}\text { Retaliation in } \\
\text { round 2 }\end{array}$ \\
\hline $\mathrm{N}=68$ & $\mathrm{~N}=68$ \\
Mean & 3.00 & 3.41 \\
(Standard Deviation) & $(5.57)$ & $(5.54)$
\end{tabular}

Panel D: $\quad$ Comparison of Retaliation in Round 1 and 2 by Agents who were overconfident in Round 1

p-value
two-value
tailed)

Retaliation in round 1 versus retaliation in round 2

$\mathrm{N}=68 \quad 0.587 \quad 0.559$




\section{Table 11}

\section{Strategic reporting by agents}

\section{Panel A: $\quad$ Mean Difference between Perception as reported at the End of the Experiment and Self-Reporting to the Principal during the Study}

\begin{tabular}{ccc}
$\begin{array}{c}\text { Self- } \\
\text { reporting } \\
\text { without } \\
\text { accuracy } \\
\text { incentives }\end{array}$ & $\begin{array}{c}\text { Self- } \\
\text { reporting } \\
\text { with } \\
\text { accuracy } \\
\text { incentives }\end{array}$ & $\begin{array}{c}\text { Self- } \\
\text { reporting to } \\
\text { the } \\
\text { experimenter }\end{array}$ \\
\hline $\mathrm{N}=20$ & $\mathrm{~N}=20$ & $\mathrm{~N}=22$
\end{tabular}

Average difference between perception and

0.35

$-0.30$

$-0.05$

estimate reported to

(5.24)

(2.13)

(1.13)

principal 
Panel B: $\quad$ Reported Performance by Agents to Principals during the Study

\begin{tabular}{ccc}
$\begin{array}{c}\text { Self- } \\
\text { reporting } \\
\text { without }\end{array}$ & $\begin{array}{c}\text { Self- } \\
\text { reporting } \\
\text { with }\end{array}$ & $\begin{array}{c}\text { Self- } \\
\text { reporting to } \\
\text { the } \\
\text { accuracy }\end{array}$ \\
$\begin{array}{c}\text { accuracy } \\
\text { incentives }\end{array}$ & $\begin{array}{c}\text { experimenter } \\
\text { incentives }\end{array}$ \\
\hline
\end{tabular}

\section{Round 1}

Average self-report

$\mathrm{N}=20 \quad \mathrm{~N}=20 \quad \mathrm{~N}=22$

Round 1
Average self-report

$<10$
10
$11-14$
15
$16-19$
20
$21-24$
25

\section{Round 2}

Average self-report

10.15

(6.38)

10.15

$(2.41)$

11.32

(4.93)

6
5
5
2
0
2
0
0

8
5
7
0
0
0
0
0

6

4

5

5

2

0

0

0

$<10$
10
$11-14$
15
$16-19$
20
$21-24$
25

25

11
2
2
2
0
2
0
1

(3.65)

10.82

(5.15)

$\begin{array}{cc}10 & 8 \\ 4 & 4 \\ 5 & 6 \\ 0 & 1 \\ 0 & 0 \\ 0 & 0 \\ 1 & 1 \\ 0 & 1\end{array}$


Figure 6

\section{Agent Retaliation}

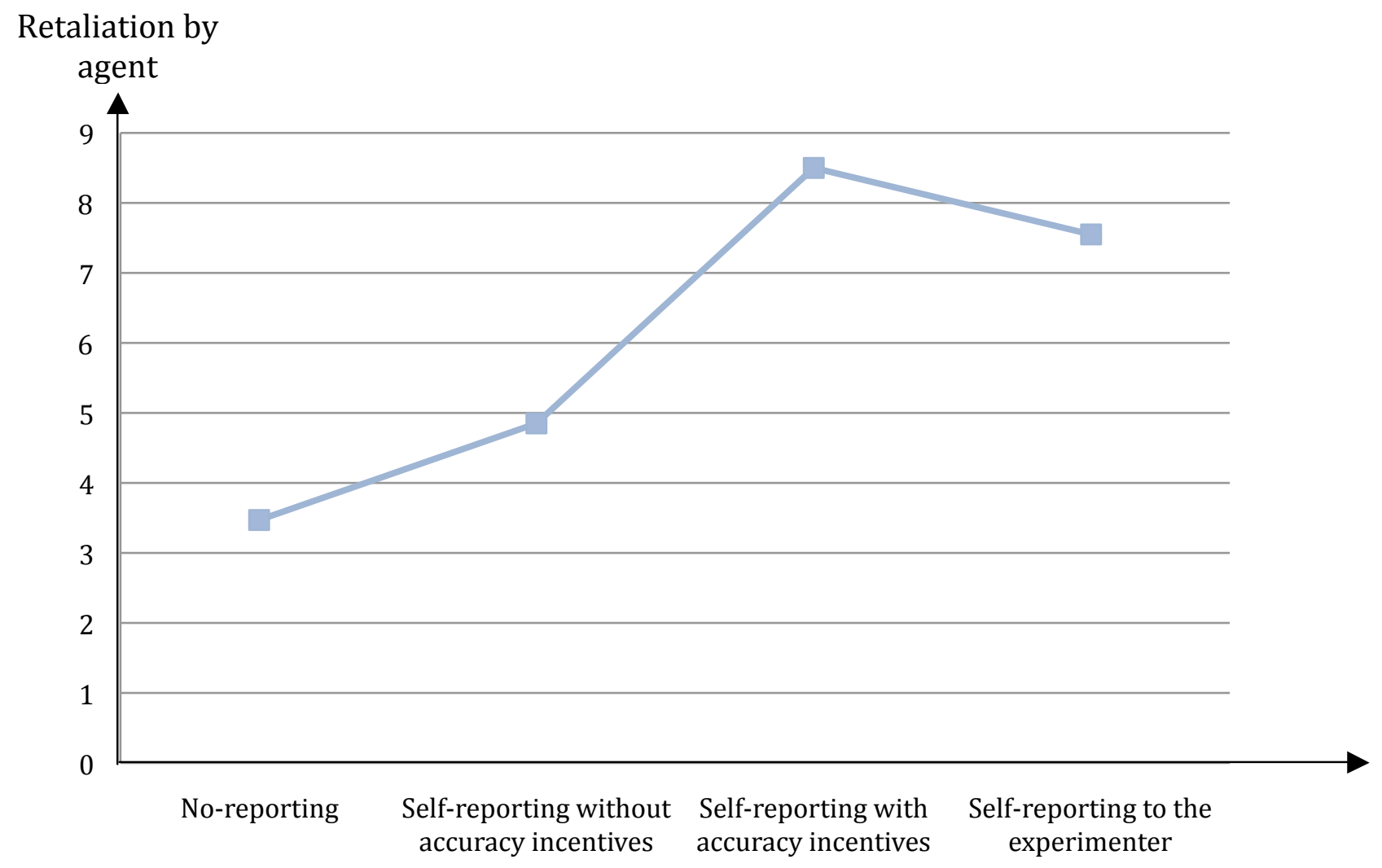

This graph shows the sum of agent retaliation in round one and two by condition, as tabulated in Table 1, Panel A. 
Figure 7

Principal and Agent Welfare

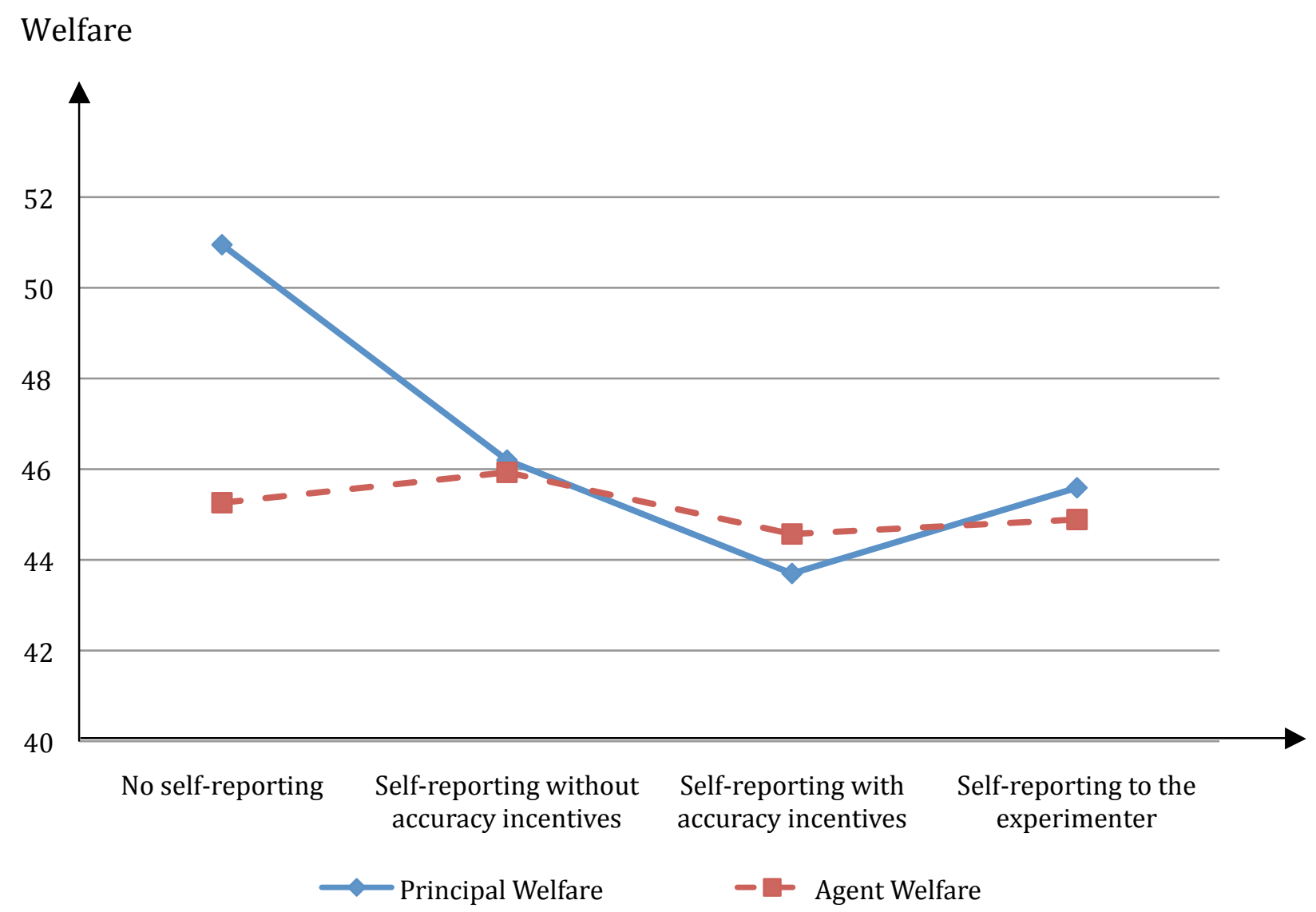

This graph shows agent and principal welfare by condition, as tabulated in Table 1, Panel A. 


\section{CHAPTER 7: CONCLUSION}

This study examines the effect of self-evaluation reports on employee retaliation against employers, by investigating a setting in which employees do not receive information about their marginal contribution to firm welfare, where employers have discretion to set compensation, and where employees can retaliate against employers. Two studies indicate against the opinion voiced in a large body of the literature a negative effect of self-evaluations on employee satisfaction without being able to identify the reason for such a negative effect (Roberson et al. 1993; Inderrieden et al. 2004). This study uses an experimental economics approach to examine potential explanations for the occurrence of negative effects and helps to answer questions raised by findings in these two studies.

Results show that asking agents to provide an estimate of performance leads to higher retaliation. Higher retaliation appears to be due to the effect of self-evaluations on perceptions of performance. Higher perceptions of performance seem to result from a difference in priors that agents in the reporting conditions have when they receive compensation information. Agents who are prompted for an estimate are often overconfident, forming a perception of performance and anchoring on their perception. When those agents receive compensation information, they do not appear to adjust their perception downward for information about performance that is inherent in the compensation received. 
In comparison, agents who are not prompted for an estimate take compensation information into account when forming a perception of their performance. They adjust their overconfidence downward and arrive at a lower estimate, which leads to less retaliation. Higher retaliation from agents who were prompted for an estimate of performance poses a cost to self-evaluations that.

A supplemental analysis of agent and principal decisions in the second round of the experiment, in comparison to their decisions in the first round, indicate that these findings are robust to learning and appear to persist over time. Agents who were overconfident in the first round do not reduce their overconfidence in the second round. This is surprising, given that agents receive feedback from two different principals. Despite receiving negative feedback from a second source, agents do not appear to adjust their bias in perception. Moreover, an additional analysis shows, that principals adjust their point taking behavior in round two to accommodate agent perception differences thereby further complicating agent learning.

These results make a contribution to the literature by showing that selfevaluations lead to a cost and by providing an explanation for the occurrence of this cost. The results indicate that higher retaliation and thereby higher dissatisfaction in the reporting conditions are due, indeed, to asking for an estimate and not to the relationship between the agent and the principal that is created by the reporting situation. The results help us to understand why empirical studies find that companies abandon performance evaluation systems that incorporate self-evaluations. 
Interestingly the results of this study also indicate low levels of strategic reporting by agents meaning that agents do not use self-evaluations to intentionally overstate performance in an effort to extract welfare from the principal. This finding might be a caveat of the specifics of the reporting environment set up in this study. However, it provides an encouraging sign, that self-evaluations can be used in a meaningful way even in environments that do not hold agents directly and strongly accountable for their reporting.

While the findings in this study help us better understand how self-evaluations affect employees, they do not provide the ultimate answer to the question whether selfevaluations are beneficial or detrimental for a company's success. Rather, these findings are a first step in examining an instrument that is widely used by companies but that has been ignored thus far in the management accounting literature.

Implications that can be drawn from this study are limited by the specifics of elements of the setting that defines the principal and agent interaction. The setting in this study emulates a world of subjective performance measures or incentives, where giving objective feedback about performance to employees can be difficult. Emulating this environment is achieved by an information asymmetry between the agent and principal about agent performance. Self-evaluations might have a different effect in a world where employees receive objective incentives and where they can clearly observe their performance or where principals can send a credible signal to agents about their performance. 
In addition, other characteristics of the setting might limit implications that can be drawn from the study. One limitation is that, in work settings, self-ratings could potentially affect other factors such as the level of trust between the superior and the subordinate, which could potentially enhance annual performance review interviews by increasing their efficiency. Specifically, the setting of this study does not allow for a development of any kind of meaningful relationship between the principal and the agent. The only relationship between the two parties consists of the one that is created by the reporting environment. The principal and agent in this study do not meet in person and their interaction is limited to communication via computer. In a real world work setting the principal and agent are likely to have a much more complex relationship. Such added complexity should be considered when drawing implications from this study about costs and benefits of self-ratings for practical use.

An additional limitation is the lack of reputation. In this study neither the principal nor the agent know the history of decisions of the other person. This simplification is done to reduce complexity. This seems a justifiable simplification, because in some work environments managers cannot identify whether an employee is a hard working or a shirking type. Hence, managers cannot identify agent reputation.

When employees perform challenging tasks, then managers cannot determine a standard of expected performance. While this study resembles such an environment by posing challenging questions to agents, it might limit the applicability of the results to 
settings where employees perform non-trivial tasks. However, hardly ever are subjective performance measures and incentives employed for trivial tasks.

Another limitation is that in this setting the principal is aware of agent performance. In real life employers might not be aware of the employee performance with the same level of certainty. Employers usually can obtain information from various sources, such as co-workers or customers, however a certain degree of uncertainty about employee performance remains. This uncertainty about employee performance could potentially work in favor of the employer by decreasing the employees' propensity to retaliate. For instance, employees might give managers the benefit of the doubt of having bad or incomplete information.

Several potential extensions could address limitations of the applicability of the results of this study. One possible extension of this study could be to examine principal compensation setting behavior over a longer horizon to examine intertemporal effects in more depth by having agents and principals interact over additional rounds. Another potential extension of the current study could be to add noise to the signal that the principal receives about agent performance and to examine how it changes the agent's attribution of differences between perceived performance and compensation. A third possible extension is to examine the role of trust between agent and principal. The literature on subjective performance measures recommends that subjective measures require trust between employer and employee. However, in this study higher retaliation 
in the reporting with accuracy incentives condition suggests the possibility that an increase in trust could potentially lead to more retaliation instead of less. 


\section{APPENDICES}




\section{APPENDIX 1 - COMPARISON OF AGENT AND PRINCIPAL CHARACTERISTICS}

Table 12

Panel A: $\quad$ Means (Std deviation) of Participant Characteristics by Role and Condition

\begin{tabular}{|c|c|c|c|c|c|c|c|c|}
\hline & \multicolumn{2}{|c|}{ No self-reporting } & \multicolumn{2}{|c|}{ Self-reporting } & \multicolumn{2}{|c|}{$\begin{array}{l}\text { Self-reporting } \\
\text { with accuracy } \\
\text { incentives }\end{array}$} & \multicolumn{2}{|c|}{$\begin{array}{l}\text { Self-reporting to } \\
\text { the experimenter }\end{array}$} \\
\hline & $\begin{array}{l}\text { Agent } \\
\mathrm{N}=19\end{array}$ & $\begin{array}{c}\text { Principal } \\
\mathrm{N}=19\end{array}$ & $\begin{array}{l}\text { Agent } \\
\mathrm{N}=20\end{array}$ & $\begin{array}{c}\text { Principal } \\
\mathrm{N}=20\end{array}$ & $\begin{array}{l}\text { Agent } \\
\mathrm{N}=20\end{array}$ & $\begin{array}{c}\text { Principal } \\
\mathrm{N}=20\end{array}$ & $\begin{array}{l}\text { Agent } \\
\mathrm{N}=22\end{array}$ & $\begin{array}{c}\text { Principal } \\
\mathrm{N}=22\end{array}$ \\
\hline Gender & $\begin{array}{c}0.63 \\
(0.50)\end{array}$ & $\begin{array}{c}0.58 \\
(0.51)\end{array}$ & $\begin{array}{c}0.63 \\
(0.50)\end{array}$ & $\begin{array}{c}0.63 \\
(0.50)\end{array}$ & $\begin{array}{c}0.50 \\
(0.51)\end{array}$ & $\begin{array}{c}0.45 \\
(0.51)\end{array}$ & $\begin{array}{c}0.41 \\
(0.50)\end{array}$ & $\begin{array}{c}0.55 \\
(.051)\end{array}$ \\
\hline Age & $\begin{array}{c}22.1 \\
(5.12)\end{array}$ & $\begin{array}{l}20.6 \\
(1.74)\end{array}$ & $\begin{array}{c}20.6 \\
(1.35)\end{array}$ & $\begin{array}{l}20.5 \\
(2.04)\end{array}$ & $\begin{array}{c}21.6 \\
(3.96)\end{array}$ & $\begin{array}{c}20.6 \\
(1.79)\end{array}$ & $\begin{array}{c}21.1 \\
(3.16)\end{array}$ & $\begin{array}{l}19.5 \\
(0.67)\end{array}$ \\
\hline GPA & 3.43 & 3.32 & 3.22 & 3.18 & 3.52 & 3.44 & 3.43 & 3.30 \\
\hline $\begin{array}{l}\text { First language } \\
\text { English }\end{array}$ & $\begin{array}{c}0.63 \\
(0.50)\end{array}$ & $\begin{array}{c}0.79 \\
(0.42)\end{array}$ & $\begin{array}{c}0.80 \\
(0.41)\end{array}$ & $\begin{array}{c}0.79 \\
(0.42)\end{array}$ & $\begin{array}{c}0.75 \\
(0.44)\end{array}$ & $\begin{array}{l}0.65 \\
(0.49)\end{array}$ & $\begin{array}{c}0.82 \\
(0.40)\end{array}$ & $\begin{array}{c}0.77 \\
(0.43)\end{array}$ \\
\hline $\begin{array}{l}\text { Familiar with } \\
\text { trivia questions }\end{array}$ & $\begin{array}{c}2.84 \\
(1.50)\end{array}$ & $\begin{array}{c}2.95 \\
(1.55)\end{array}$ & $\begin{array}{l}3.50 \\
(1.67)\end{array}$ & $\begin{array}{l}3.10 \\
(1.62)\end{array}$ & $\begin{array}{c}2.85 \\
(1.14)\end{array}$ & $\begin{array}{l}3.05 \\
(1.91)\end{array}$ & $\begin{array}{c}3.18 \\
(1.44)\end{array}$ & $\begin{array}{l}3.00 \\
(1.75)\end{array}$ \\
\hline History knowledge & $\begin{array}{c}3.42 \\
(1.22)\end{array}$ & $\begin{array}{c}3.63 \\
(1.83)\end{array}$ & $\begin{array}{c}3.55 \\
(1.54)\end{array}$ & $\begin{array}{l}3.70 \\
(1.26)\end{array}$ & $\begin{array}{c}3.30 \\
(1.13)\end{array}$ & $\begin{array}{l}3.10 \\
(1.55)\end{array}$ & $\begin{array}{c}3.50 \\
(1.34)\end{array}$ & $\begin{array}{c}3.41 \\
(1.87)\end{array}$ \\
\hline Need to excel & $\begin{array}{c}6.11 \\
(1.05)\end{array}$ & $\begin{array}{c}6.32 \\
(0.95)\end{array}$ & $\begin{array}{l}5.90 \\
(1.62)\end{array}$ & $\begin{array}{c}6.15 \\
(0.93)\end{array}$ & $\begin{array}{c}6.20 \\
(1.15)\end{array}$ & $\begin{array}{c}6.30 \\
(0.87)\end{array}$ & $\begin{array}{c}6.64 \\
(0.49)\end{array}$ & $\begin{array}{c}6.45 \\
(0.74)\end{array}$ \\
\hline $\begin{array}{l}\text { Need for } \\
\text { achievement }\end{array}$ & $\begin{array}{c}5.79 \\
(1.08)\end{array}$ & $\begin{array}{l}5.68 \\
(1.49)\end{array}$ & $\begin{array}{c}5.40 \\
(1.70)\end{array}$ & $\begin{array}{c}5.60 \\
(1.27)\end{array}$ & $\begin{array}{c}5.75 \\
(1.48)\end{array}$ & $\begin{array}{c}6.00 \\
(1.08)\end{array}$ & $\begin{array}{c}5.77 \\
(1.11)\end{array}$ & $\begin{array}{c}5.73 \\
(0.99)\end{array}$ \\
\hline $\begin{array}{l}\text { Importance of } \\
\text { money }\end{array}$ & $\begin{array}{c}5.42 \\
(1.58)\end{array}$ & $\begin{array}{c}5.32 \\
(1.53)\end{array}$ & $\begin{array}{c}4.85 \\
(1.57)\end{array}$ & $\begin{array}{l}5.30 \\
(1.22)\end{array}$ & $\begin{array}{l}5.20 \\
(1.67)\end{array}$ & $\begin{array}{c}5.50 \\
(1.36)\end{array}$ & $\begin{array}{c}5.14 \\
(1.49)\end{array}$ & $\begin{array}{l}5.55 \\
(1.06)\end{array}$ \\
\hline $\begin{array}{l}\text { Estimated } \\
\text { performance in } \\
\text { part } 1\end{array}$ & $\begin{array}{c}7.63 \\
(4.67)\end{array}$ & $\begin{array}{c}8.89 \\
(3.70)\end{array}$ & $\begin{array}{l}9.05 \\
(3.50)\end{array}$ & $\begin{array}{c}9.25 \\
(3.14)\end{array}$ & $\begin{array}{l}9.35 \\
(4.89)\end{array}$ & $\begin{array}{l}10.30 \\
(4.37)\end{array}$ & $\begin{array}{l}10.55 \\
(3.36)\end{array}$ & $\begin{array}{c}9.86 \\
(4.09)\end{array}$ \\
\hline $\begin{array}{l}\text { Actual } \\
\text { performance in } \\
\text { part } 1\end{array}$ & $\begin{array}{c}5.95 \\
(2.53)\end{array}$ & $\begin{array}{c}5.21 \\
(1.78)\end{array}$ & $\begin{array}{c}5.70 \\
(2.58)\end{array}$ & $\begin{array}{l}5.40 \\
(2.21)\end{array}$ & $\begin{array}{c}5.80 \\
(1.74)\end{array}$ & $\begin{array}{l}4.60 \\
(2.56)\end{array}$ & $\begin{array}{c}5.77 \\
(2.47)\end{array}$ & $\begin{array}{c}5.00 \\
(1.85)\end{array}$ \\
\hline $\begin{array}{l}\text { Difference } \\
\text { perception and } \\
\text { actual performance } \\
\text { in part } 1\end{array}$ & $\begin{array}{c}1.68 \\
(4.84)\end{array}$ & $\begin{array}{c}3.68 \\
(4.28)\end{array}$ & $\begin{array}{c}3.35 \\
(3.90)\end{array}$ & $\begin{array}{c}3.85 \\
(4.18)\end{array}$ & $\begin{array}{c}3.55 \\
(4.44)\end{array}$ & $\begin{array}{c}5.70 \\
(3.73)\end{array}$ & $\begin{array}{c}4.77 \\
(4.01)\end{array}$ & $\begin{array}{c}4.86 \\
(4.14)\end{array}$ \\
\hline
\end{tabular}


Panel B: $\quad$ ANOVAs Participant Characteristics for Agents on Reporting

\begin{tabular}{|c|c|c|c|c|}
\hline Factor & $\begin{array}{l}\text { Sum of } \\
\text { Squares }\end{array}$ & d.f. & F-value & $\begin{array}{c}p \text {-value } \\
\text { (two-tailed) }\end{array}$ \\
\hline Gender & 0.22 & 1 & 0.875 & 0.353 \\
\hline Age & 24.23 & 1 & 1.871 & 0.175 \\
\hline GPA & 0.02 & 1 & 0.076 & 0.784 \\
\hline First language English & 0.37 & 1 & 1.970 & 0.164 \\
\hline $\begin{array}{l}\text { Familiar with trivia } \\
\text { questions }\end{array}$ & 1.64 & 1 & 0.780 & 0.380 \\
\hline History knowledge & 0.14 & 1 & 0.008 & 0.929 \\
\hline Importance of excelling & 0.34 & 1 & 0.254 & 0.616 \\
\hline Need for achievement & 0.34 & 1 & 0.165 & 0.686 \\
\hline Importance of money & 1.85 & 1 & 0.759 & 0.386 \\
\hline $\begin{array}{l}\text { Estimated performance } \\
\text { in part } 1\end{array}$ & 60.87 & 1 & 3.578 & 0.062 \\
\hline $\begin{array}{l}\text { Actual performance in } \\
\text { part } 1\end{array}$ & 0.52 & 1 & 0.097 & 0.757 \\
\hline $\begin{array}{l}\text { Difference between } \\
\text { perception and actual } \\
\text { performance in part } 1\end{array}$ & 72.66 & 1 & 3.962 & 0.050 \\
\hline
\end{tabular}


Panel C: $\quad$ ANOVAs Participant Characteristics for Principals on Reporting

\begin{tabular}{|c|c|c|c|c|}
\hline Factor & $\begin{array}{l}\text { Sum of } \\
\text { Squares }\end{array}$ & d.f. & F-value & $\begin{array}{c}p \text {-value } \\
\text { (two-tailed) }\end{array}$ \\
\hline Gender & 0.02 & 1 & 0.082 & 0.775 \\
\hline Age & 3.40 & 1 & 1.237 & 0.270 \\
\hline GPA & $<0.01$ & 1 & 0.008 & 0.930 \\
\hline First language English & 0.04 & 1 & 0.202 & 0.654 \\
\hline $\begin{array}{l}\text { Familiar with trivia } \\
\text { questions }\end{array}$ & 0.15 & 1 & 0.052 & 0.820 \\
\hline History knowledge & 0.76 & 1 & 0.281 & 0.598 \\
\hline Importance of excelling & $<0.01$ & 1 & 0.002 & 0.967 \\
\hline Need for achievement & 0.12 & 1 & 0.081 & 0.777 \\
\hline Importance of money & 0.27 & 1 & 0.164 & 0.687 \\
\hline $\begin{array}{l}\text { Estimated performance } \\
\text { in part } 1\end{array}$ & 12.09 & 1 & 0.825 & 0.366 \\
\hline $\begin{array}{l}\text { Actual performance in } \\
\text { part } 1\end{array}$ & 0.65 & 1 & 0.144 & 0.705 \\
\hline $\begin{array}{l}\text { Difference between } \\
\text { perception and actual } \\
\text { performance in part } 1\end{array}$ & 18.36 & 1 & 1.095 & 0.299 \\
\hline
\end{tabular}




\section{APPENDIX 2 - INSTRUCTIONS TO PARTICIPANTS}

\subsection{Instructions Part 1}

Participants received instructions in form of a Powerpoint slide show. The slides are depicted in the this section. The heading above each slide describes to which condition the slide applied. 
[Instructions in part 1 are identical for all conditions]

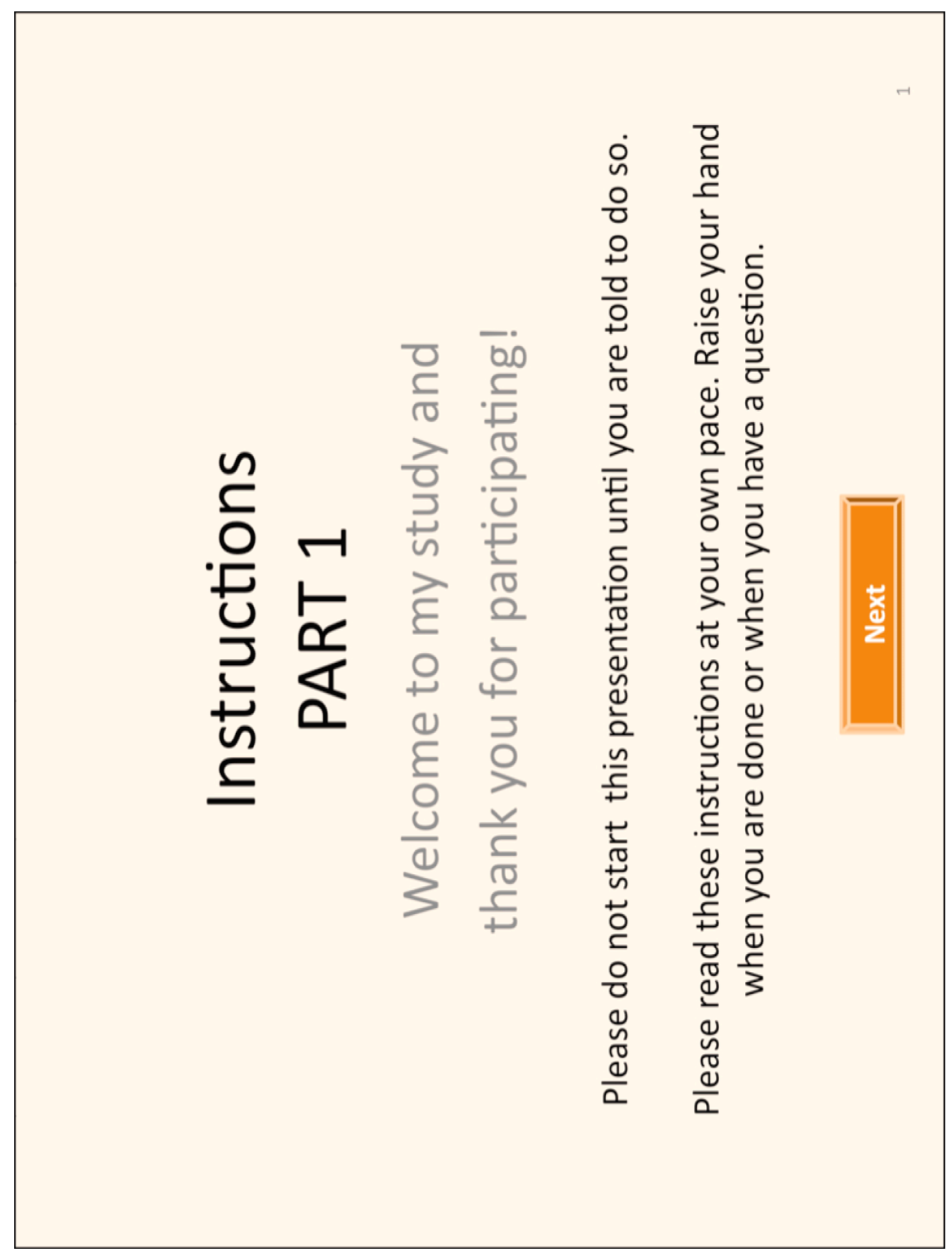




\section{[All conditions]}

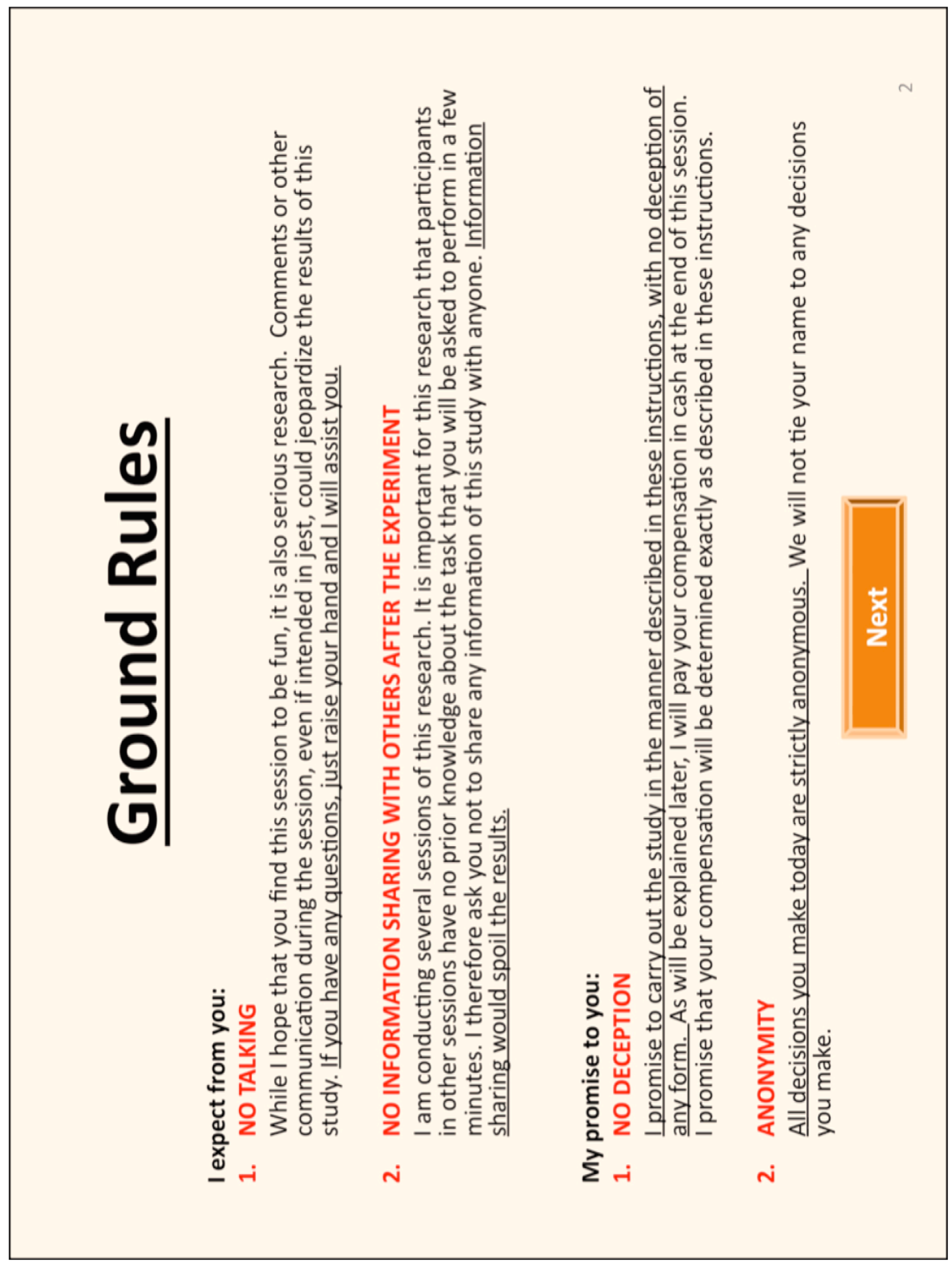


[All conditions]

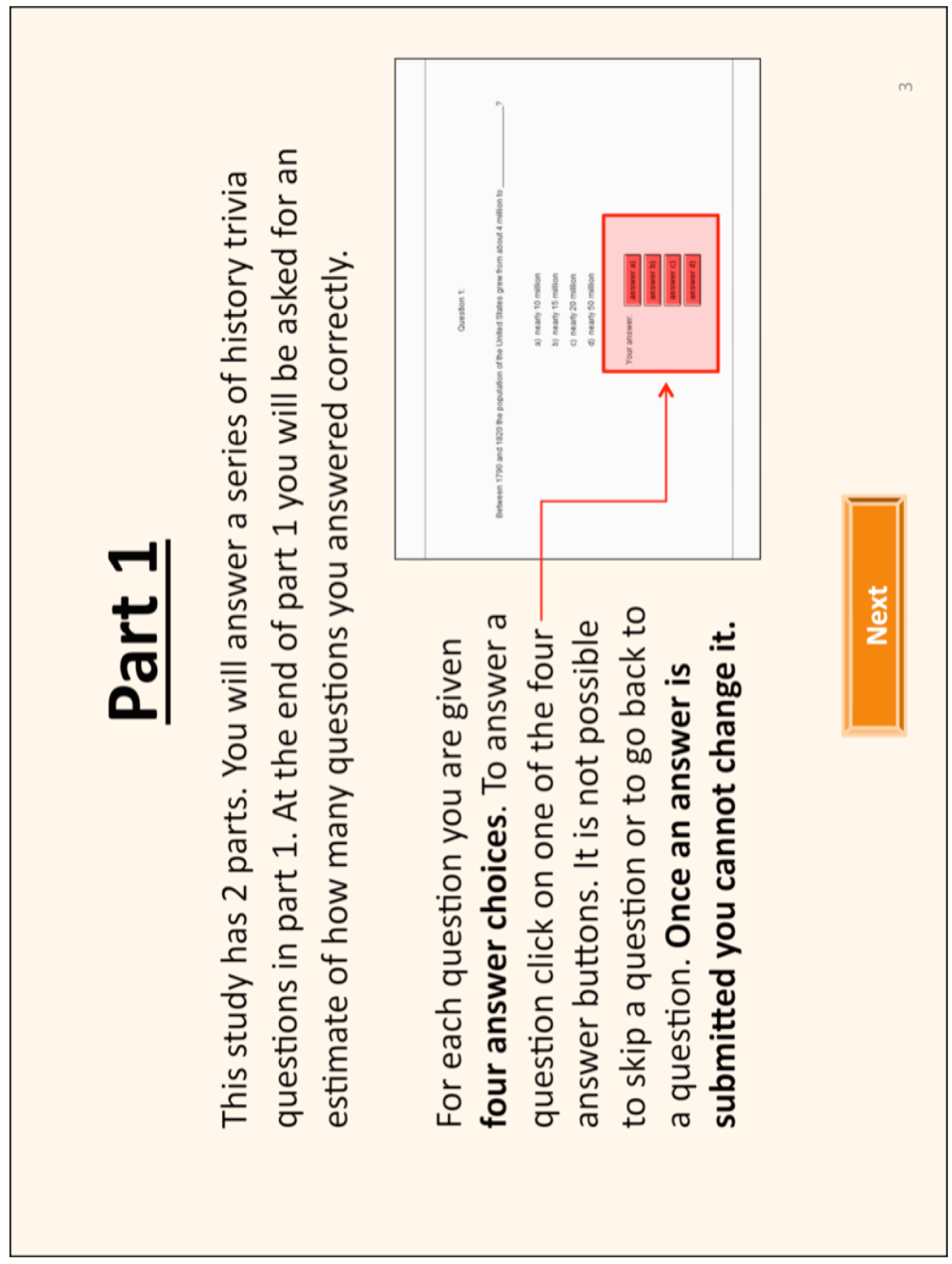


[All conditions]

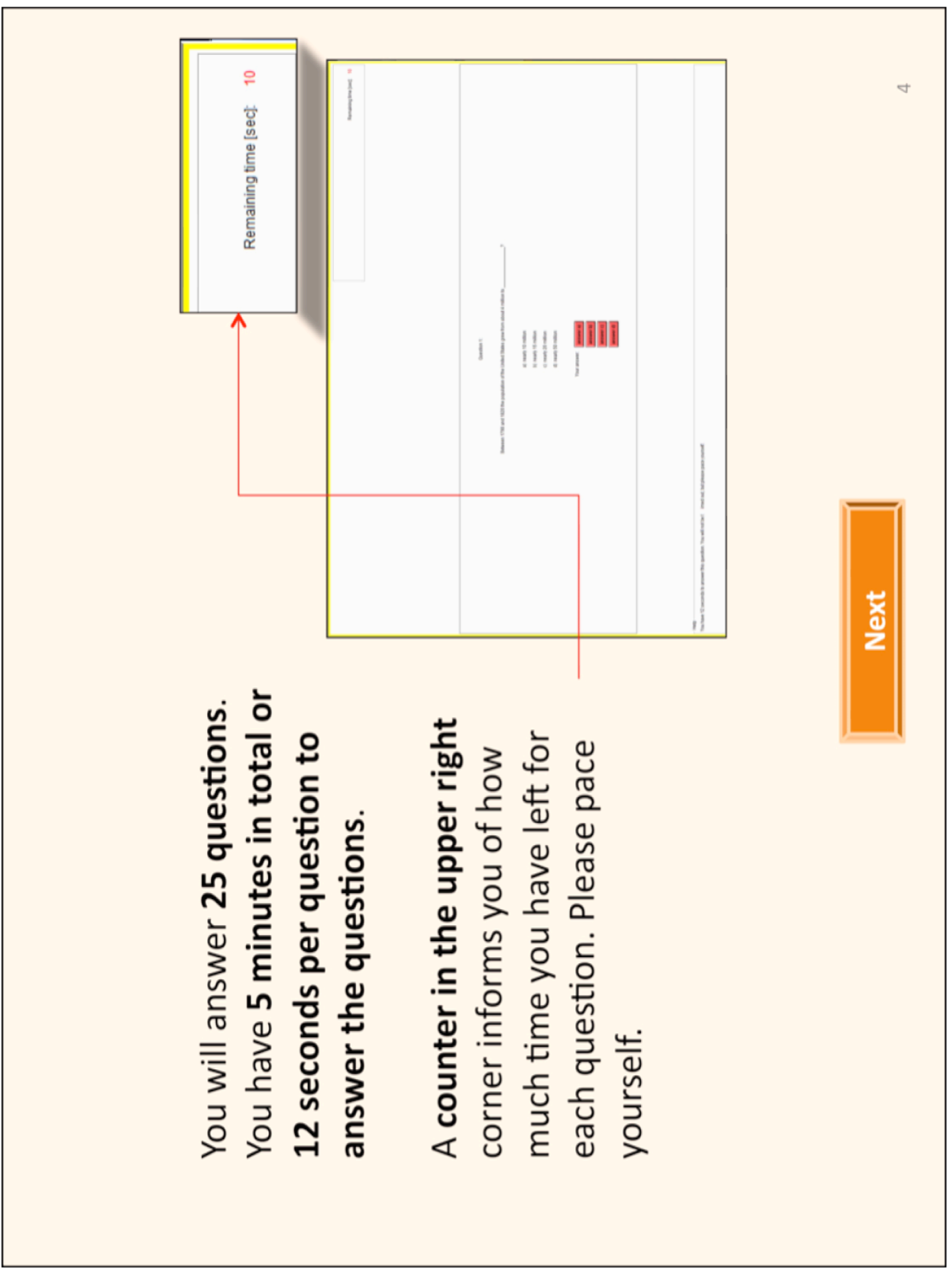


[All conditions]

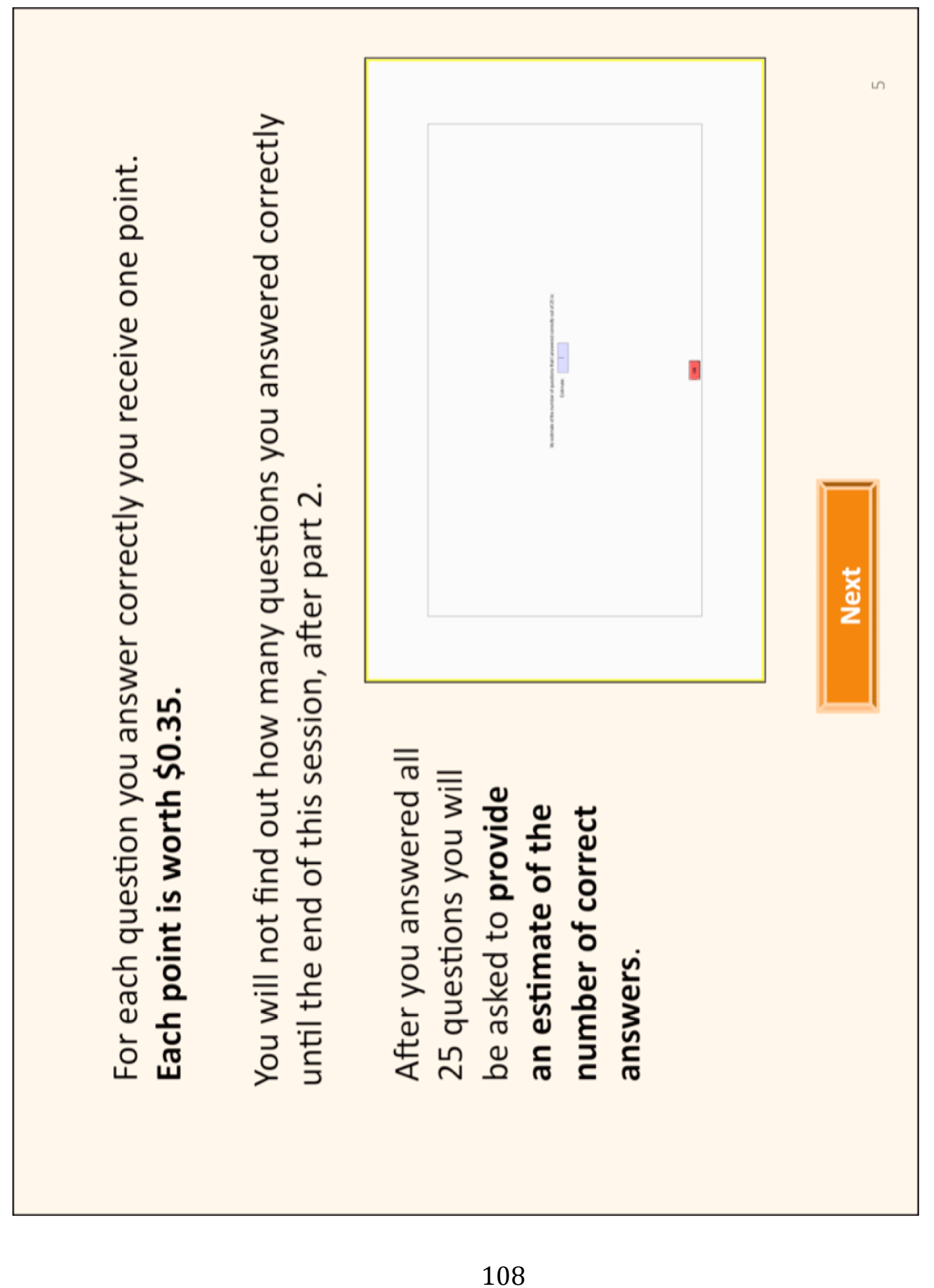


[All conditions]

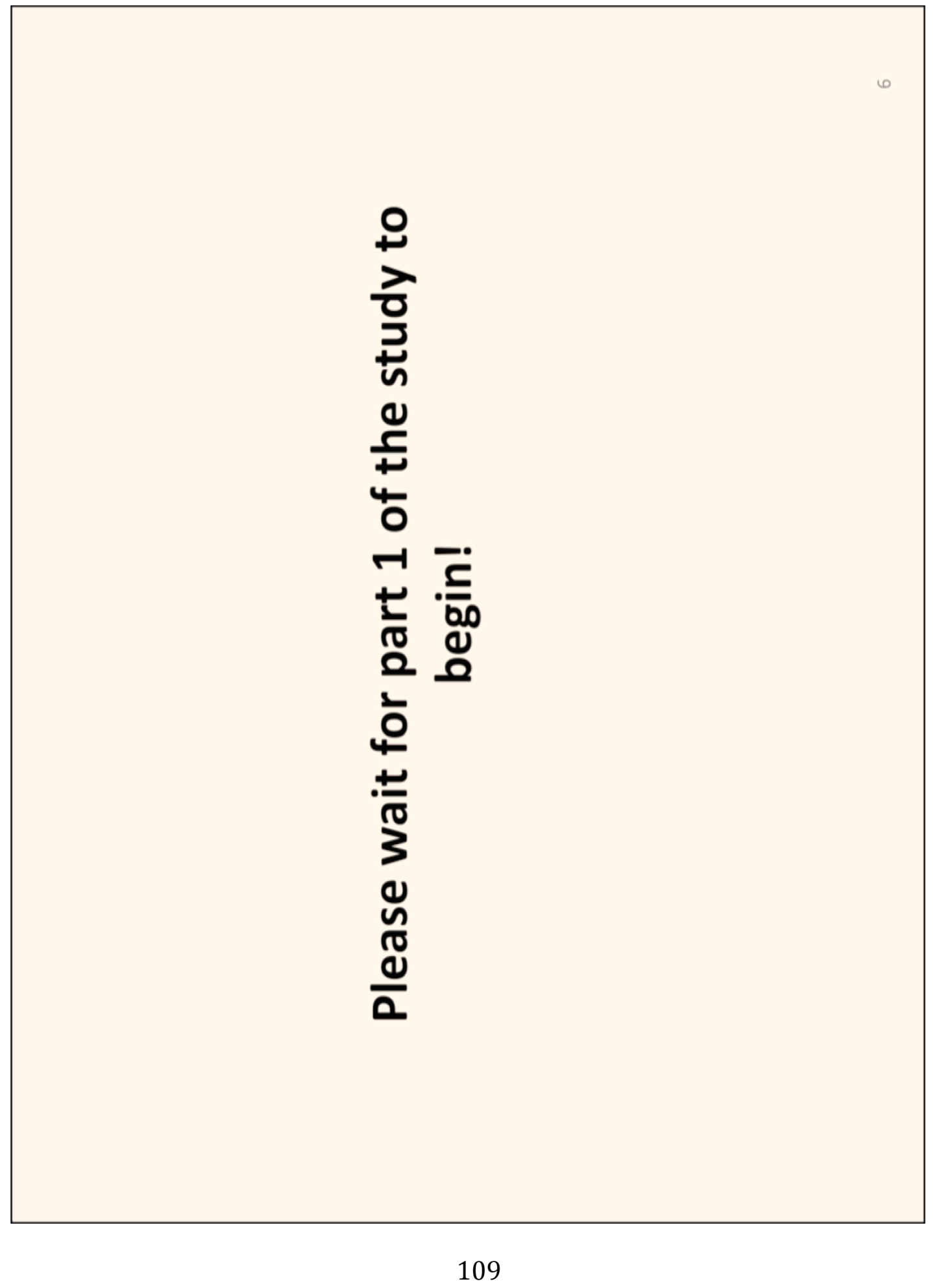




\subsection{Instructions Part 2}

Participants received instructions in form of a Powerpoint slide show. The instructions for part 2 of the study are depicted in the this section. The heading above each slide describes to which condition the slide was shown. 
[All conditions]

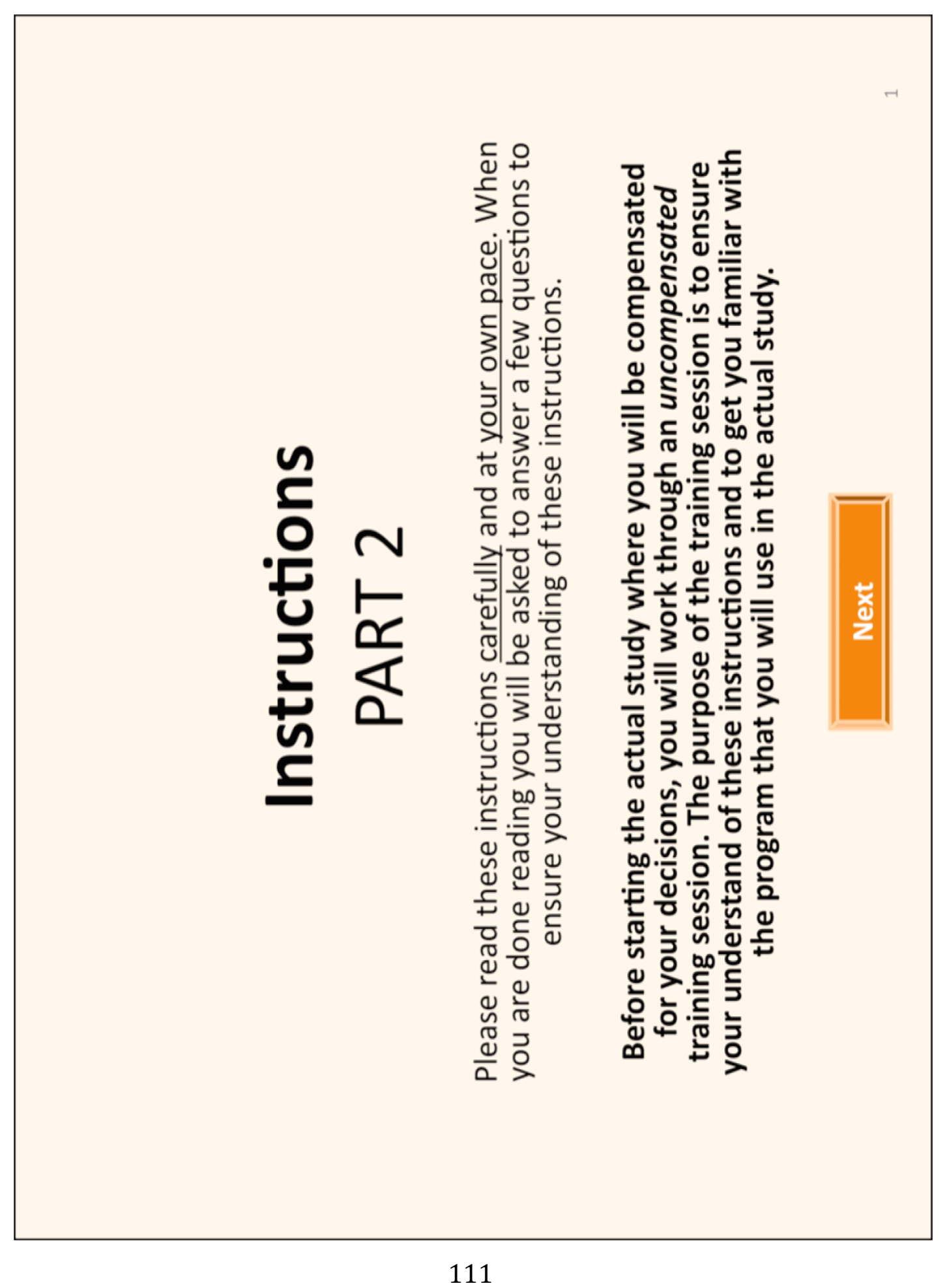




\section{[All conditions]}

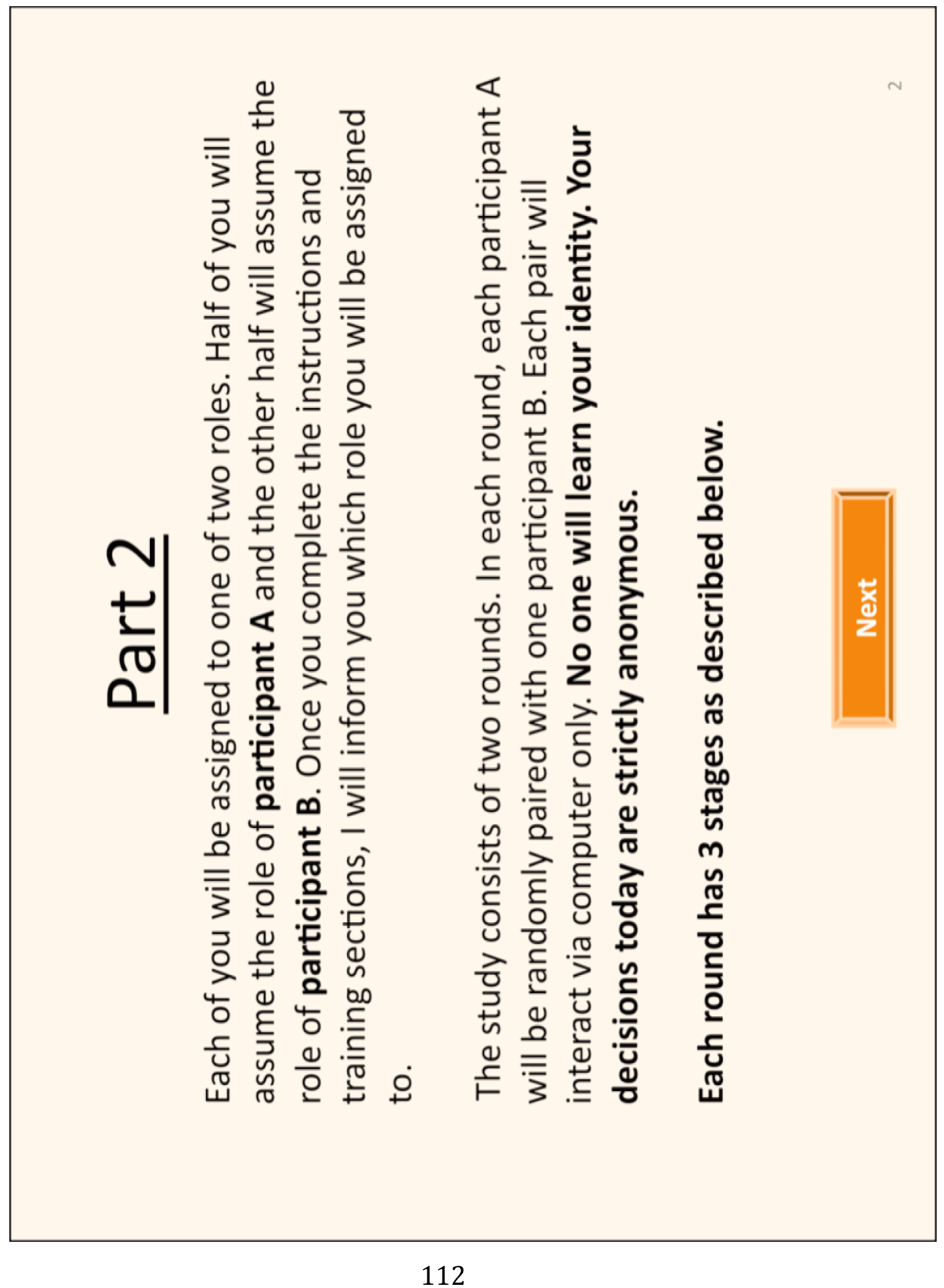


[All conditions]

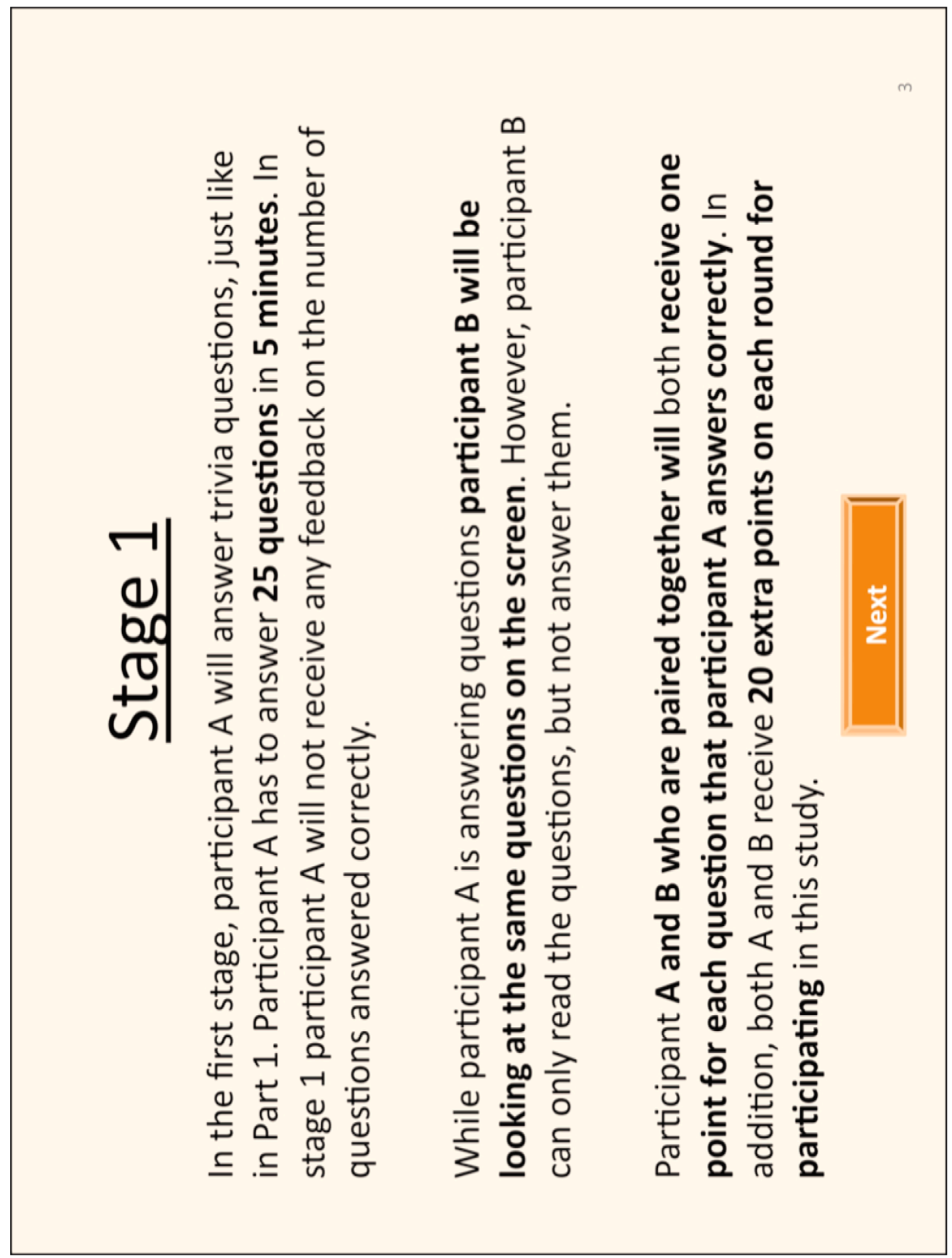


[Reporting to principal without accuracy incentives condition]

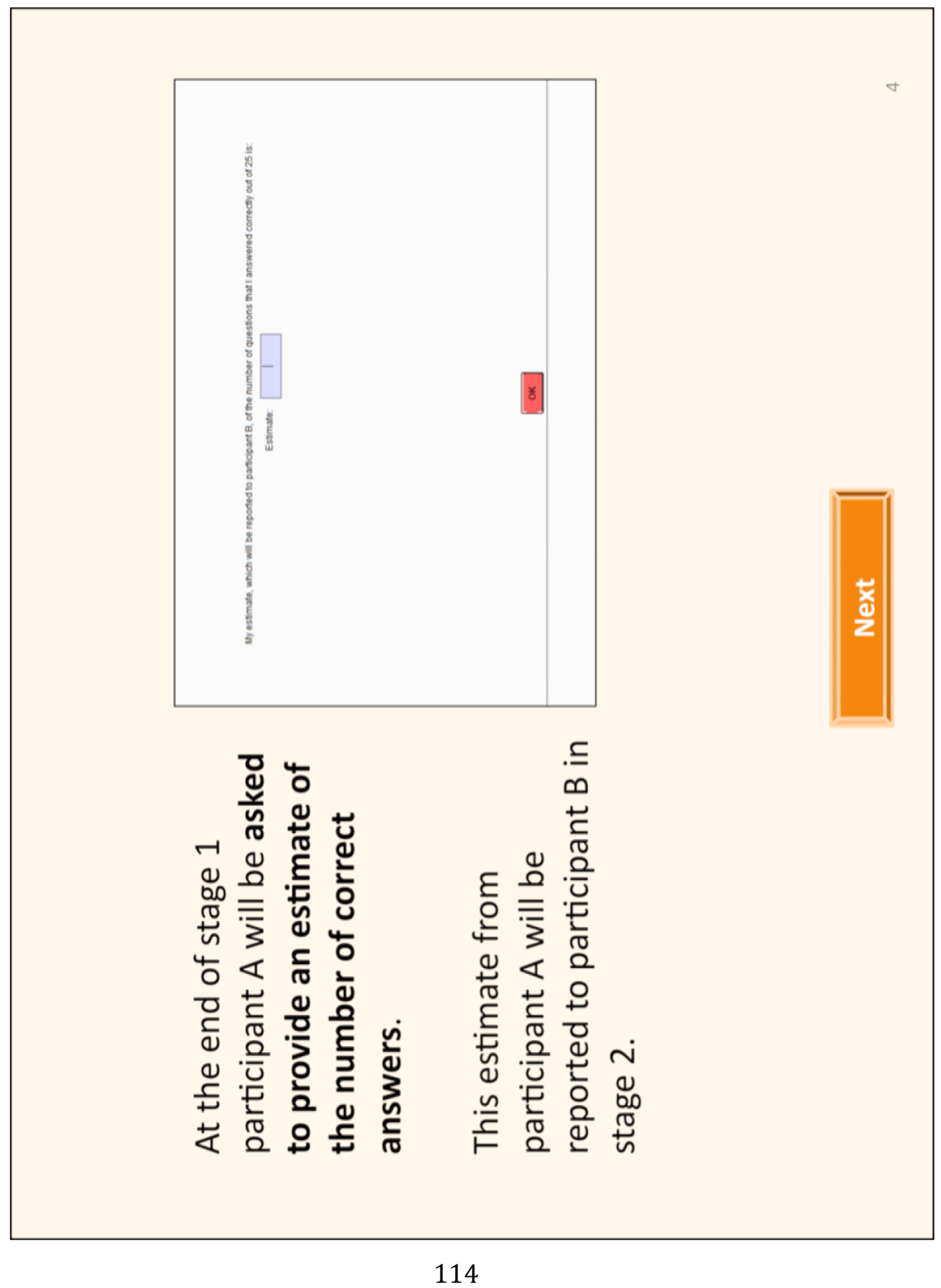


[Reporting to principal with accuracy incentives condition]

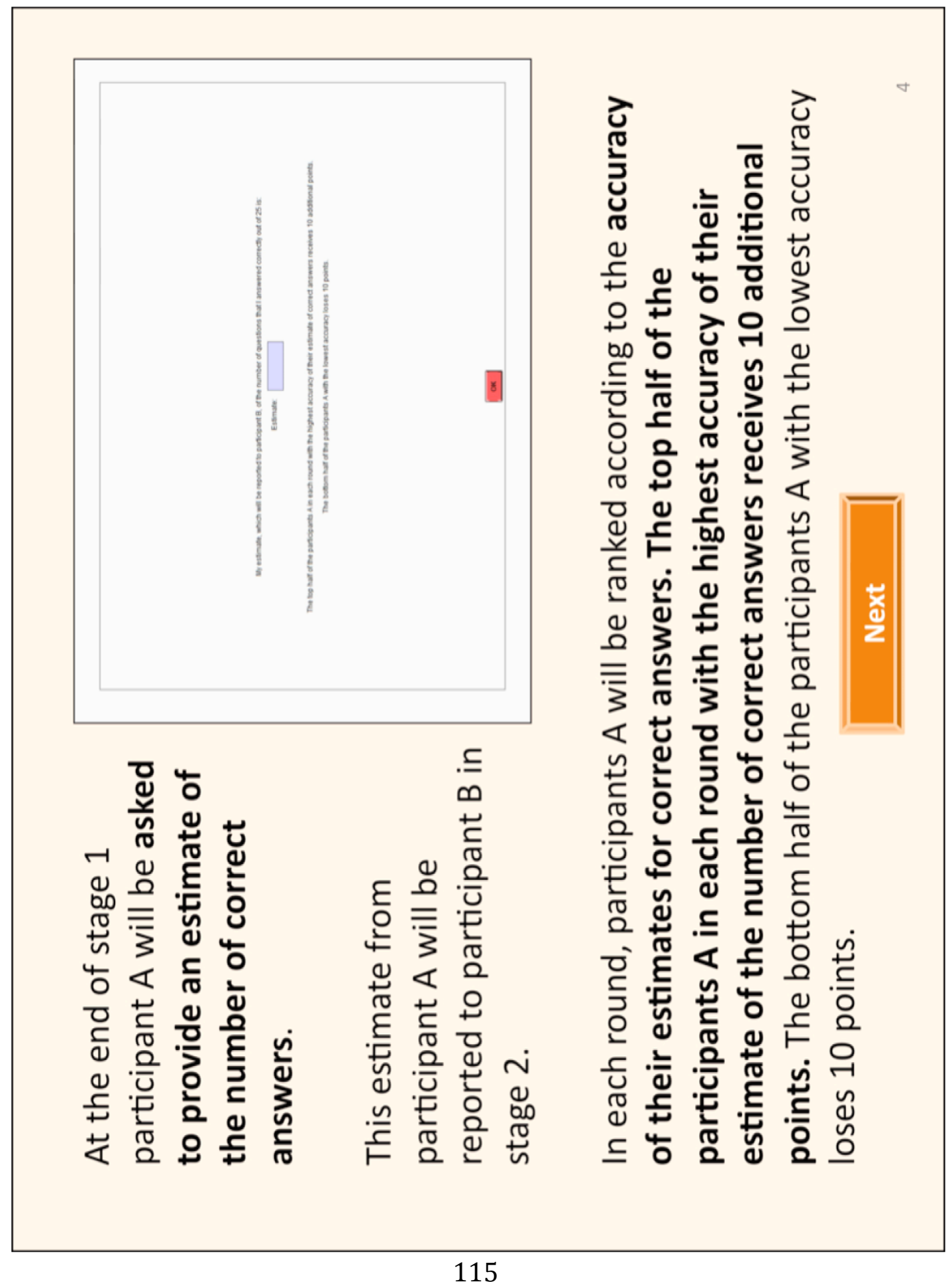


[Reporting to experimenter condition]

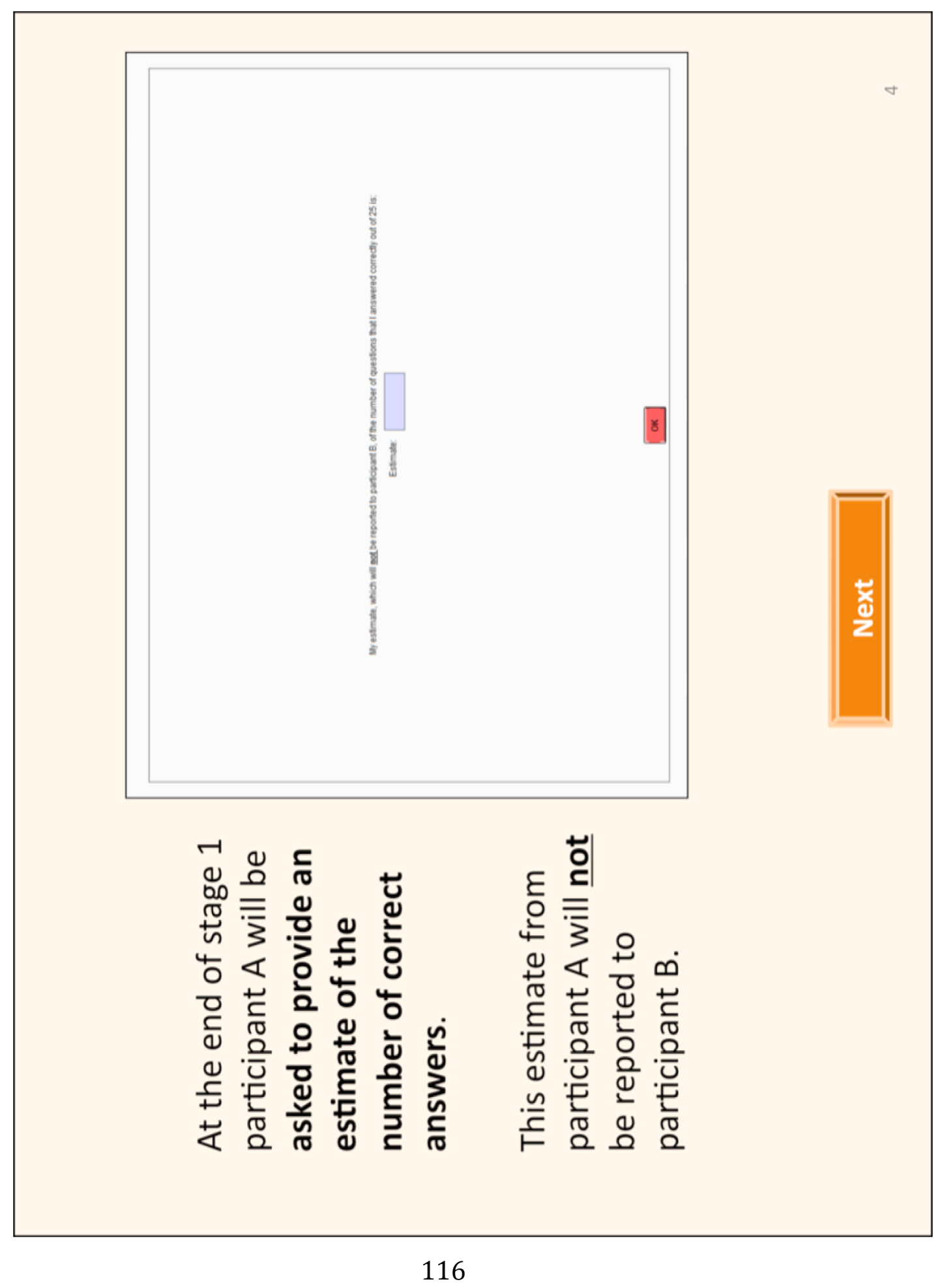


[All conditions]

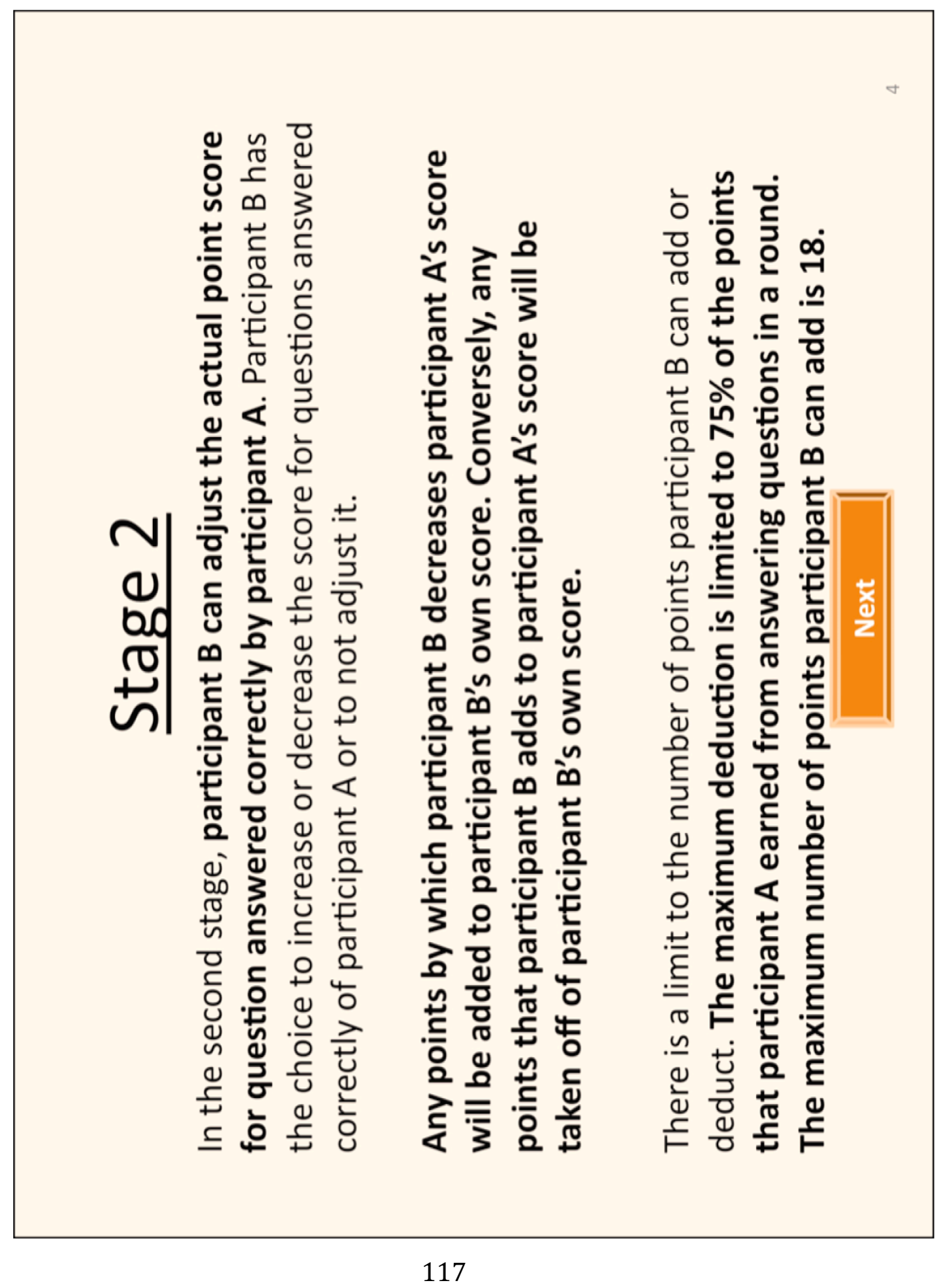


[No reporting/ Reporting to the experimenter conditions]

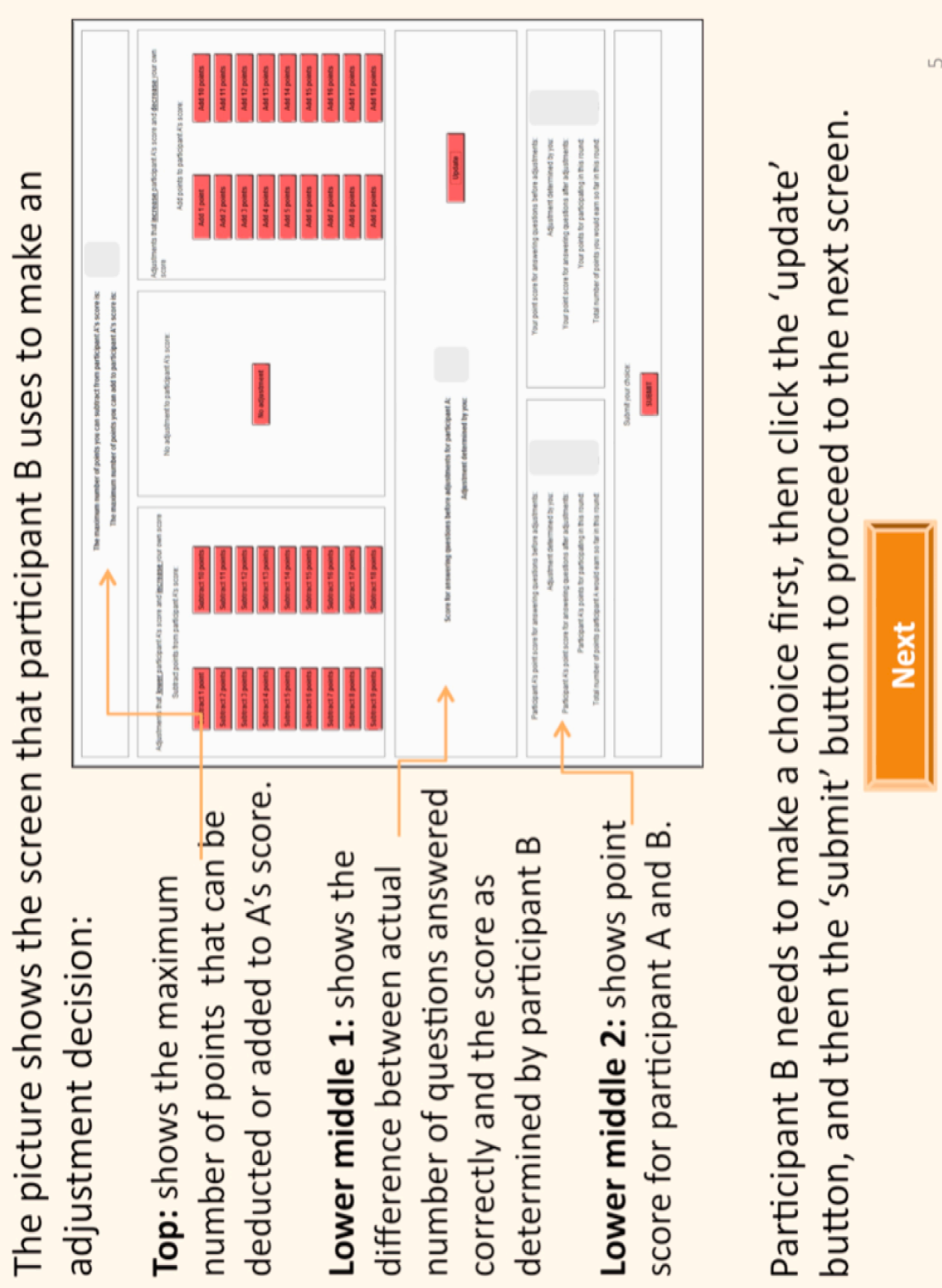


[Reporting to principal without/ with accuracy incentives conditions]

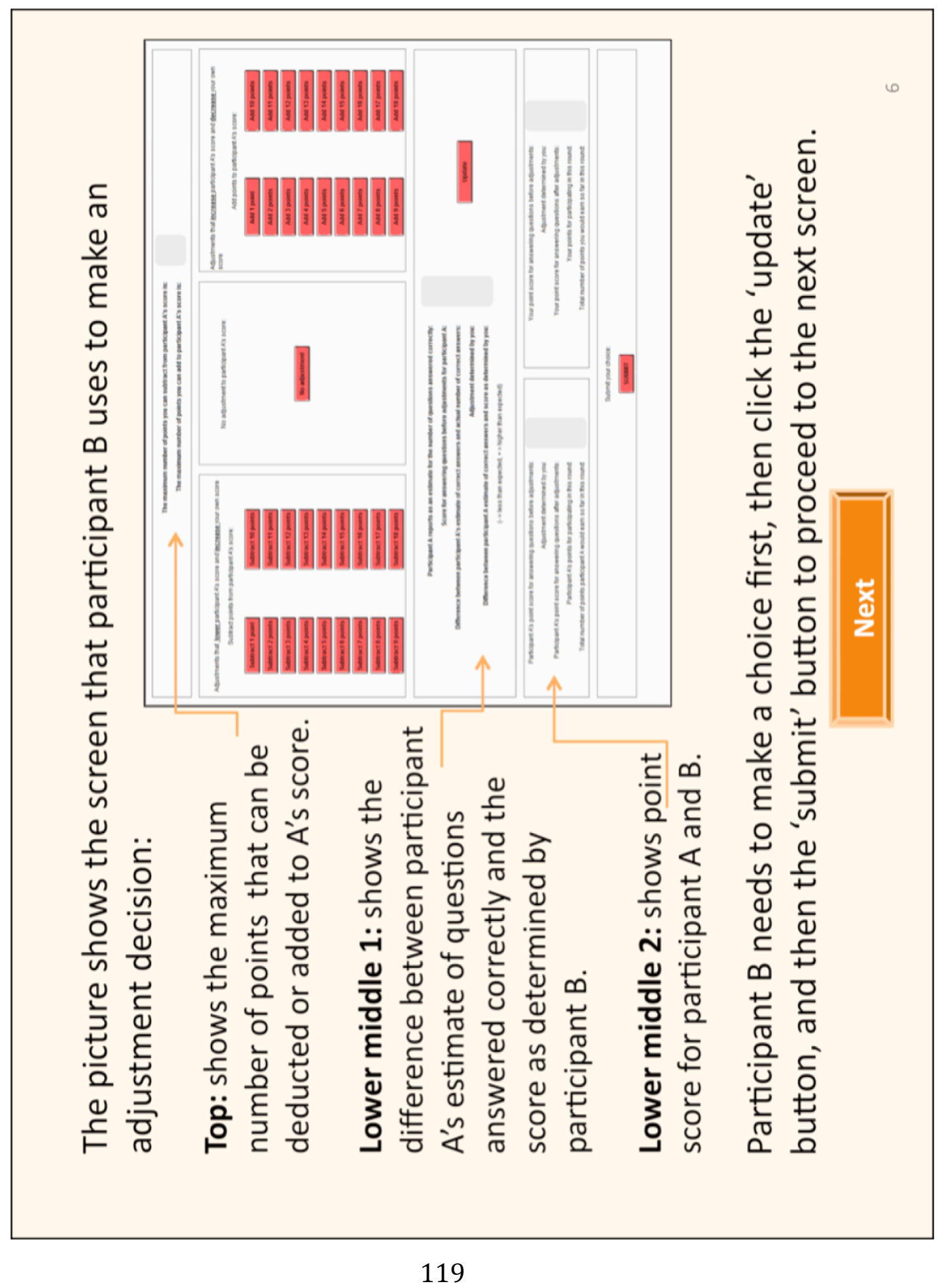


[Reporting to principal without/ with accuracy incentives conditions]

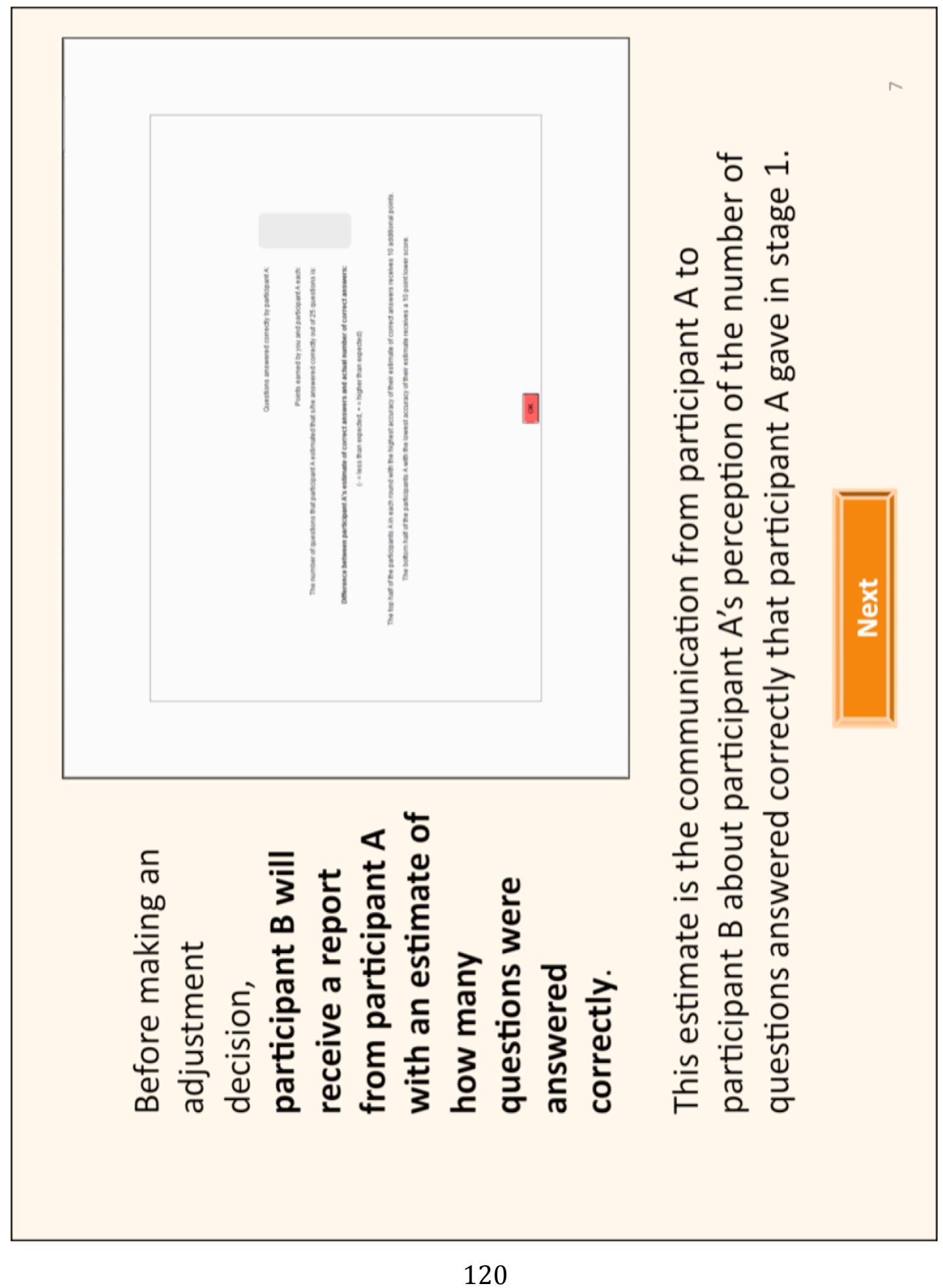


[All conditions]

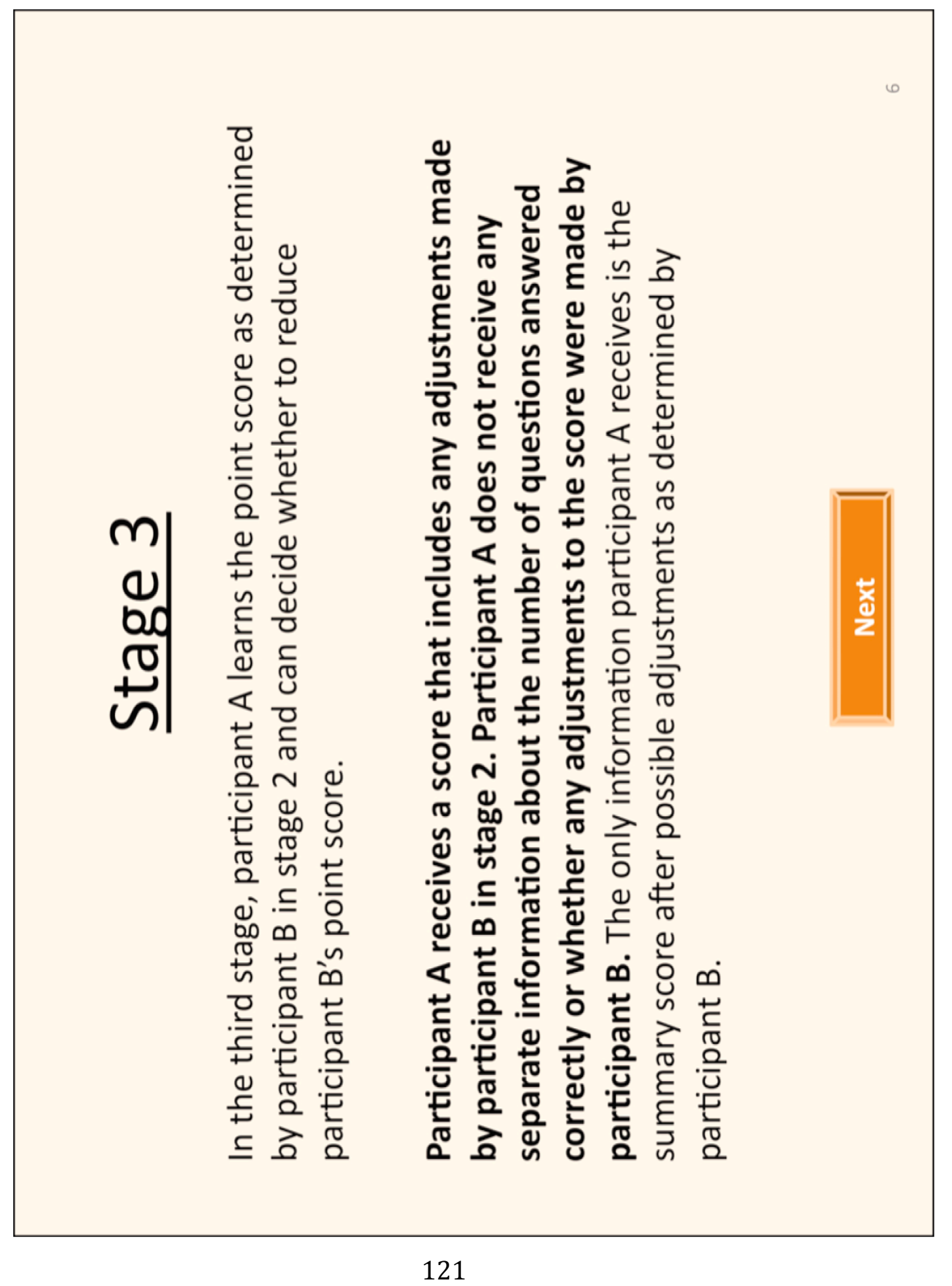


[All conditions]

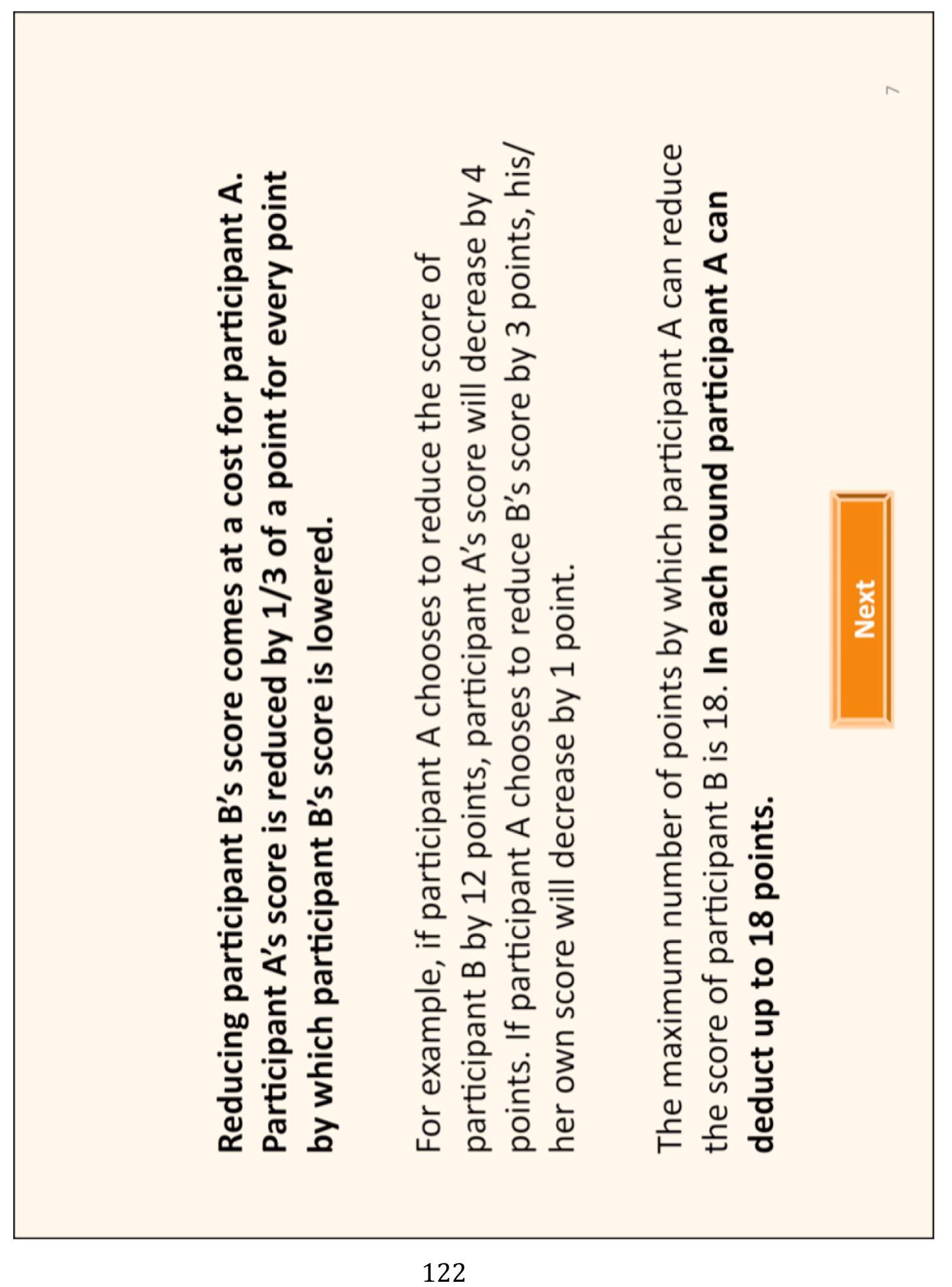


[No reporting/ Reporting to the experimenter conditions]

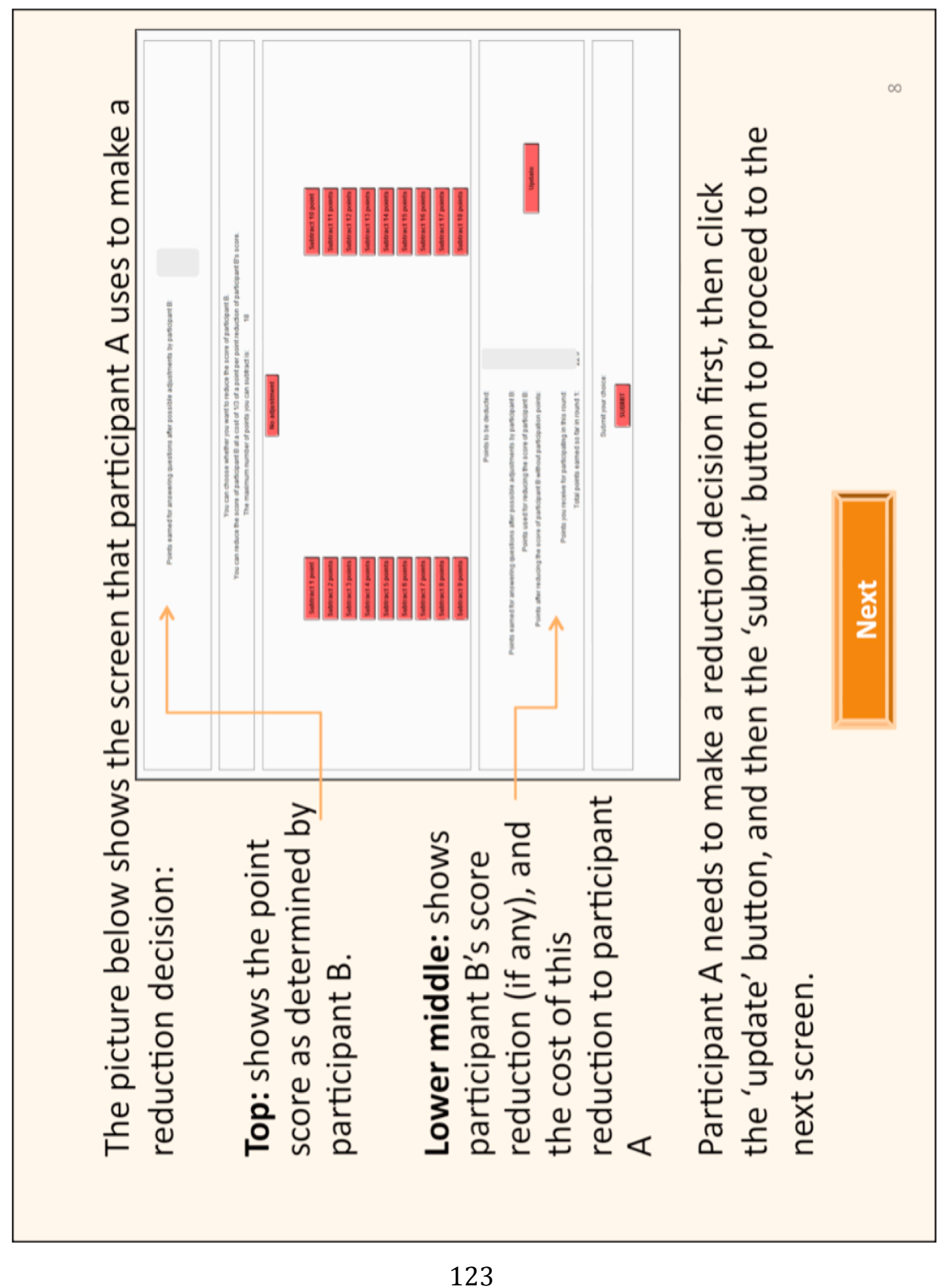


[Reporting to principal without/ with accuracy incentives conditions]

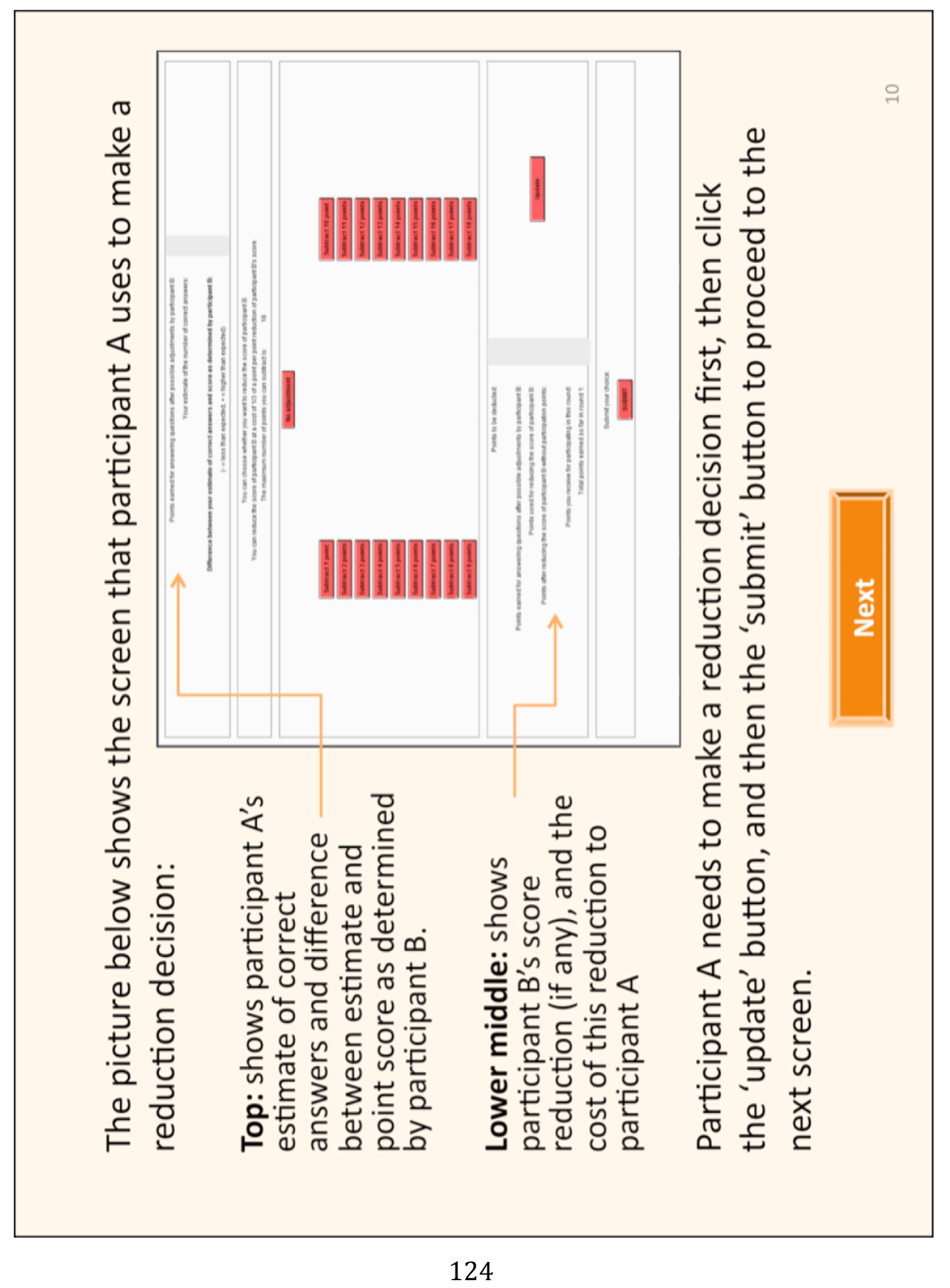


[No-reporting/ Reporting to the principal without accuracy incentives/ Reporting to the experimenter conditions]

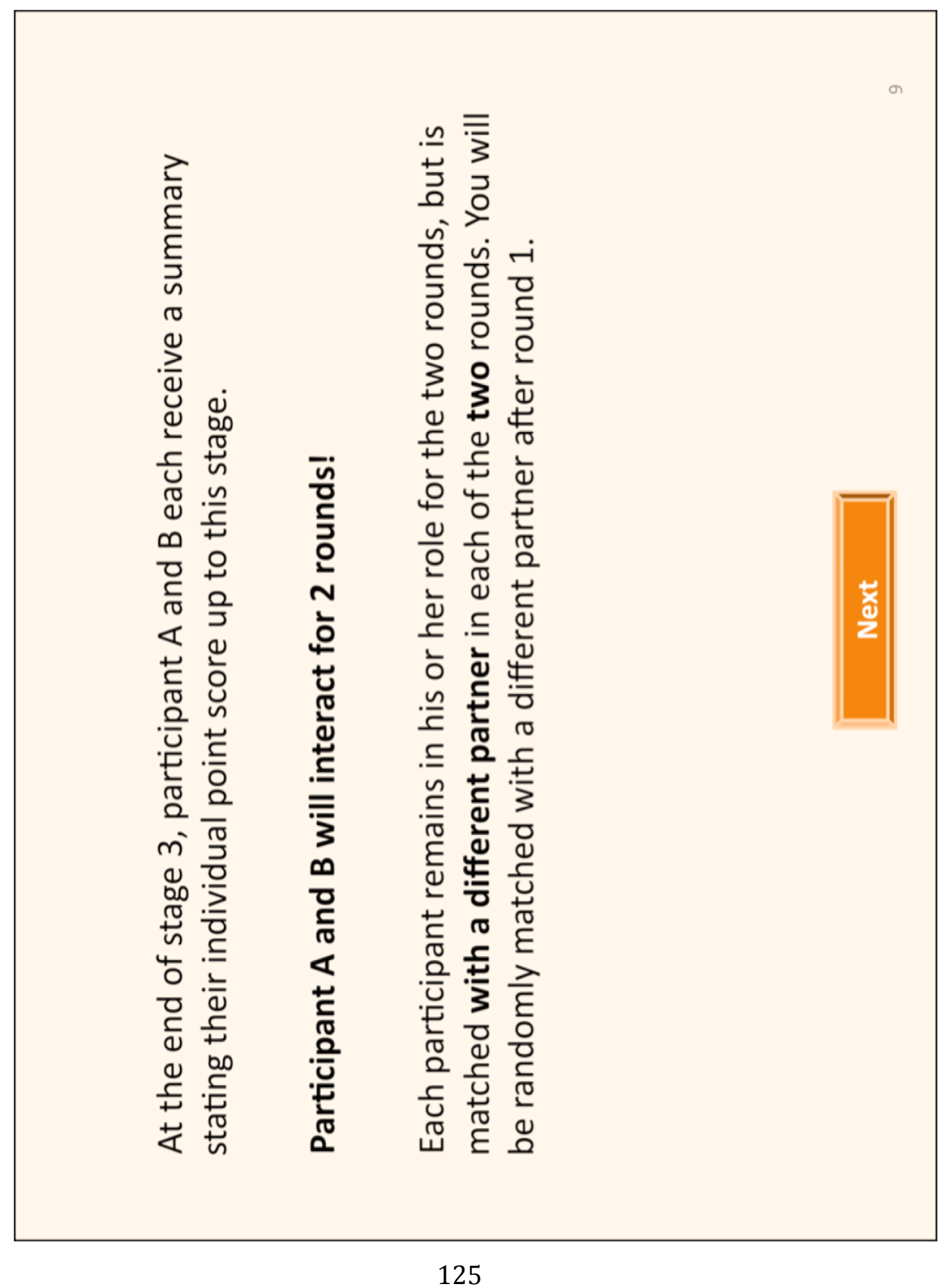


[Reporting to the principal with accuracy incentives condition]

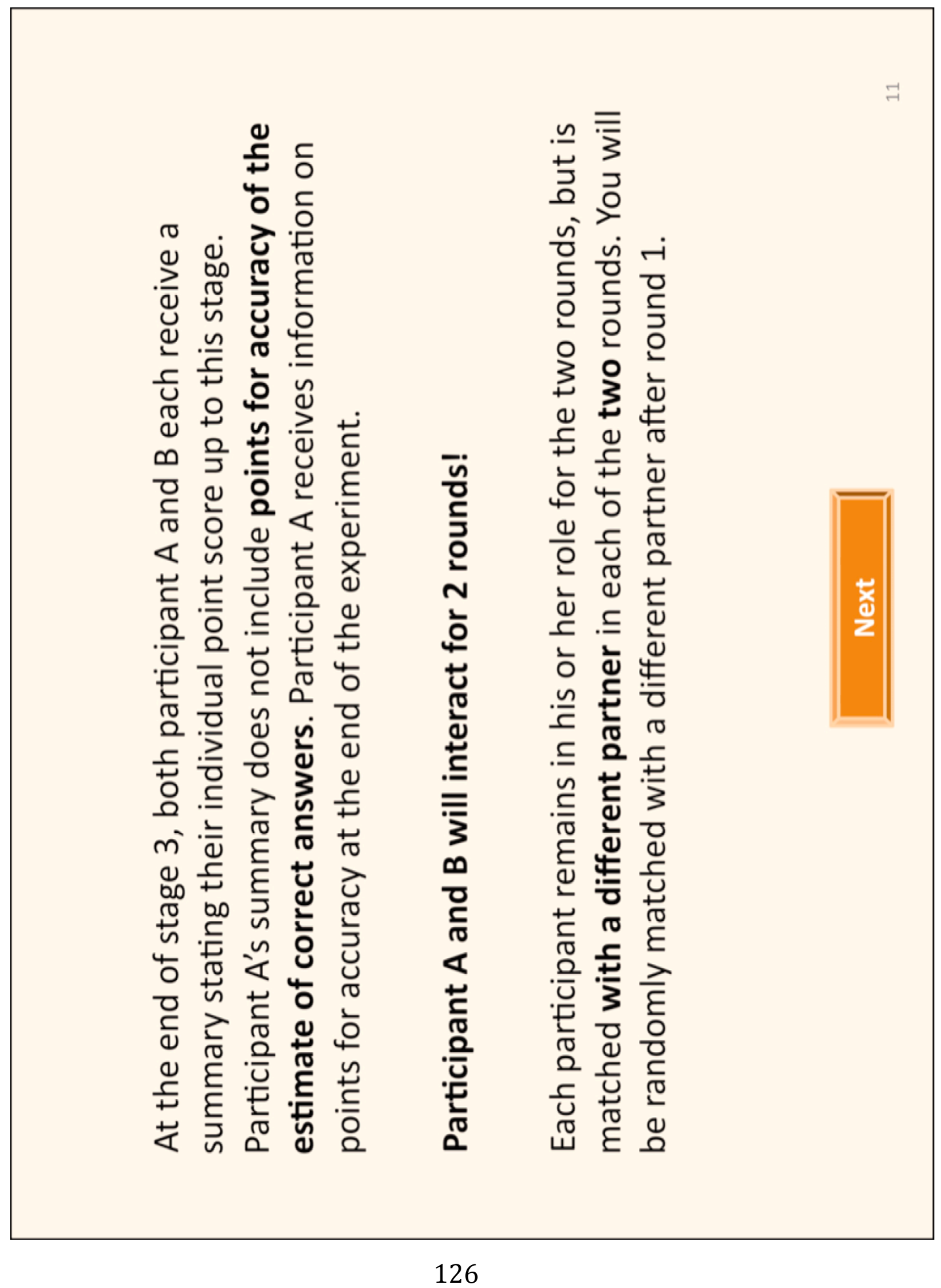


[No-reporting/ Reporting to the principal without accuracy incentives/ Reporting to the experimenter conditions]

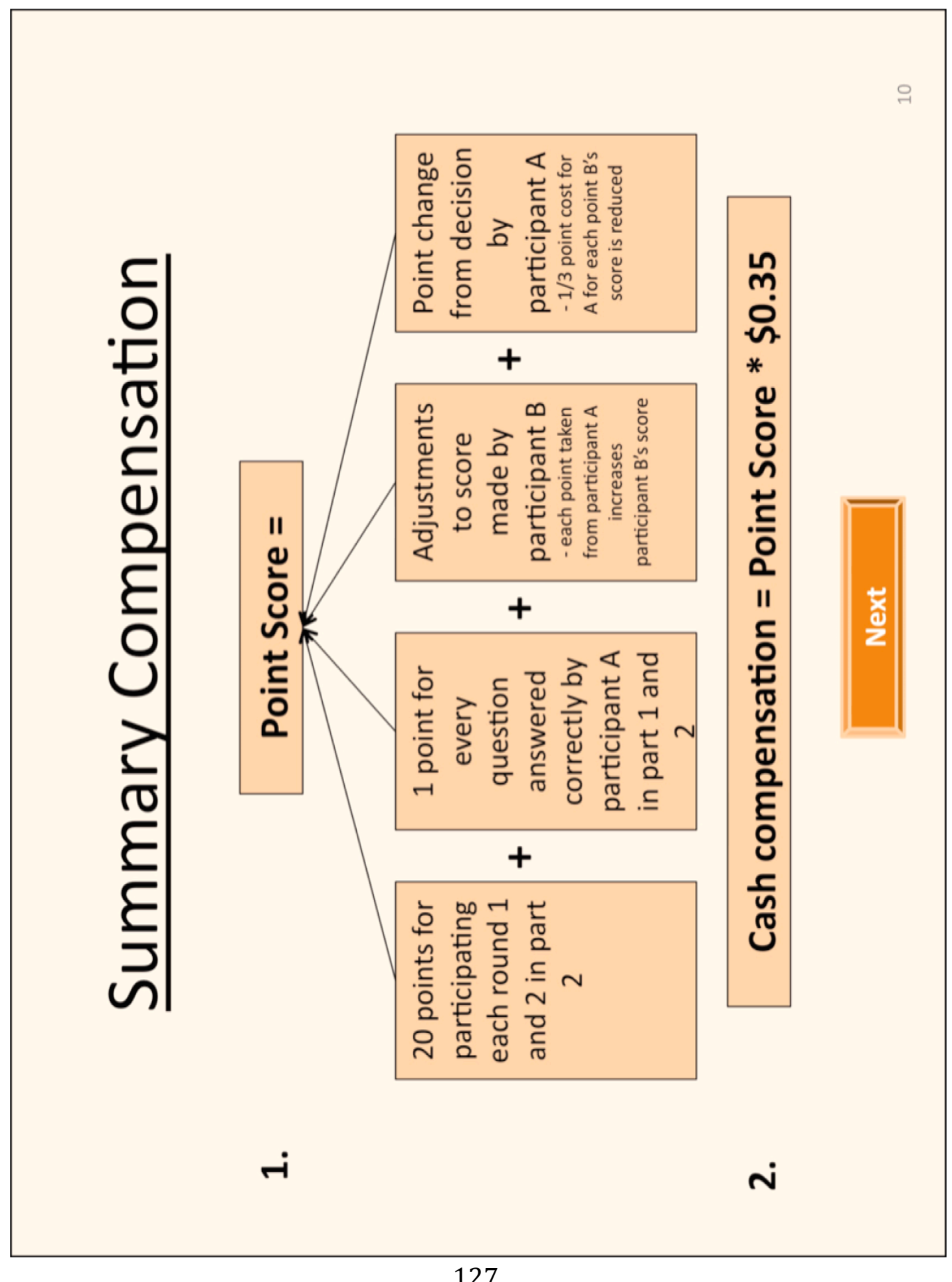


[Reporting to the principal with accuracy incentives condition]

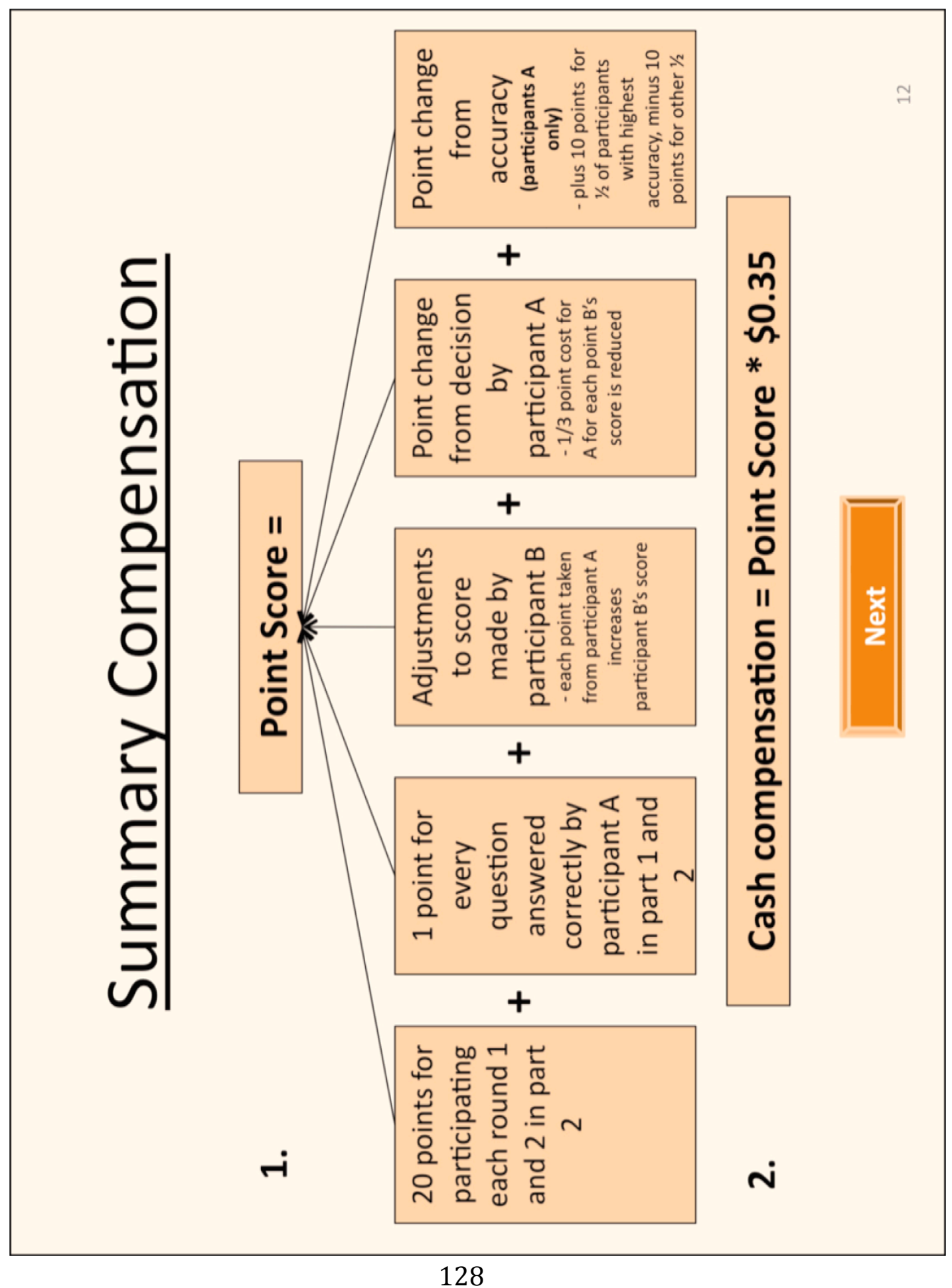




\section{APPENDIX 3 - UNDERSTANDING AND MANIPULATION CHECK QUESTIONS}

\subsection{Questions in all conditions}

The following questions were provided to all participations. Participants in the noreporting condition received only these questions. Participants in the other conditions received additional questions as listed in the subsequent sections.

[All conditions]

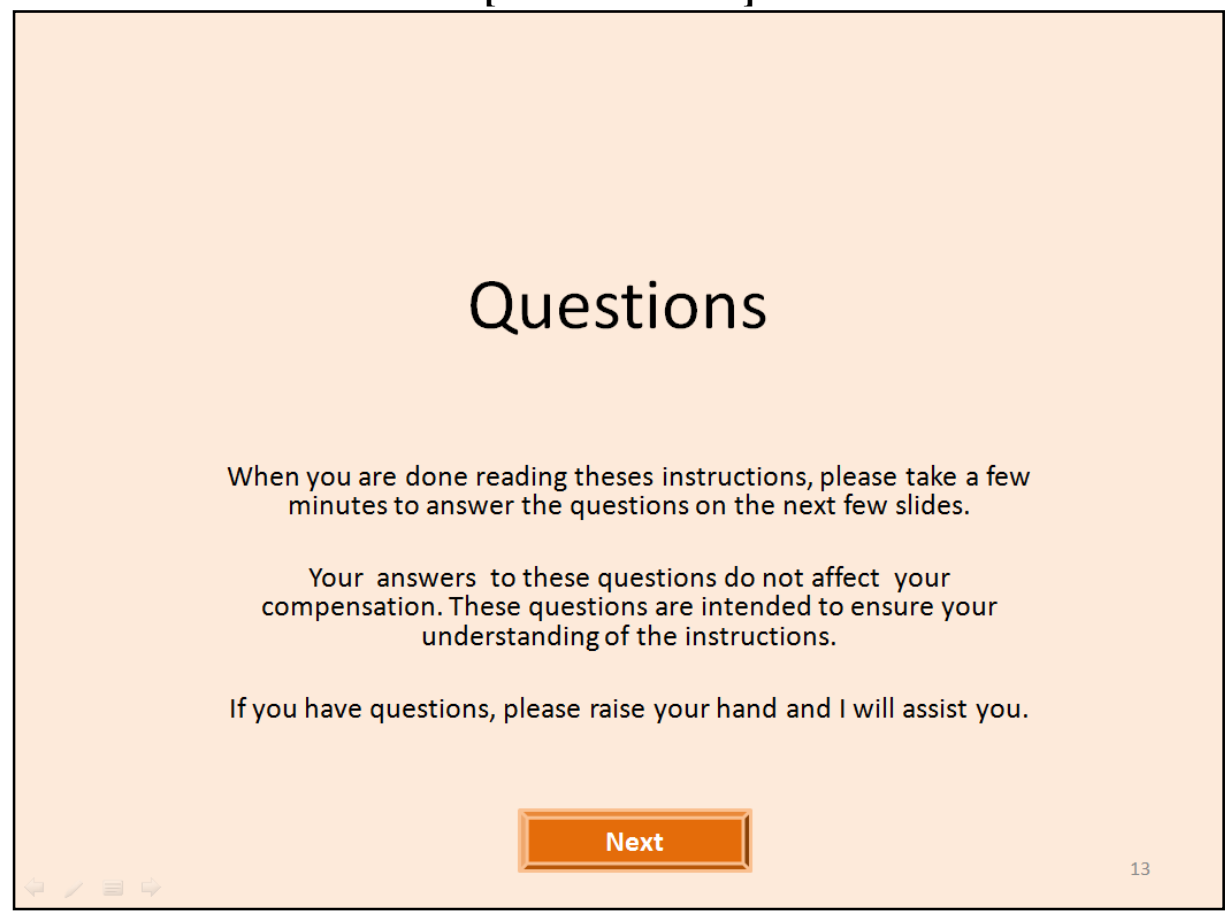


[All conditions]

\section{Question 1}

Participant A receives feedback on the number of questions answered correctly right after $\mathrm{s} /$ he is done answering the questions.

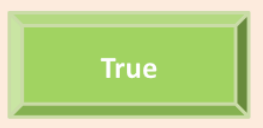

[All conditions]

\section{$\underline{\text { Incorrect }}$}

Participant $A$ does not receive information on the correct answers. All participant $A$ receives is a cumulative score as determined by participant B.

\section{Try Again}




\section{Correct}

Participant A does not learn actual performance. All participant $A$ receives is a cumulative score as determined by participant $B$.

[All conditions]

\section{Question 2}

Participant B's can increase [decrease] his/ her point score by reducing [increasing] participant A's point score in stage 2 of part 2 of the study.
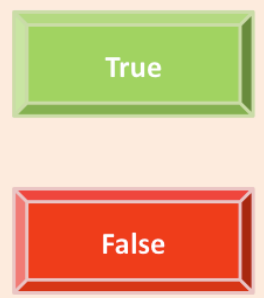
[All conditions]

\section{$\underline{\text { Incorrect }}$}

Participant $B$ benefits from reducing participant

A's point score.

[All conditions]

\section{Correct}

Participant $B$ benefits from reducing participant A's point score. 
[All conditions]

\section{Question 3}

Participant $A$ can reduce the point score of participant $B$ in the third stage in part 2 of the study.

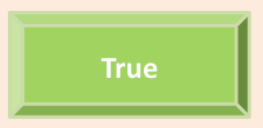

[All conditions]

\section{$\underline{\text { Incorrect }}$}

Participant A can reduce the point score of participant $B$ in the third stage in part 2 of the study. 
[All conditions]

\section{Question 4}

Part 2 of the study has 2 rounds.

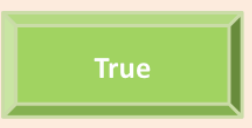

[All conditions]

\section{Incorrect}

Part 2 of the study has 2 rounds. 


\section{[All conditions]}

\section{Correct}

Part 2 of the study has 2 rounds.

[All conditions]

\section{Question 5}

You will interact with the same partner for both rounds in part 2 of the study.

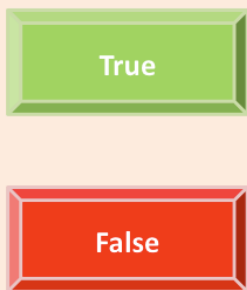




\section{$\underline{\text { Incorrect }}$}

You will not interact with the same partner for both rounds. You will be randomly rematched with a different partner after round 1.

[All conditions]

\section{Correct}

You will be rematched with a different partner after round 1. 
[All conditions]

\section{Question 6}

Participants A and B will learn each other's identify.

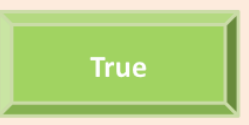

False

[All conditions]

\section{Incorrect}

Participants $A$ and $B$ will interact through computers only and will never learn each other's actual names. Your decisions will be completely anonymous. 


\section{[All conditions]}

\section{Correct}

Your decisions today are completely anonymous.

[All conditions]

\section{Question 7}

18 is the maximum number of points that participant $A$ can deduct from the score of participant B in stage 3 .

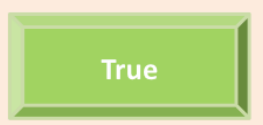




\section{[All conditions]}

\section{$\underline{\text { Incorrect }}$}

Participant A can always deduct up to 18 points.

\section{[All conditions]}

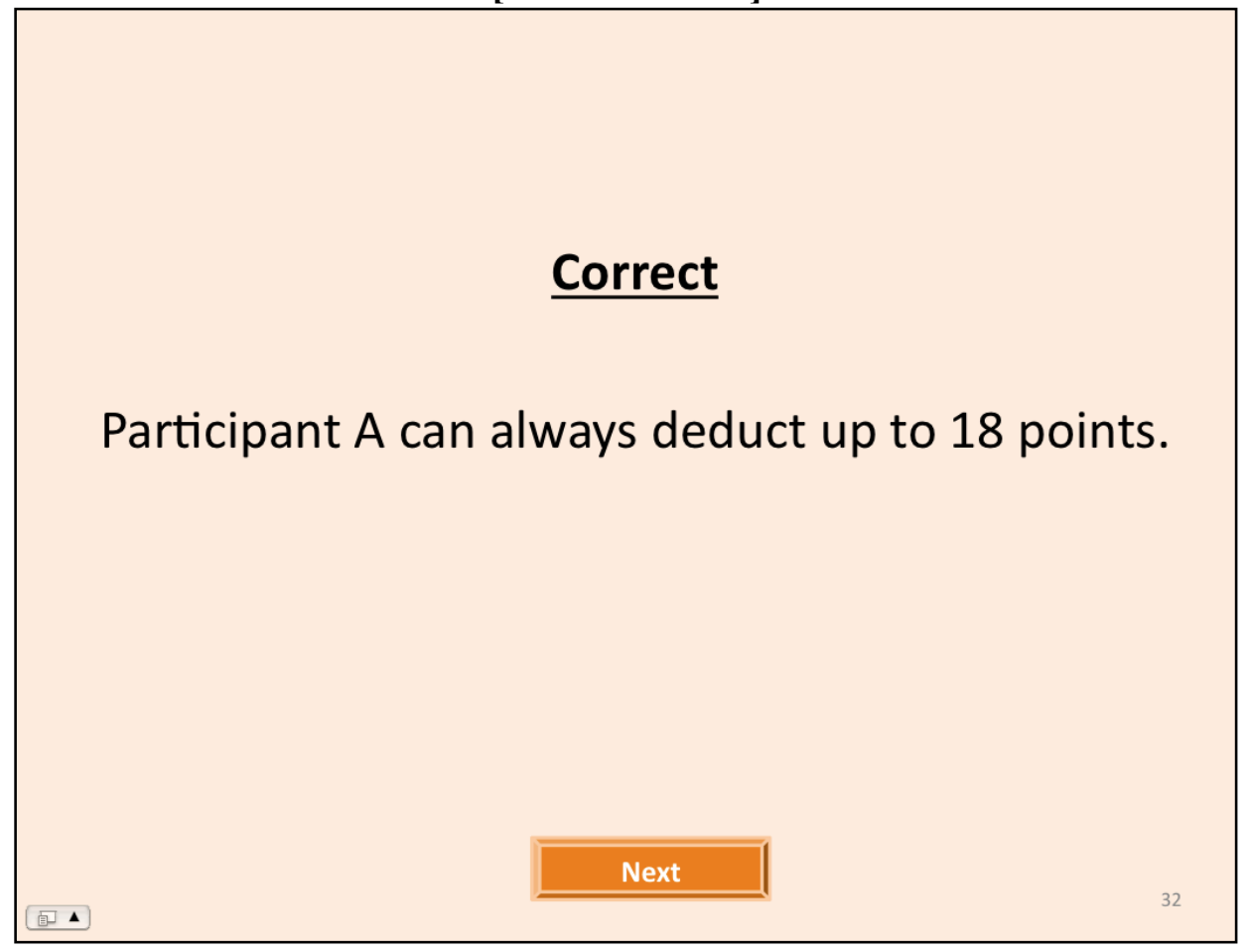




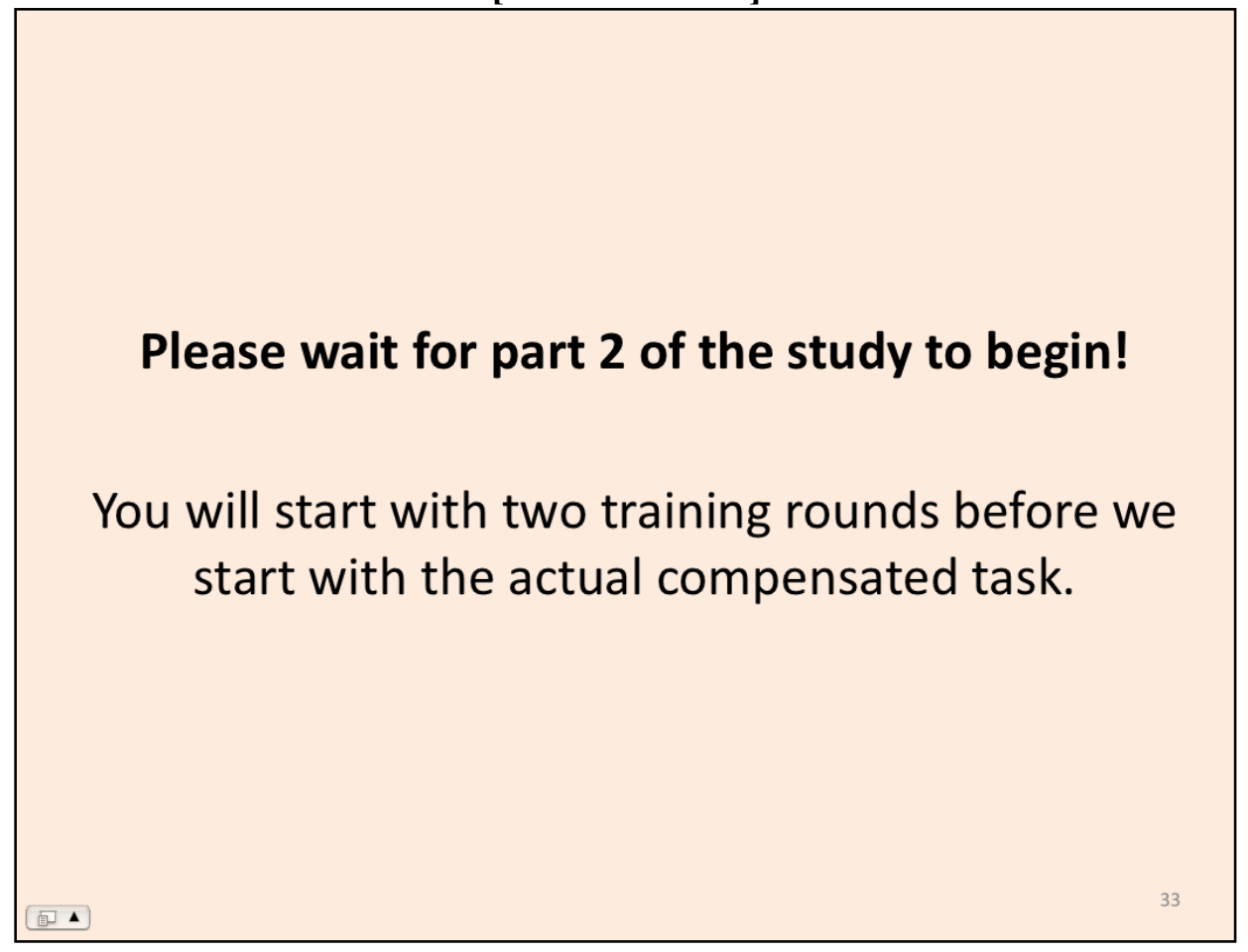


3.2. Additional question in the reporting of self-evaluations to the experimenter condition

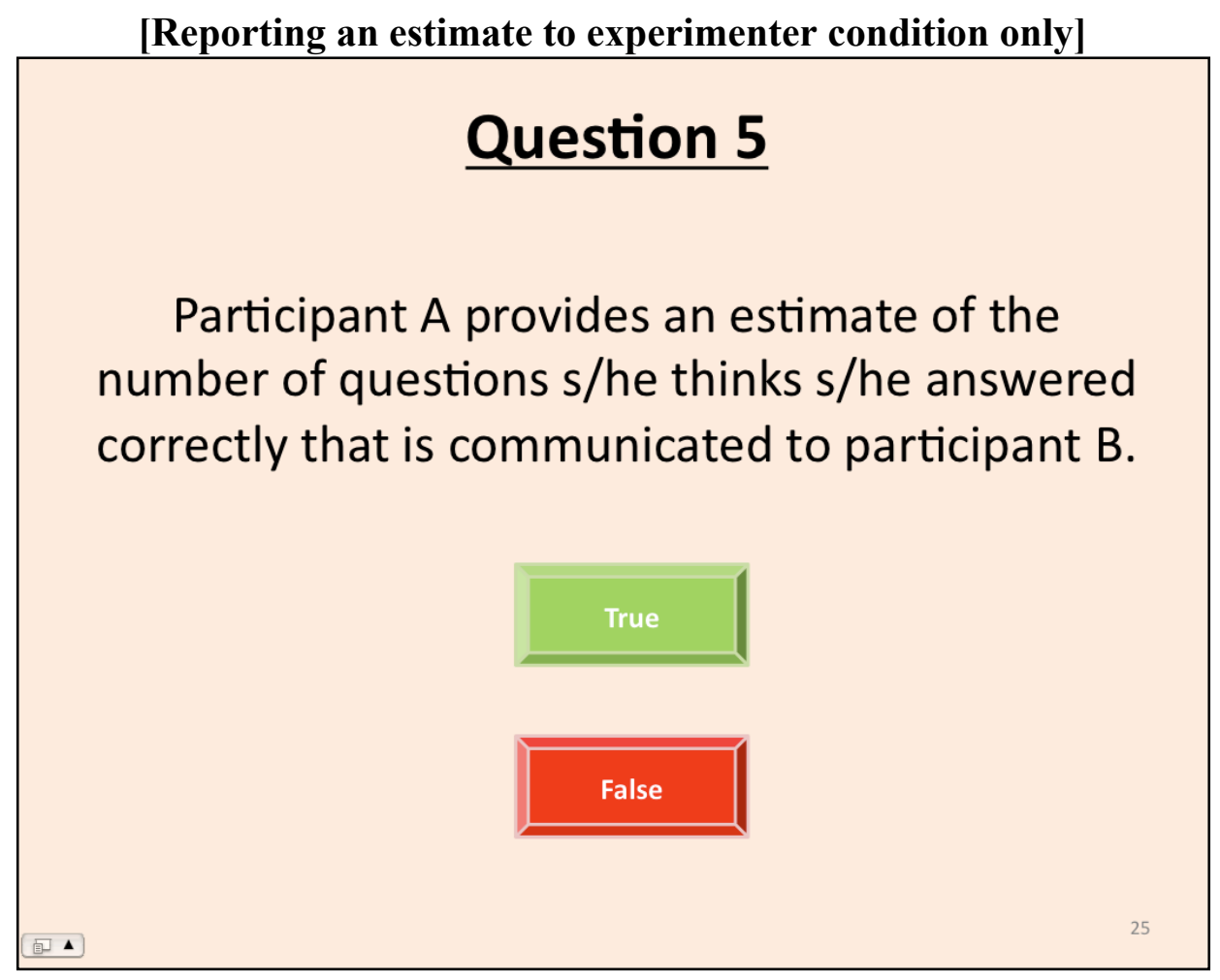


[Reporting an estimate to experimenter condition only]

\section{Incorrect}

Participant A provides an estimate that is not communicated to participant $B$.

[Reporting an estimate to experimenter condition only]

\section{Correct}

Participant A provides an estimate that is not communicated to participant B. 
3.3. Additional question in the reporting of self-evaluations without accuracy incentives condition

[Reporting an estimate to principal without accuracy incentives condition only]

\section{Question 5}

Participant A provides an estimate of the number of questions $s / h e$ thinks $s /$ he answered correctly.
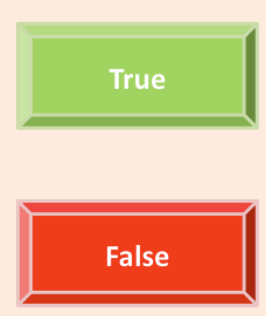
[Reporting an estimate to principal without accuracy incentives condition only]

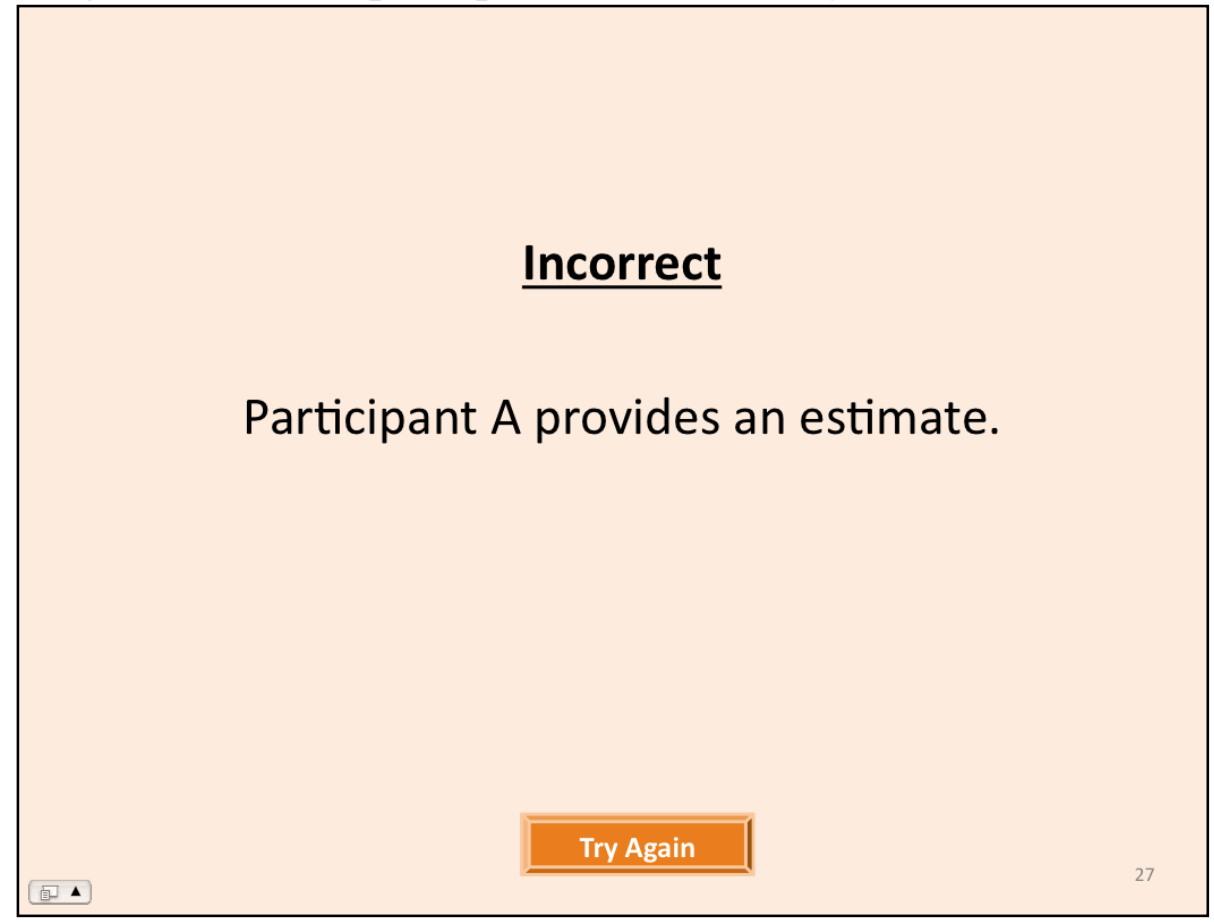

[Reporting an estimate to principal without accuracy incentives condition only]

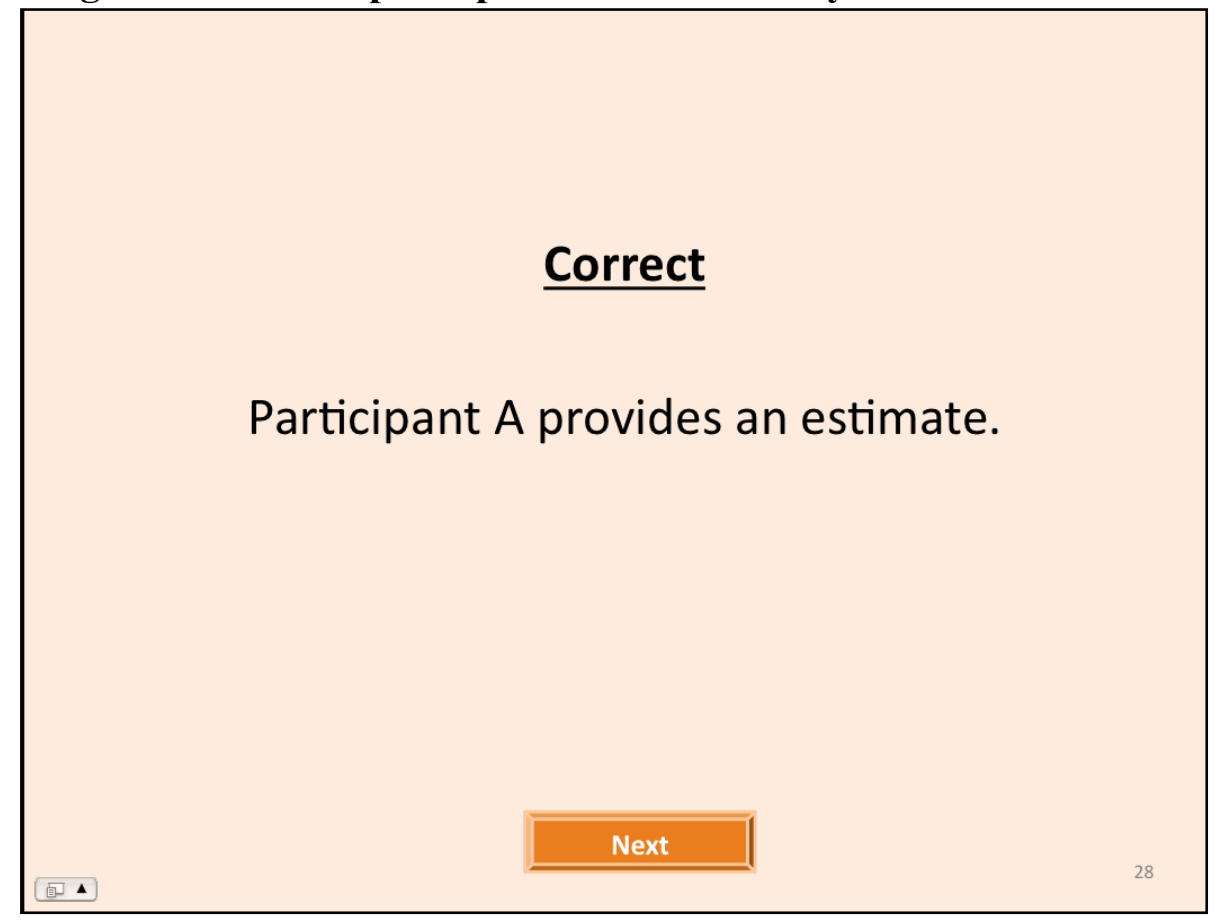


3.4. Additional questions in the reporting of self-evaluations with accuracy incentives condition

[Reporting an estimate to principal with accuracy incentives condition only]

\section{Question 5}

Participant A receives additional points for the accuracy of the estimate of the number of correct answers in part 2 round 1 and 2 .

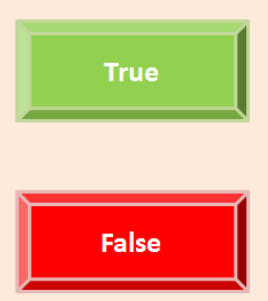


[Reporting an estimate to principal with accuracy incentives condition only]

\section{$\underline{\text { Incorrect }}$}

The top half of the participants $A$ in each round with the highest accuracy of their estimate of the number of correct answers receives 10 additional points. The bottom half of the participants A with the lowest accuracy loses 10 points.

\section{Try Again}

[Reporting an estimate to principal with accuracy incentives condition only]

\section{Correct}

The top half of the participants $A$ in each round with the highest accuracy of their estimate of the number of correct answers receives 10 additional points. The bottom half of the participants A with the lowest accuracy loses 10 points. 
[Reporting an estimate to principal with accuracy incentives condition only] Question 6

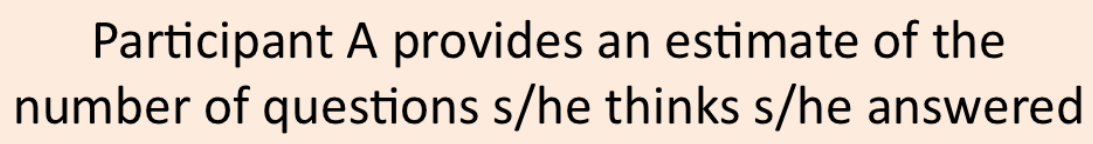
correctly.

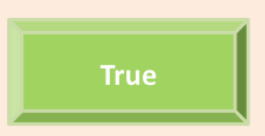

[Reporting an estimate to principal with accuracy incentives condition only]

$\underline{\text { Incorrect }}$

Participant A provides an estimate. 
[Reporting an estimate to principal with accuracy incentives condition only]

\section{Correct}

Participant A provides an estimate. 


\section{APPENDIX 4 - Z-TREE SCREENSHOTS}

The following pages provide a selection of screen shots from the Z-Tree user interface from part 2 round 1 of the study. The screen shots are from the noreporting condition. At the bottom of each screen is a short description of the

purpose of the screen. This description was added to identify each image for the reader, but was not part of the original interface. 


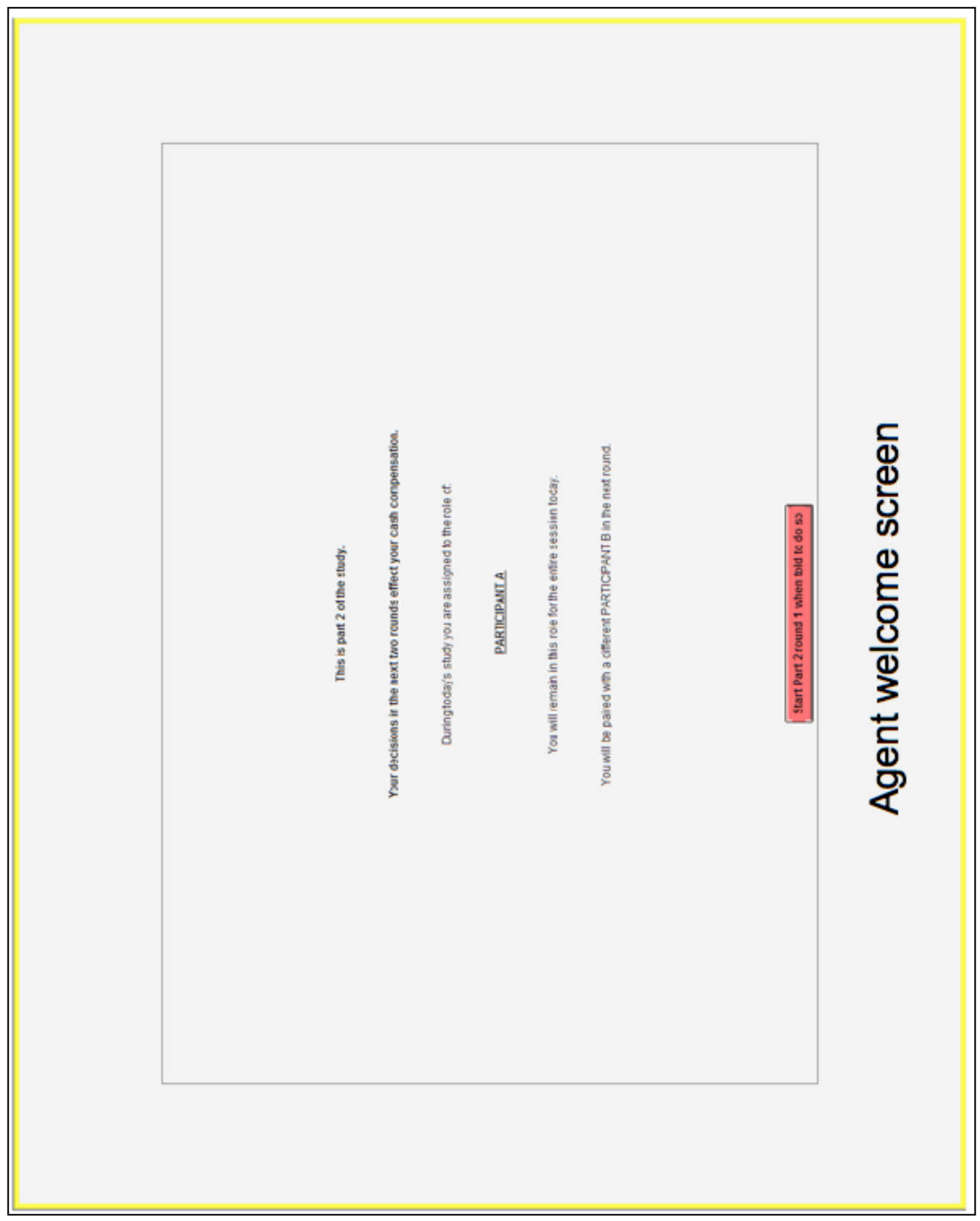




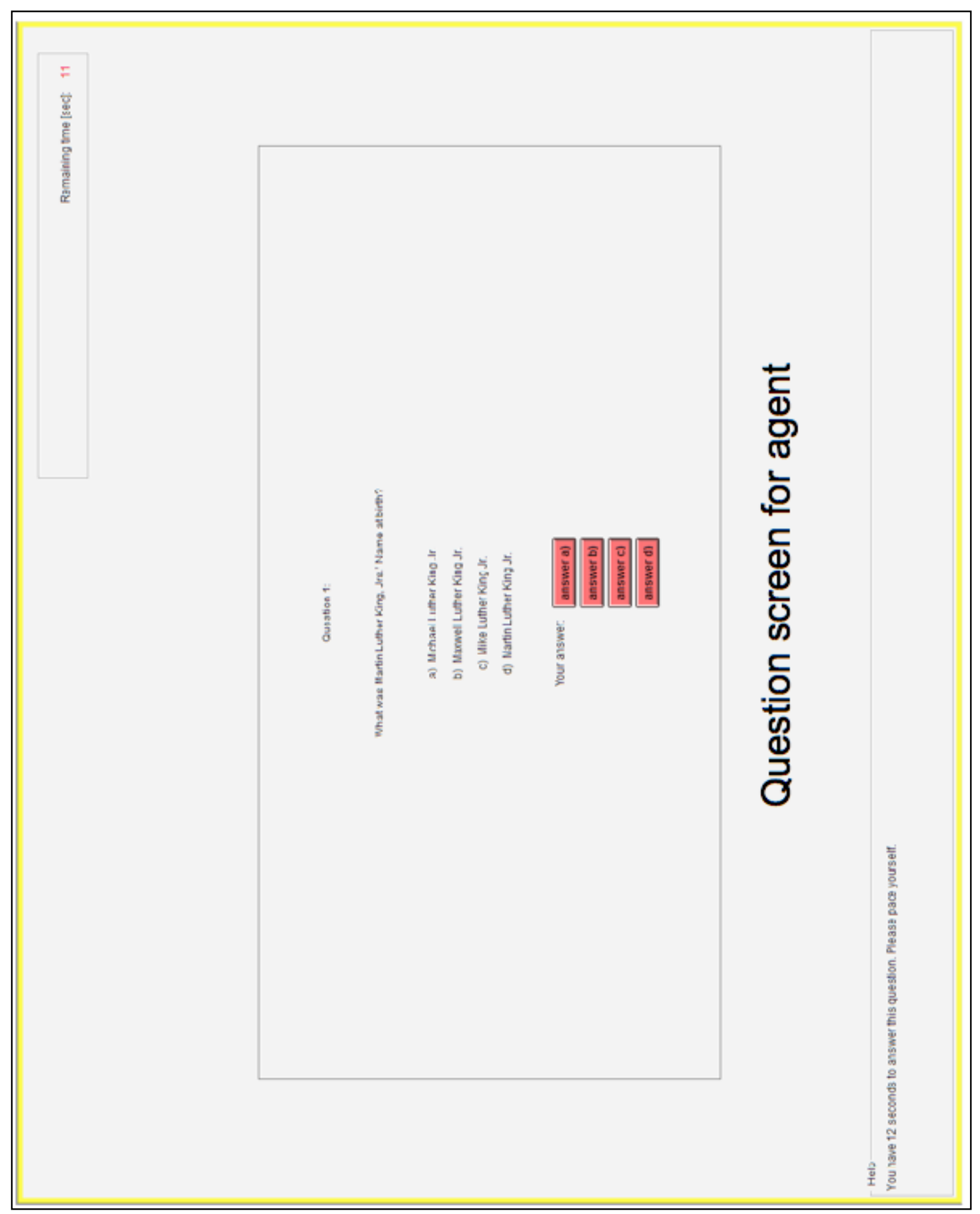

151 


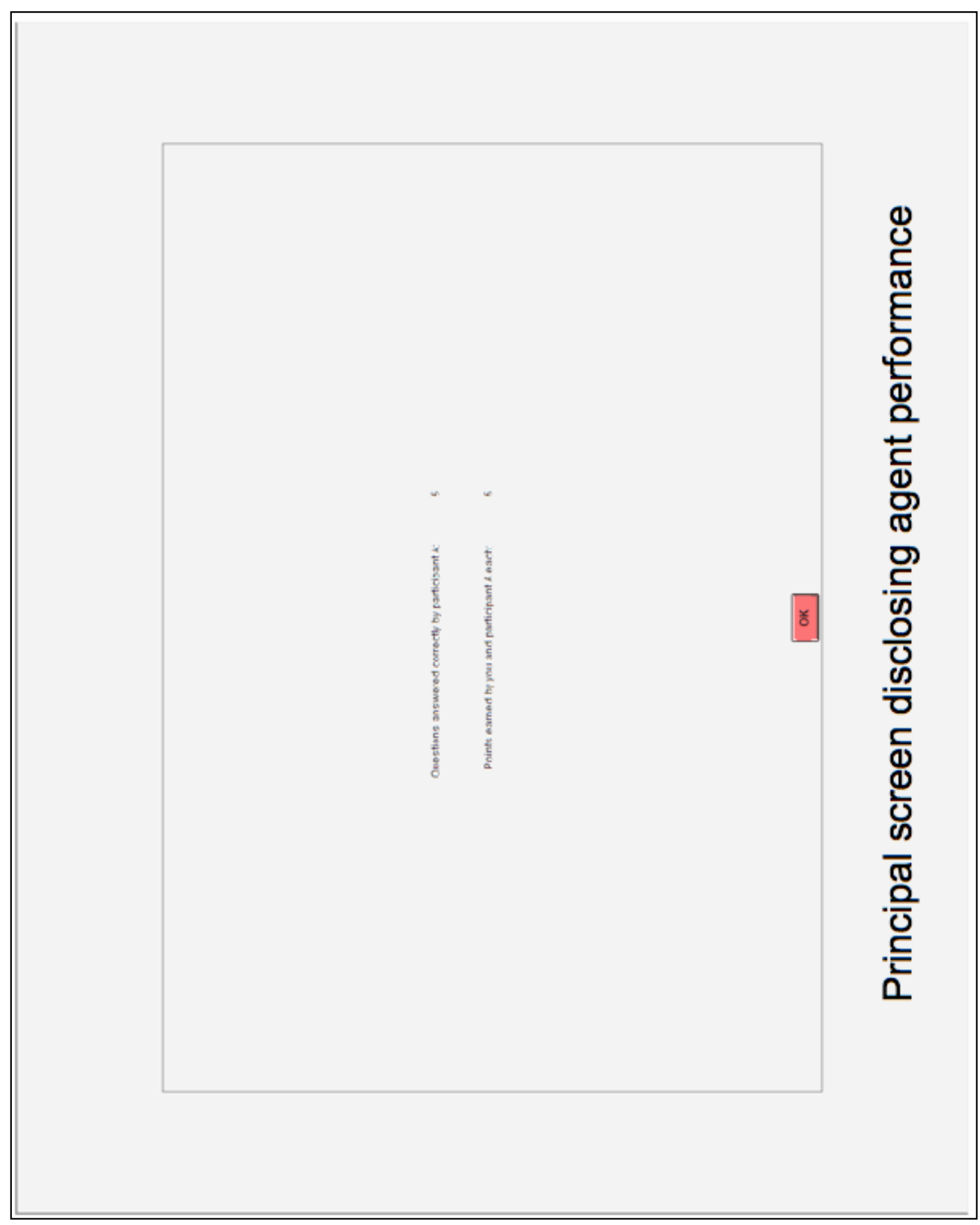




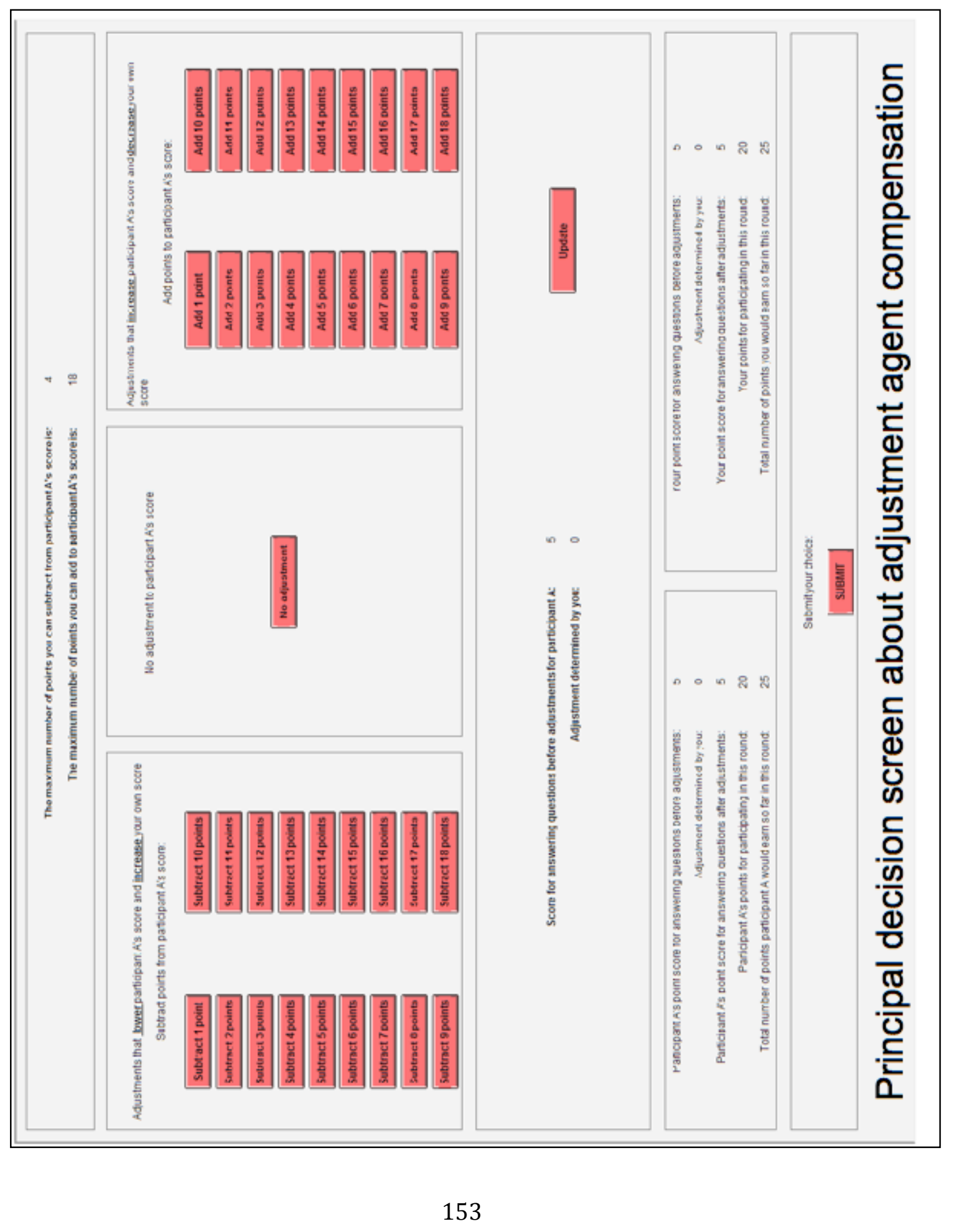




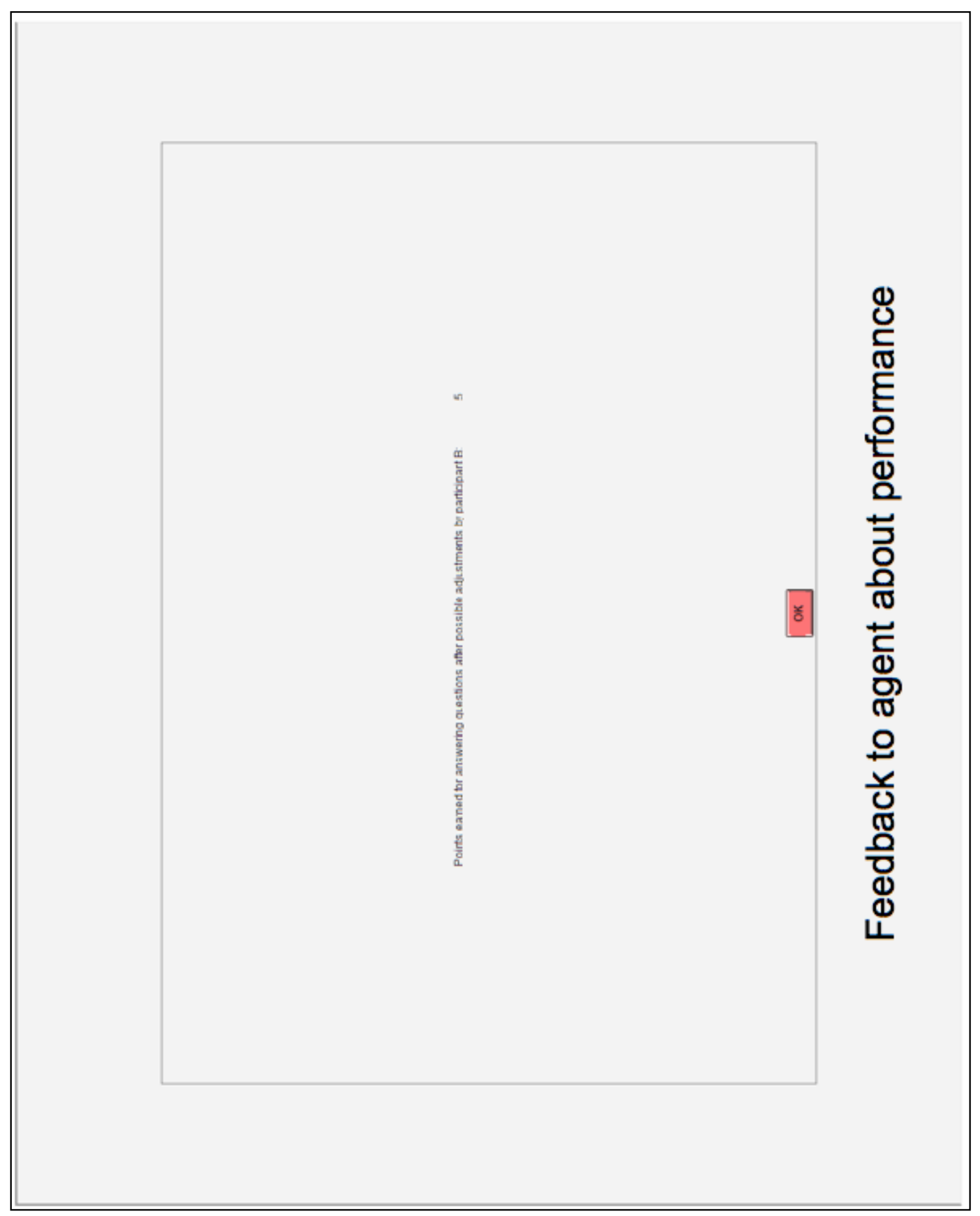

154 


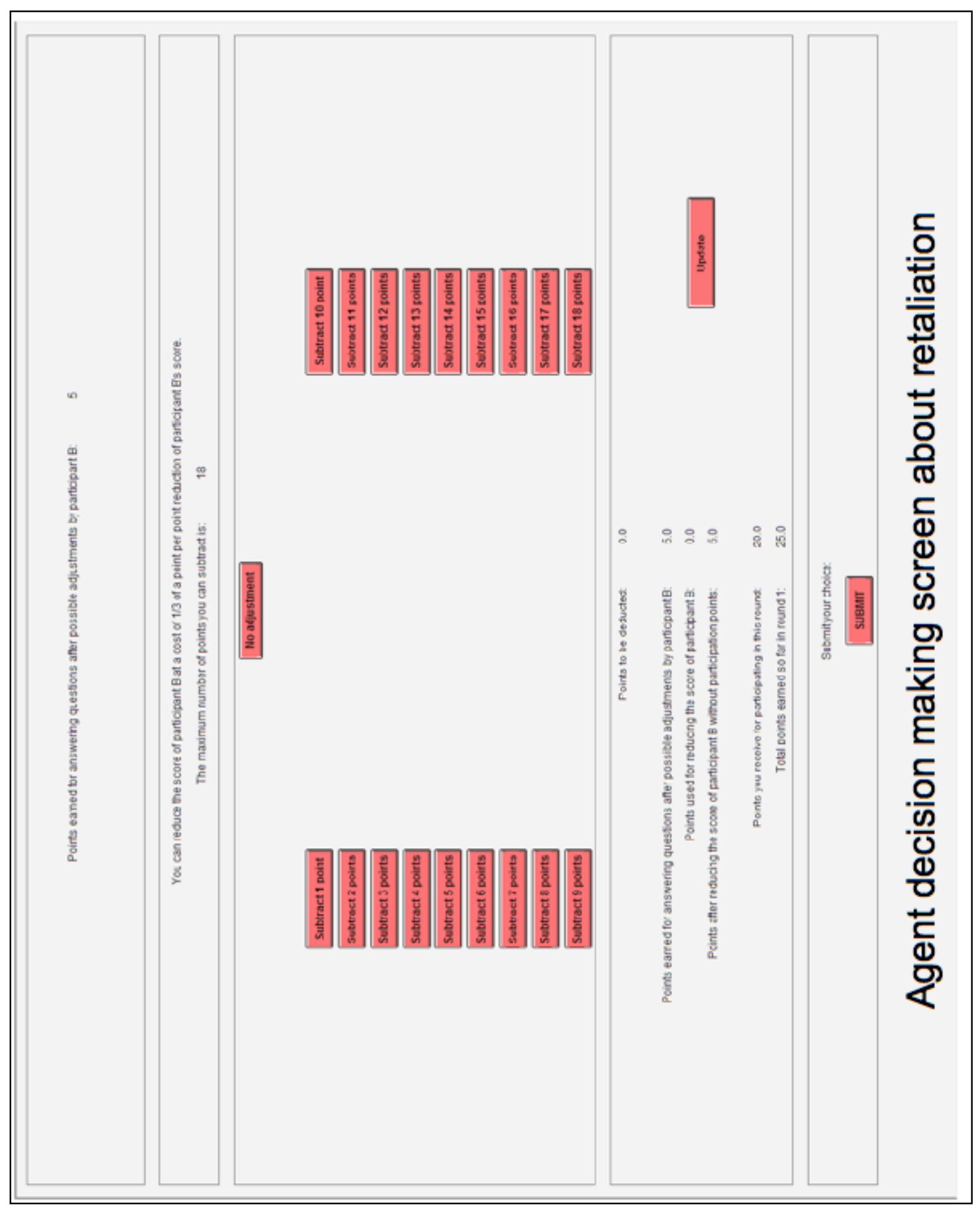




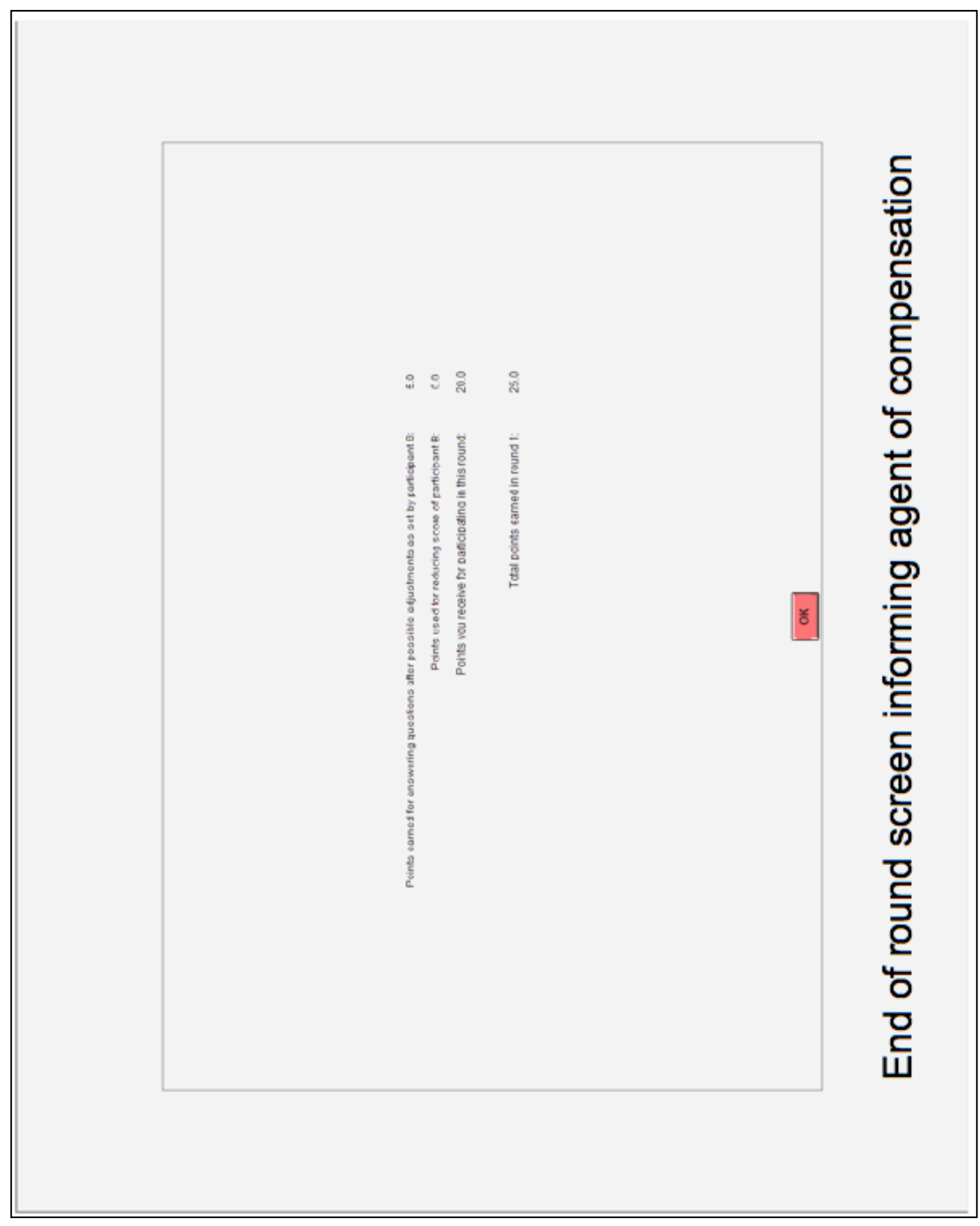

156 


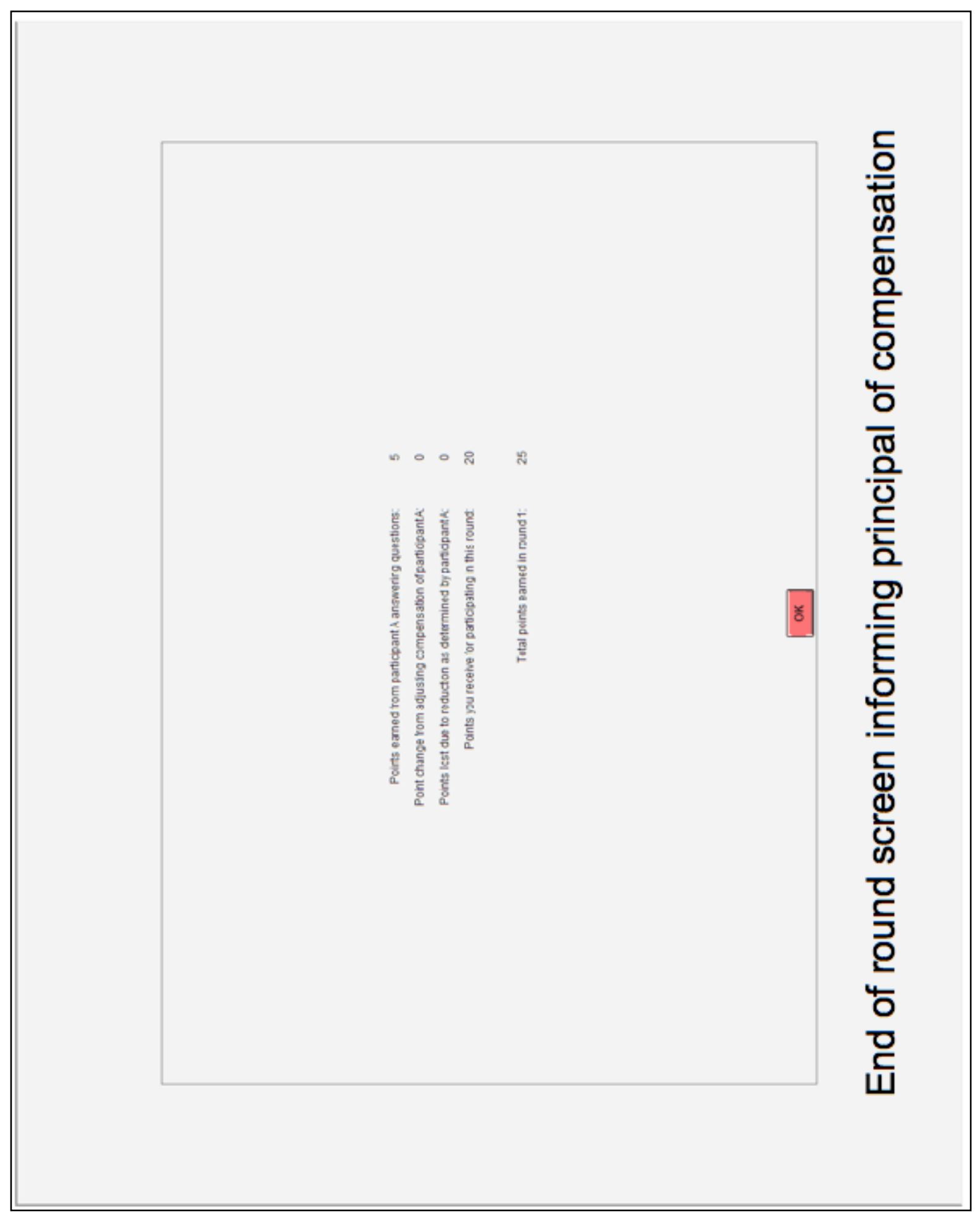




\section{APPENDIX 5 - POST-EXPERIMENTAL QUESTIONNAIRE (AGENT)}

\subsection{Questionnaire Part 1}

QUESTIONNAIRE - Part 1

FOR PARTICIPANT A

Participant ID

Please complete the following

questionnaire by filling in the answer that

best corresponds to your judgment.

Thank you for your effort! 
1. When you provided an estimate of the number of correct answers after answering the questions in part 2 round 1 , how many questions did you think you answered correctly?

2. When you provided an estimate of the number of correct answers after answering the questions in part 2 round 2 , how many questions did you think you answered correctly? 


\title{
5.2. Questionnaire Part 2
}

\section{QUESTIONNAIRE - Part 2 FOR PARTICIPANT B}

\author{
Participant ID
}

Please complete the following questionnaire by either circling a number, marking your choice on the line, or filling in the answer that best corresponds to your judgment.

Thank you for your effort! 
1. I play trivia games with friends in my free time.

\begin{tabular}{lllllll}
1 & 2 & 3 & 4 & 5 & 6 & 7 \\
\hline & $\mid$ & $\mid$ & $\mid$ & $\mid$
\end{tabular}

2. I have a good knowledge of historical events.

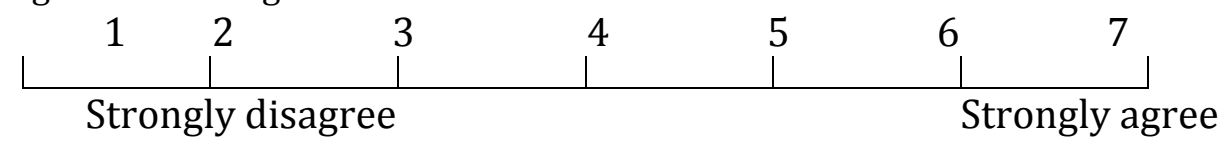

3. It is important to me to excel at tasks that I pursue in my life.

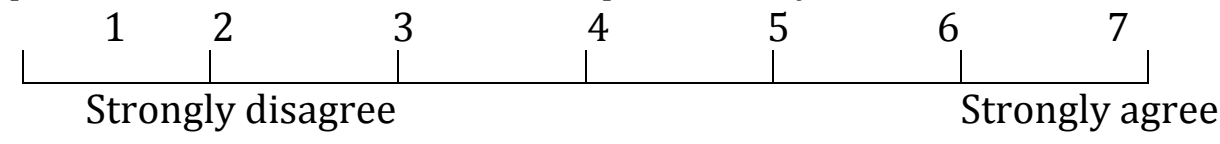

4. I am a competitive person.

\begin{tabular}{lllllll}
1 & 2 & 3 & 4 & 5 & 6 & 7 \\
\hline & $\mid$ & & $\mid$ & $\mid$
\end{tabular}

5. Money is important to me.

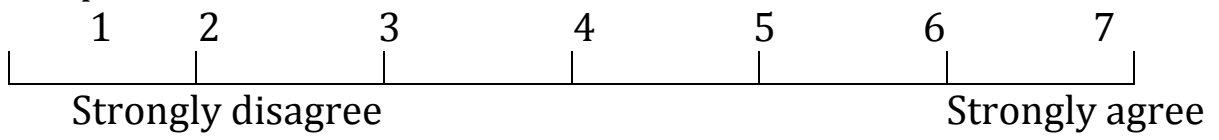

6. Fairness and behaving ethically are important to me.

\begin{tabular}{lllllll}
1 & 2 & 3 & 4 & 5 & 6 & 7 \\
\hline Strongly disagree & & & & & & \multicolumn{1}{l}{ Strongly agree }
\end{tabular}


7. I am not afraid to take risks.

\begin{tabular}{lllllll}
1 & 2 & 3 & 4 & 5 & 6 & 7 \\
\hline & $\mid$ & 1 & $\mid$ & $\mid$
\end{tabular}

8. The setting and parameters in this study were fair.

\begin{tabular}{lllllll}
1 & 2 & 3 & 4 & 5 & 6 & 7 \\
\hline & $\mid$ & $\mid$ & $\mid$ & & \\
\hline Strongly disagree & & & \multicolumn{3}{l}{ Strongly agree }
\end{tabular}

If you disagree, what specifically about the study do you consider unfair?

9. I have read the questions while participant $\mathrm{A}$ was working on them.

$\begin{array}{lllllll}1 & 2 & 3 & 4 & 5 & 6 & 7 \\ & \mid & 1 & & \mid & \mid\end{array}$

10. The questions in part 1 of the study were difficult.

\begin{tabular}{lllllll}
1 & 2 & 3 & 4 & 5 & 6 & 7 \\
& $\mid$ & & $\mid$ & $\mid$ & \\
\hline Strongly disagree & & & & Strongly agree
\end{tabular}


11. The questions in part 2 round 1 of the study were difficult.

$\begin{array}{|llllll|}1 & 2 & 3 & 4 & 5 & 6\end{array}$

12. The questions in part 2 round 2 of the study were difficult.

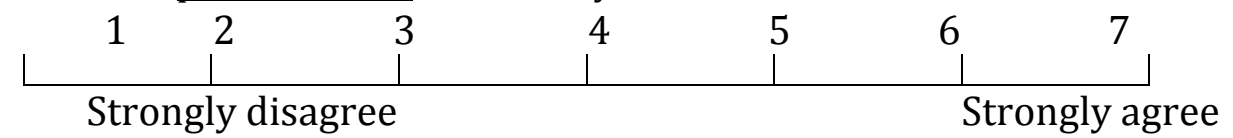

13. What factors did you consider when setting the point score for participant $A$ in the part 2 ?

a) I was concerned that participant A would reduce my point score in stage 3 .

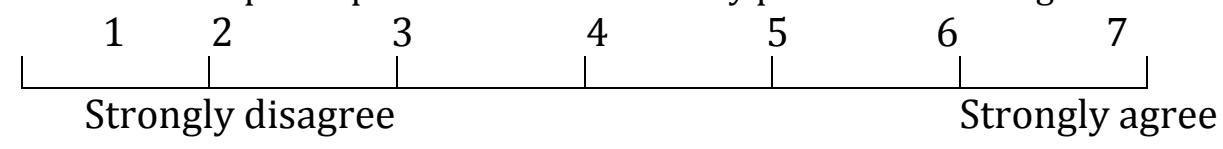

b) I wanted to minimize the difference between the estimate of the number of questions answered correctly by participant $A$ and the point score for participant $A$ after adjustments made by me.

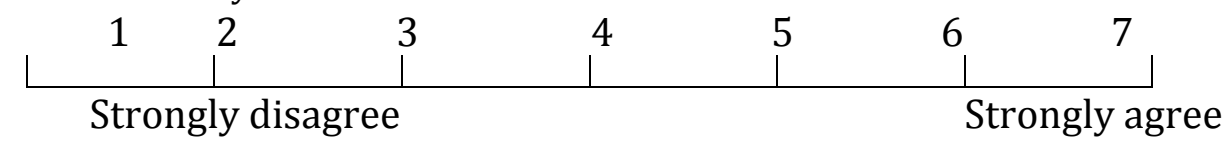

c) I wanted to maximize my point score.

$\begin{array}{|llllll|}1 & 2 & 3 & 4 & 5 & 6\end{array}$


d) I wanted to set a fair level of points.

$\begin{array}{|llllll|}1 & 2 & 3 & 4 & 5 & 6\end{array}$

e) I felt bad about reducing the point score of participant A.

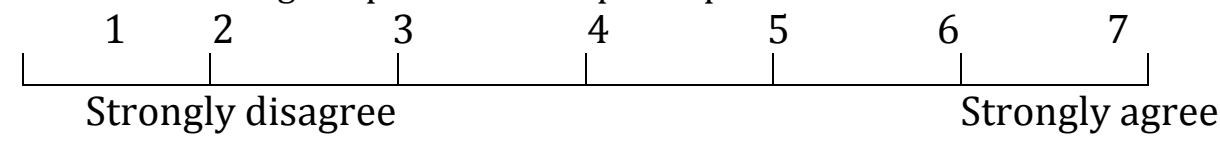

f) I considered participant A's estimate of the number of questions answered correctly.

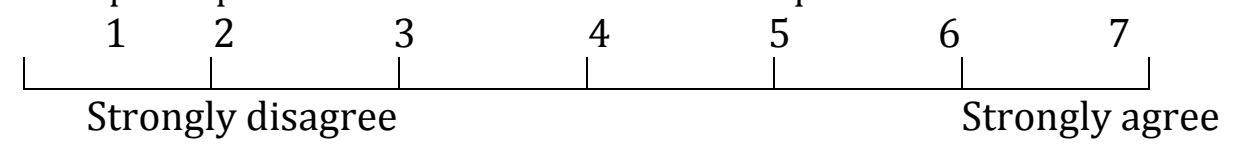

g) I felt participant A cost me points by not working hard enough and not answering enough questions correctly.

\begin{tabular}{|llllll}
1 & 2 & 3 & 4 & 5 & 6
\end{tabular}

h) I wanted to increase the point score for participant A because participant A did all the work.

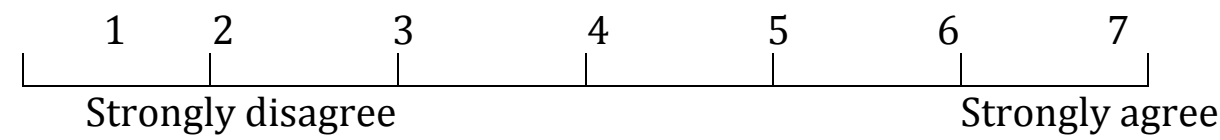

i) I wanted both of us, participant A and B to receive comparable point scores.

$\begin{array}{|llllll|}1 & 2 & 3 & 4 & 5 & 6\end{array}$

14. I would have felt bad if I would have reduced the point score of participant A below the number of questions answered correctly by participant $\mathrm{A}$.

$\begin{array}{|llllll|}1 & 2 & 3 & 4 & 5 & 6\end{array}$


15. I would have felt bad if I would have reduced the point score of participant A below the estimate of the number of questions that participant A reported as answered correctly.

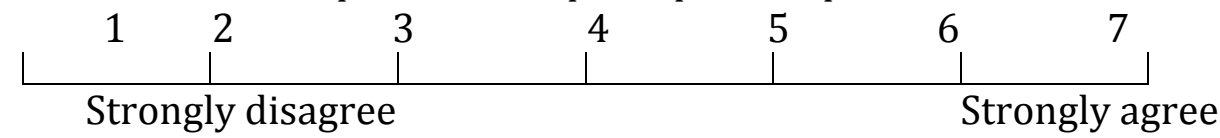

16. I considered the estimate of correct answers that participant A provided a credible estimate of how well participant A thought s/he did.

\begin{tabular}{ccccccc}
1 & 2 & 3 & 4 & 5 & 6 & 7 \\
& & 1 & & & & \\
\hline
\end{tabular}


Please describe the strategy you used for answering questions and reducing the score of participant $A$ in part 2 round 1 and why you used this strategy:

Please describe any changes you made to your strategy in part 2 round 2 and why you made those changes:

Please provide any additional comments that you believe be useful in examining the data from this study. 
Major:

Years in school:

Age:

Gender:

$\square$ Male

$\square$ Female

Estimated GPA:

Was English your first language?

$\square$ Yes

$\square$ No 


\section{REFERENCES}

Alicke, M. 1985. Global self-evaluation as determined by the desirability and controllability of trait adjectives. Journal of Personality and Social Psychology 49(6): 1621-1630.

Ariely, D., G. Loewenstein, and D. Prelec. 2003. Coherent arbitrariness: stable demand curves without stable preferences. The Quarterly Journal of Economics 118(1): 73-105.

Atwater, L. and F. Yammarino. 1992. Does self-other agreement on leadership perceptions moderate the validity of leadership and performance predictions. Personnel Psychology 45: 141-164.

Avery, R., and K. Murphy. 1998. Performance evaluation in the work settings. Annual Review in Psychology 49: 141-168.

Banaji, M., and D. Prentice. 1994. The self in social contexts. Annual Review in Psychology 45: 297-332.

Bettenhausen, K., and D. Fedor. 1997. Peer and Upward Appraisals. Group \& Organization Management 22(2): 236-263.

Blakely, G. 1993. The effects of performance ratings discrepancies on supervisors and subordinates. Organizational Behavior and Human Decision Processes 54: 57-80.

Blanton, H., B. Pelham, T. DeHart, and M. Carvallo. 2001. Overconfidence as dissonance reduction. Journal of Experimental Social Psychology 37: 373-385.

Block, R., and D. Harper. 1991. Overconfidence in estimation: testing the anchoringand-adjustment hypothesis. Organizational Behavior and Human Decision Processes 49: 188-207.

Bloomfield, R., and J. Luft. 2006. Responsibility for cost management hinders learning to avoid the winner's curse. The Accounting Review 81: 29-47.

Bol, J. 2008. The determinants and performance effects of supervisor bias. Working paper University of Illinois. 
Bommer, W., J. Johnson, G. Rich, P. Podsakoff, and S. MacKenzie. 1995. On the interchangeability of objective and subjective measures of employee performance: a meta-analysis. Personnel Psychology 48: 587-605.

Brenner, L. V. Libermann, and A. Tversky. 1996. Overconfidence in probability and frequency judgments: a critical examination. Organizational Behavior and Human Decision Processes 65(3): 212-219.

Byrne, S., and F. Damon. 2008. To participate or not to participate? Voice and explanation effects on performance in a multi-period budget setting. The British Accounting Review 40: 207-227.

Camerer, C., and D. Lovallo. 1999. Overconfidence and excess entry: an experimental approach. The American Review 89(1): 306-318.

Campbell, D., and C. Lee. 1988. Self-appraisal in performance evaluation: development versus evaluation. The Academy of Management Review 13: 302-314.

Campbell, K., and C. Sedikides. 1999. Self-threat magnifies the self-serving bias: a metaanalytic integration. Review of General Psychology 3(1): 23-43.

Cawley, B., L. Keeping, and P. Levy. 1998. Participation in the performance appraisal process and employee reactions: a meta-analytic review of field investigations. Journal of Applied Psychology 83(4): 615-633.

Cheung, D. 1999. Multifaceted conceptions of self-other ratings disagreement. Personnel Psychology. 52: 1-36.

Church, A. 1997. Managerial self-awareness in high-performing individuals in organizations. Journal of Applied Psychology 82(2): 281-292.

Diefendorff, J., S. Silverman, and G. Greguras. 2005. Measurement equivalence and multisource ratings for non-managerial positions: recommendations for research and practice. Journal of Business and Psychology 19(3): 399-425.

Elicker, J., P. Leavy, and R. Hall. 2006. The role of leader-member exchange in the performance appraisal process. Journal of Management 32(4): 531-551.

Elicker, J., P. Levy, and R. Hall. 2006. The role of leader-member exchange in the performance appraisal process. Journal of Management 32(4): 531-551.

Facteau, J., and B. Craig. 2001. Are performance appraisal ratings from different rating sources comparable? Journal of Applied Psychology 86(2): 215-227. 
Fahr, J., and J. Werbel. 1986. Effects of purpose of the appraisal and the expectation of validation on self-appraisal leniency. Journal of Applied Psychology 71(3): 527529.

Fehr, E., and A. Falk. 2002. Psychological foundations of incentives. European Economic Review 46: 687-724.

Fischbacher, U. 2007. Z-tree Zurich toolbox for ready-made economic experiments. Experimental Economics 10: 171-178.

Folger, R. and Greenberg, J. 1985. Procedural justice: an interpretive analysis of personnel systems. In K. Rowland and G. Ferris: Research in personnel and human resources management. Greenwich.

Geddes, D, K. Merrimam, G. Ross, and D. Dunlap-Hinkler. 2003. Self appraisal 'voice' and perceptions of justice: examining the impact and interdependence of instrumental and value-expressive effects. The International Journal of Conflict Management 14(1): 23-41.

Goerke, M., J. Moeller, U. Napiersky, S. Schulz-Hardt, and D. Frey. 2004. It's not my fault - but only I can change it: counterfactual and prefactual thoughts of managers. Journal of Applied Psychology 89(2): 279-292.

Gramzow, R., A. Elliot, E. Asher, and H. McGregor. 2003. Self-evaluation bias and academic performance: some ways and some reasons why. Journal of Research in Personality 37: 41-61.

Green, S., M. Lightfoot, C. Bandy, and D. Buchanan. 1985. A general model of the attribution process. Basic and Applied Social Psychology 6(2): 159-179.

Greenberg, J. 1986. Determinants of perceived fairness of performance evaluations. Journal of Applied Psychology 71(2): 340-342.

Hales, J. 2007. Directional preferences, information processing, and investors' forecasts of earnings. Journal of Accounting Research 45(3): 607-628.

Harris, M. 1994. Rater motivation in the performance appraisal context: a theoretical framework. Journal of Management 20(4): 737-756.

Harris, M., and J. Schaubroeck. A meta-analysis of self-supervisor, self-peer, and peersupervisor ratings. Personnel Psychology 41: 43-62.

Inderrieden, E., R. Allen, T. Keaveny. 2004. Managerial discretion in the use of selfratings in an appraisal system. Journal of Managerial Issues XVI(4): 460-482. 
Ittner, C., D. Larcker, and M. Meyer. 2003. Subjectivity and the weighting of performance measures: evidence from a balanced scorecard. The Accounting Review 78(3): 725-758.

Jaramillo, F., F. Carrillat, and W. Locander. 2005. A meta-analytic comparison of managerial ratings and self-evaluations. Journal of Personal Selling \& Sales Management XXV(4): 315-328.

Jawahar, I. 2007. The influence of perceptions of fairness on performance appraisal reactions. Journal of Labor Research 28: 735-754.

John, O., and R. Robins. 1994. Accuracy and bias in self-perception: individual differences in self-enhancement and the role of narcissism. Journal of Personality and Social Psychology 66(1): 206-219.

Johnston, W., and K. Kim. 1994. Performance, attribution, and expectancy linkages in personal selling. Journal of Marketing 58(4): 68-81.

Jones, L, and C. Fletcher. 2002. Self-assessment in selection situation: an evaluation of different measurement approaches. Journal of Occupational and Organizational Psychology 75: 145-161.

Jussim, L., H. Yen, and J. Aiello. 1995. Self-consistency, self-enhancement, and accuracy in reactions to feedback. Journal of Experimental Social Psychology 31:322-356.

Kelley, H., and J. Michela. 1980. Attribution theory and research. Annual Review in Psychology. 31:457-501.

Klayman, J., J. Soll, C. Gonzalez-Vallejo, S. Barlas. 1999. Overconfidence: It depends on how, what, and whom you ask. Organizational Behavior and Human Decision Processes 79(3): 216-247.

Korsgaard, A. 1996. The impact of self-appraisals on the reactions to feedback from others: the role of self-enhancement and self-consistency concerns. Journal of Organziational Behavior 17: 301-311.

Korsgaard, A., and L. Roberson. 1995. Procedural justice in performance evaluation: the role of instrumental and non-instrumental voice in performance appraisal discussions. Journal of Management 21(4): 657-69.

Korsgaard, M., B. Meglino, and S. Lester. 2004. The effect of other orientation on selfsupervisor rating agreement. Journal of Organizational Behavior 25: 873-891. 
Korsgaard, M., L. Roberson. 1995. Procedural justice in performance evaluation: the role of instrumental and non-instrumental voice in performance appraisal discussions. Journal of Management 21(4): 657-669.

Kranes, M. 5087 trivia questions \& answers. New York, NY: Black Dog \& Leventhal Publishers, 1998.

Kruger, J. and D. Dunning. 1999. Unskilled and unaware of it: how difficulties in recognizing one's own incompetence lead to inflated self-assessments. Journal of Personality and Social Psychology 77(6): 1121-1354.

Kunda, Z. 1990. The case for motivated reasoning. Psychological Bulletin 108(3): 480498.

Lang, S. The big book of American trivia. Carol Stream, IL: Tyndale House Publishers, 1997.

Lau, C., and A. Moser. 2008. Behavioral effects of nonfinancial performance measures: the role of procedural fairness. Behavioral Research in Accounting 20(2): 55-71.

Leary, M., 2007. Motivational and emotional aspects of the self. Annual Review in Psychology 58: 317-344.

Libby, T. 1999. The influence of voice and explanation on performance in a participative budget setting. Accounting, Organizations and Society 24: 125-137.

Liden, R., and T. Mitchell. 1985. Reactions to feedback: the role of attributions. The Academy of Management Journal 28(2): 291-308.

Ludwig, S., J. Nafziger. 2001. Do you know that I am biased? An experiment. Working paper University of Bonn.

Mabe, P., and S. West. 1982. Validity of self-evaluations of ability: a review and metaanalysis. Journal of Applied Psychology 67(3): 280-296.

MacLeod, B. 2003. Optimal contracting with subjective evaluation. The American Economic Review 93(1): 216-240.

Metcalf, J. 1998. Cognitive optimism: self-deception or memory-based processing heuristics. Personality and Social Psychology Review 2(2): 100-110.

Mellers, B., A. Schwartz, K. Ho, and I. Ritov. 1997. Decision affect theory: emotional reactions to the outcomes of risky options. Psychological Science 8(6): 423-429. 
Moers, F. 2005. Discretion and bias in performance evaluation: the impact of diversity and subjectivity. Accounting, Organizations and Society 30: 67-80.

Moore, D., and D. Cain. 2007. Overconfidence and underconfidence: When and why people underestimate (and overestimate) the competition. Organizational Behavior and Human Decision Processes 103: 197-213.

Motowidlo, S. 1982. Relationship between self-rated performance and pay satisfaction among sales representatives. Journal of Applied Psychology 67(2): 209-213.

Prendergast, C. 1999. The provision of incentives in firms. Journal of Economic Literature 37(1): 7-63.

Pronin, E., L. Ross, and T. Gilovich. 2004. Objectivity in the eye of the beholder: divergent perceptions of bias in self versus others. Psychology Review 111(3): 781-799.

Raymark, P., W. Balzer, and F. DeLaTorre. 1999. A preliminary investigation of the sources of information used by raters when appraising performance. Journal of Business and Psychology. 14(2): 319-339.

Reifenberg, R., 1986. The self-serving bias and use of objective and subjective methods for measuring success and failure. The Journal of Social Psychology 126: 627631.

Roberson, L., S. Torkel, A. Koorsgard, D. Klein, M. Diddams, and M. Cayer. 1993. Self-rating and perceptions of the appraisal discussion: a field experiment. Journal of Organizational Behavior, 14(2): 129-142.

Roese, N. 1997. Counterfactual Thinking. Psychological Bulletin 121(1): 133-148.

Romano, C. 1994. Conquering the fear of feedback. Management Review 71(3): 9-10.

Shore, T., J. Adams, and A. Tashchian. 1998. Effects of self-appraisal information, appraisal purpose, and feedback target on performance appraisal ratings. Journal of Business and Psychology 12(3): 283-298.

Suantak, L., F. Bolger, and W. Ferrell. 1996. The hard-easy effect in subjective probability calibration. Organizational Behavior and Human Decision Processes 67: 201-221.

Swann, W., and S. Read. 1981. Acquiring self-knowledge: the search for feedback that fits. Journal of Personality and Social Psychology 41(6): 119-1128. 
Taylor, S., K. Tracy, M. Renard, K. Harrison, and S. Carroll. 1995. Due process in performance appraisal: a quasi-experiment in procedural justice. Administrative Science Quarterly 40(3): 495-523.

Teas, K., and J. McElroy. 2004. Causal attributions and expectancy estimates: a framework for understanding the dynamics of salesforce motivation. Journal of Marketing 50(1): 75-86.

Thaler, R. 1988. The ultimatum game. Journal of Economic Perspectives 2(4): 195206.

Thornton, G. 1980. Psychometric properties of self-appraisals of job performance. Personnel Psychology 33: 263-271.

Waldman, D., L. Atwater, and D. Antonioni. 1998. Has 360 degree feedback gone amok? The Academy of Management Executive 12(2): 86-94.

Wilson, T., and E. Dunn. 2004. Self-knowledge: its limits, value, and potential for improvement. Annual Review of Psychology 55: 493-518.

Wohler, A., and M. London. 1989. Ratings of managerial characteristics: evaluation difficulty, co-worker agreement, and self-awareness. Personnel Psychology 42: 235-261.

Yammarino, F., and L. Atwater. 1997. Do managers see themselves as others see them? Implications of self-other rating agreement for human resources management. Organizational Dynamics: 35-44.

Yates, F, J. Lee, and H. Shinotsuka. 1996. Beliefs about overconfidence, including its cross-national variation. Organizational Behavior and Human Decision Processes 65(2): 138-147. 


\section{VITA}

Bernhard Erich Reichert is the son of I. Reichert and Prof. Dr. E. Reichert. He was born on July $25^{\text {th }} 1975$ in Karlsruhe, Germany. He is married to E. R. Reichert. After graduating from Humboldt High School in Karlsruhe, Germany, he served in the $10^{\text {th }}$ Tank Division of the Bundeswehr. He received an MBA from the Western Illinois University in 2000 and was awarded the degree of Diplom-Kaufmann from the University of Mannheim in 2001. In August 2004, Bernhard entered the Graduate School at the University of Texas at Austin.

Permanent email: Bernhardreichert@gmail.com.

This dissertation was typed by the author. 